\title{
DGMETA (Version 1): Dissolved Gas Modeling and Environmental Tracer Analysis Computer Program
}
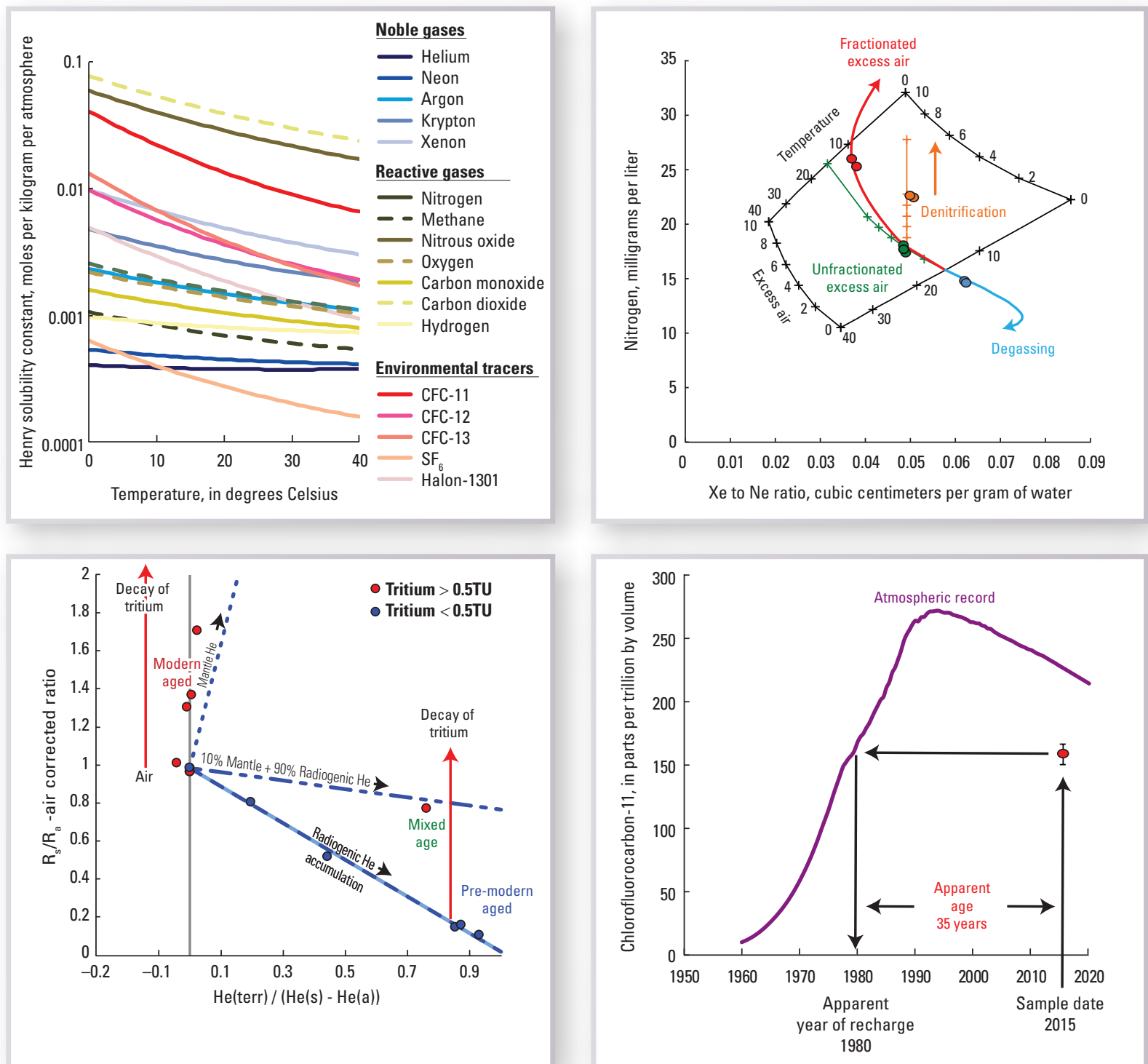

Techniques and Methods 4-F5

U.S. Department of the Interior

U.S. Geological Survey 


\section{Cover Photos:}
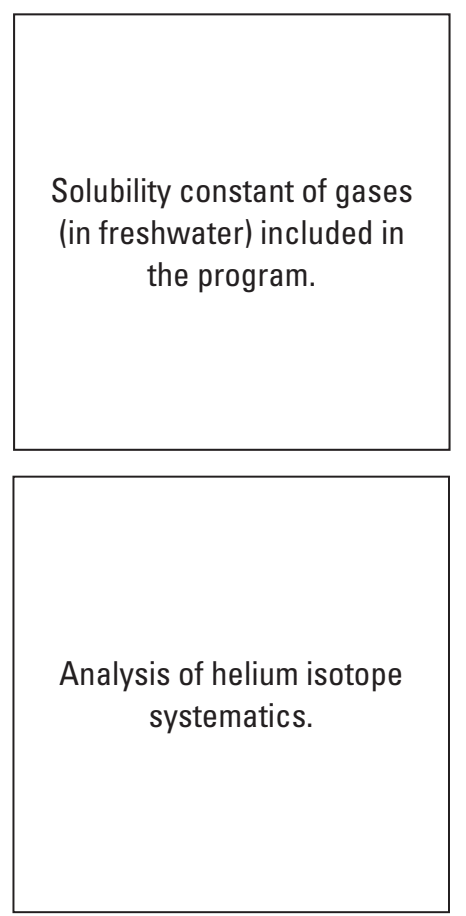
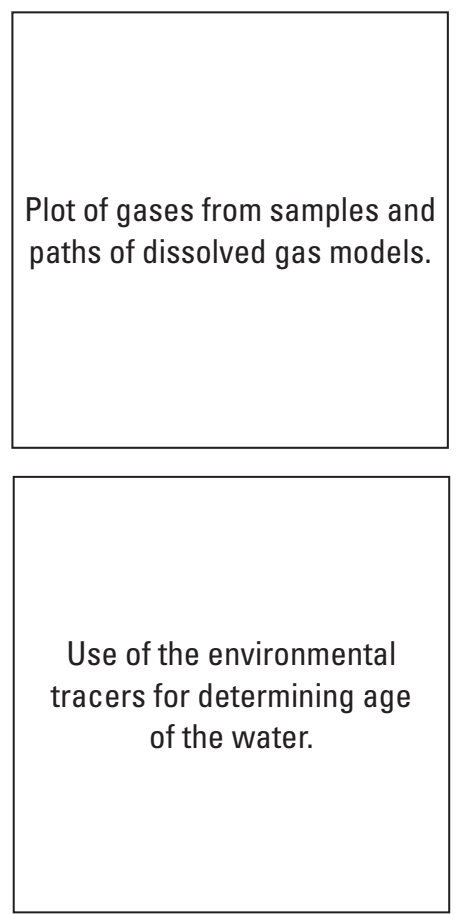


\section{DGMETA (Version 1): Dissolved Gas Modeling and Environmental Tracer Analysis Computer Program}

By Bryant C. Jurgens, J.K. Böhlke, Karl Haase, Eurybiades Busenberg, Andrew G. Hunt, and Jeffrey A. Hansen

National Water Quality Assessment Project

Techniques and Methods 4-F5 


\title{
U.S. Department of the Interior \\ DAVID BERNHARDT, Secretary
}

\author{
U.S. Geological Survey \\ James F. Reilly II, Director
}

U.S. Geological Survey, Reston, Virginia: 2020

For more information on the USGS - the Federal source for science about the Earth, its natural and living resources, natural hazards, and the environment—visit https://www.usgs.gov or call 1-888-ASK-USGS.

For an overview of USGS information products, including maps, imagery, and publications, visit https://store.usgs.gov/.

Any use of trade, firm, or product names is for descriptive purposes only and does not imply endorsement by the U.S. Government.

Although this information product, for the most part, is in the public domain, it also may contain copyrighted materials as noted in the text. Permission to reproduce copyrighted items must be secured from the copyright owner.

Suggested citation:

Jurgens, B.C., Böhlke, J., Haase, K., Busenberg, E., Hunt, A.G., and Hansen, J.A., 2020, DGMETA (version 1)—

Dissolved gas modeling and environmental tracer analysis computer program: U.S. Geological Survey Techniques and Methods 4-F5, 50 p., https://doi.org/10.3133/tm4F5.

ISSN 2328-7055 (online) 


\section{Contents}

Abstract

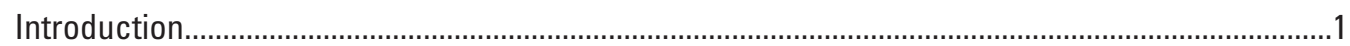

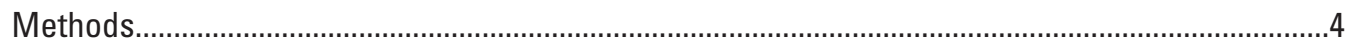

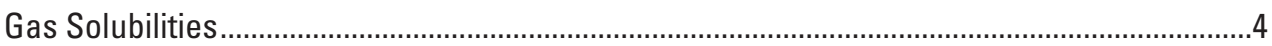

Approximations for Local Pressure, Water Vapor Pressure, and Salinity ........................5

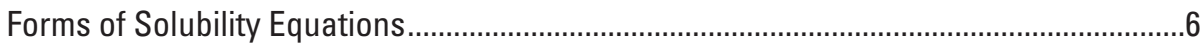

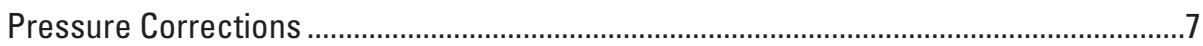

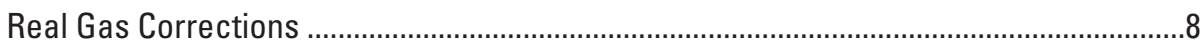

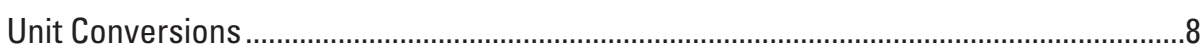

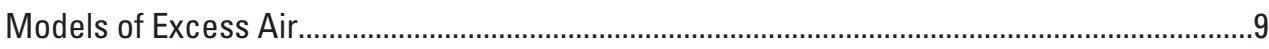

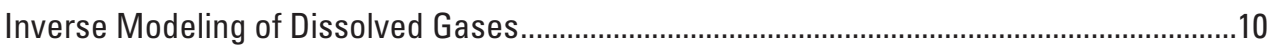

Monte Carlo Simulations .......................................................................................................

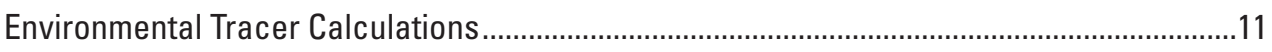

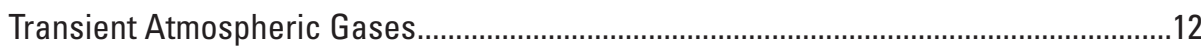

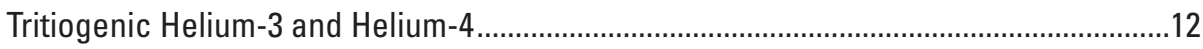

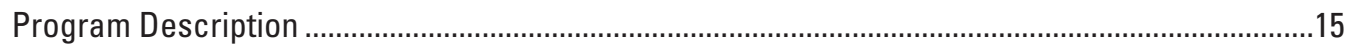

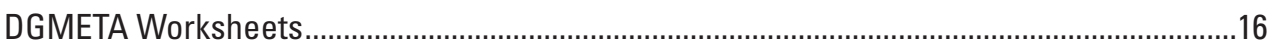

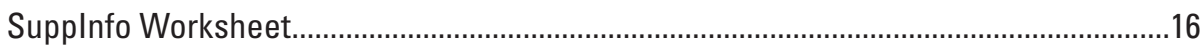

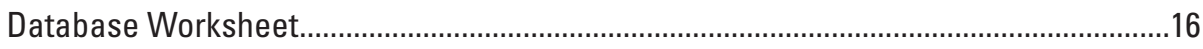

Input_Gases Worksheet ............................................................................................

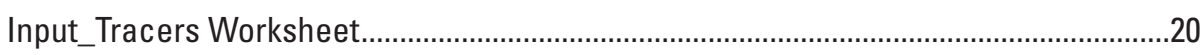

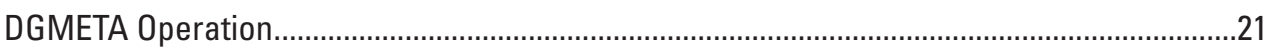

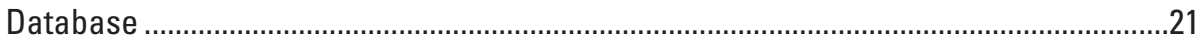

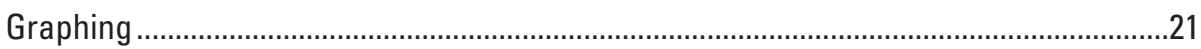

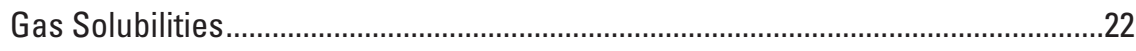

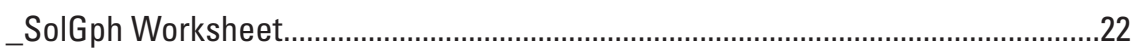

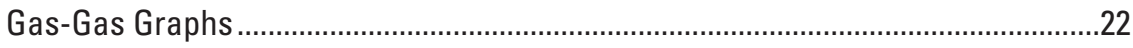

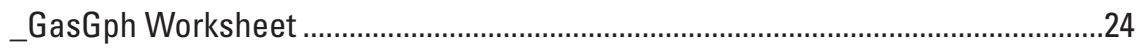

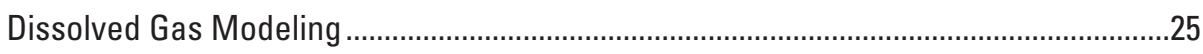

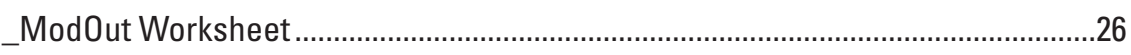

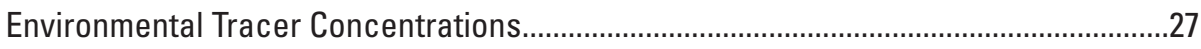

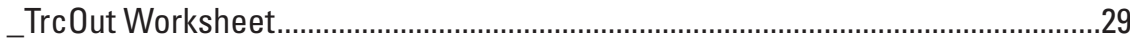

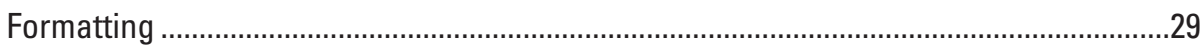

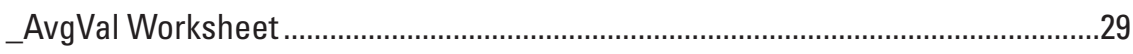

_ModFlt, _TrcFlt, and_AvgFlt Worksheets........................................................29

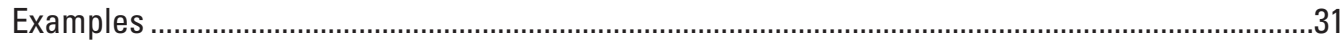

Example 1-Comparison of Noble Gas Solubility Data in Freshwater and Seawater............31

Example 2-Inverse Modeling of Air-Equilibrated Freshwater and Seawater Samples .......34

Example 3-Dissolved Gas Modeling with Neon, Argon, and Nitrogen or Argon and Nitrogen ..............................................................................................................35

Example 4-Tritiogenic Helium-3 Analysis in the Central Eastside San Joaquin

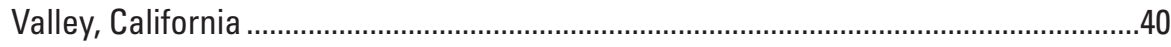

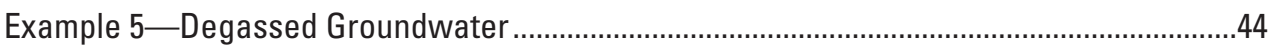




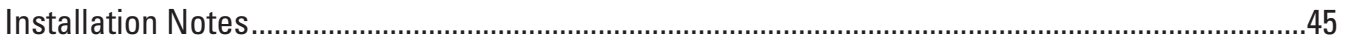

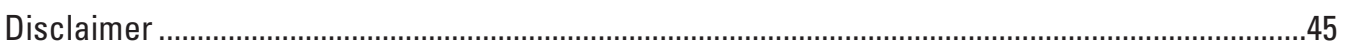

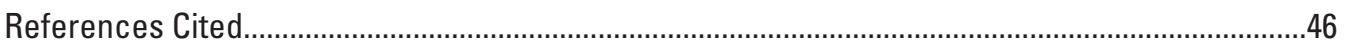

\section{Figures}

1. Graphs showing air-water solubility equilibrium concentration of inert noble gases helium, neon, argon, krypton, and xenon in water that are commonly used for modeling air-water equilibrium conditions; air-water solubility equilibrium concentration of the biogeochemically reactive gases nitrogen, oxygen, carbon dioxide, methane, carbon monoxide, hydrogen, and nitrous oxide; air-water solubility equilibrium concentration of environmental tracers chlorofluorocarbon-11, -12 , and -113 , sulfur hexafluoride, and bromotrifluoromethane that are commonly used for determining residence times of water; and Henry solubility constant of noble gases, reactive gases, and environmental tracers.

2. Graph of the excess air-corrected helium isotope ratio of the sample relative to air versus the concentration of terrigenic helium as a fraction of the total helium in the sample corrected for excess-air.

3. Image showing the Dissolved Gas Modeling and Environmental Tracer Analysis tab in the Excel ribbon

4. Image showing the Supplnfo worksheet, which contains supporting information on and references to program implementation; models of excess air; equations of local pressure, water density, and vapor pressure; conversion factors; gas solubility formulations used by the program; and a set of sample calculations of pressure, salinity, model gas concentrations, and mole fractions of environmental tracers

5. Image showing the Database worksheet

6. Image showing the Input_Gases worksheet and the Dissolved Gas Modeling and Environmental Tracer Analysis tab in the Excel ribbon.

7. Image showing the Input_Tracers worksheet and the DGMETA (Dissolved Gas Modeling and Environmental Tracer Analysis)tab in the Excel ribbon

8. Image showing the form used for creating graphs of the solubility of a gas in water at equilibrium with the atmosphere ...

9. Image showing the_SolGph worksheet created by the program that is used to compute and graph the solubility of a gas in water with different temperature, elevation (pressure), and salinity conditions

10. Image showing the form used for creating graphs of gas concentrations from samples and dissolved gas models

11. Image showing an example_GasGph worksheet created by the program to compute and graph gas concentrations for samples and models ....................................25

12. Image showing the form for modeling dissolved gases...............................................26

13. Image showing the _ModOut worksheet .....................................................................27

14. Images showing the forms for selecting a model output worksheet for computing tracer concentrations and for selecting a tracer output worksheet for computing average tracer concentrations 
15. Image showing the _TrcOut worksheet, which contains calculations of atmospheric dry-air mole fractions and concentrations of tritium-helium-3 components.

16. Image showing the _AvgVal worksheet, which contains average values of tracer concentrations for each sample and date listed on the _TrcOut worksheet.......30

17. Image showing a ModFlt worksheet, which is a single-row header version of a_ModOut, _TrcOut, or_AvgVal worksheet..

18. Graphs showing neon ( $\mathrm{Ne}$ ) concentrations in freshwater and saltwater at equilibrium with air, based on solubility equations by Weiss (1971) that were expressed as the moist-air solubility (Ne_Weiss) and Bunsen solubility constant (Ne_WeissB), by Clever (1979a; Smith and Kennedy, 1983; Ne_Clvr), by Hamme and Emerson (2004; Ne_H\&E), and by Jenkins and others (2019; Ne_Jnk) .......32

19. Graph showing percentage of deviation of neon solubility from measured data reported by Sano and Takahata (2005) in seawater for a range of temperatures . .33

20. Image showing the Dissolved Gas Modeling form used to evaluate air-equilibrated samples prepared at the U.S. Geological Survey Noble Gas Laboratory in Denver, Colorado, and seawater samples from Sano and Takahata (2005).

21. Graphs showing concentrations of nitrogen gas and argon and neon ratio, and nitrogen gas and argon only were measured in groundwater samples from the Texas coastal lowlands aquifer in 2013 .

22. Image showing the form for Dissolved Gas Modeling for modeling recharge conditions and denitrification using neon, argon, and nitrogen gas concentrations .....37

23. Image showing the form for Dissolved Gas Modeling for modeling recharge conditions with denitrification using argon and nitrogen gases only......

24. Images showing the helium isotope separation plot and table of helium isotope control variables on the TX_Final_TrcOut worksheet

25. Graph showing tritium and sulfur hexafluoride concentrations in groundwater in the Texas coastal lowlands aquifer.

26. Image showing the Dissolved Gas Modeling form used to generate unfractionated excess air models and closed-system equilibration models of dissolved gases on the basis of dissolved neon, argon, krypton, and xenon concentrations in groundwater in the central eastside of the San Joaquin Valley, California, in 2006

27. Graph showing comparison of closed-system equilibration and unfractionated excess air model results for recharge temperatures among different age classifications based on tritium measurements of groundwater samples from the central eastside of the San Joaquin Valley, California, in 2006.

28. Images showing graphs of sample concentrations of argon versus xenon to neon and krypton versus xenon to neon.

29. Images showing views of the modified Weise plot for samples that are tritiated and samples that are tritium-dead, and a table of helium isotope control variables on the Final_TrcOut worksheet.

30. Images showing views of the modified Weise plot showing mixing of groundwater endmembers and a table of helium isotope control variables on the Final_TrcOut worksheet.

31. Graphs showing solubility concentrations for argon and krypton plotted versus the ratio of the solubility concentrations of xenon and neon for different recharge temperatures and excess air values. 


\section{Conversion Factors}

International System of Units to U.S. customary units

\begin{tabular}{|c|c|c|}
\hline Multiply & By & To obtain \\
\hline \multicolumn{3}{|c|}{ Length } \\
\hline centimeter $(\mathrm{cm})$ & 0.3937 & inch (in.) \\
\hline meter $(\mathrm{m})$ & 3.281 & foot $(\mathrm{ft})$ \\
\hline \multicolumn{3}{|c|}{ Volume } \\
\hline cubic meter $\left(\mathrm{m}^{3}\right)$ & 6.290 & barrel $($ petroleum, 1 barrel $=42$ gal $)$ \\
\hline liter $(\mathrm{L})$ & 33.81402 & ounce, fluid (fl. oz) \\
\hline cubic meter $\left(\mathrm{m}^{3}\right)$ & 264.2 & gallon (gal) \\
\hline cubic meter $\left(\mathrm{m}^{3}\right)$ & 0.0002642 & million gallons (Mgal) \\
\hline cubic centimeter $\left(\mathrm{cm}^{3}\right)$ & 0.06102 & cubic inch $\left(\mathrm{in}^{3}\right)$ \\
\hline liter (L) & 61.02 & cubic inch (in $\left.{ }^{3}\right)$ \\
\hline cubic meter $\left(\mathrm{m}^{3}\right)$ & 35.31 & cubic foot $\left(\mathrm{ft}^{3}\right)$ \\
\hline cubic meter $\left(\mathrm{m}^{3}\right)$ & 1.308 & cubic yard $\left(\mathrm{yd}^{3}\right)$ \\
\hline cubic meter $\left(\mathrm{m}^{3}\right)$ & 0.0008107 & acre-foot (acre-ft) \\
\hline \multicolumn{3}{|c|}{ Mass } \\
\hline gram $(g)$ & 0.03527 & ounce, avoirdupois (oz) \\
\hline kilogram (kg) & 2.205 & pound avoirdupois (lb) \\
\hline \multicolumn{3}{|c|}{ Pressure } \\
\hline kilopascal (kPa) & 0.009869 & atmosphere, standard (atm) \\
\hline \multicolumn{3}{|c|}{ Energy } \\
\hline joule $(\mathrm{J})$ & 0.0000002 & kilowatthour (kWh) \\
\hline
\end{tabular}

Temperature in degrees Celsius $\left({ }^{\circ} \mathrm{C}\right)$ may be converted to degrees Fahrenheit $\left({ }^{\circ} \mathrm{F}\right)$ as follows:

$$
{ }^{\circ} \mathrm{F}=\left(1.8 \times{ }^{\circ} \mathrm{C}\right)+32
$$

\section{Datum}

Elevation, as used in this report, refers to distance above the vertical datum.

\section{Supplemental Information}

Specific conductance (SC) is given in microsiemens per centimeter at 25 degrees Celsius $(\mu \mathrm{S} / \mathrm{cm})$.

Activities for radioactive constituents in water are given in picocuries per liter (pCi/L). 
Salinity (S) is given in parts per thousand (per mil).

${ }_{3}^{3} \mathrm{He}$ and $4 \mathrm{He}$. The element helium ( $\mathrm{He}$ ) has atoms with different masses: ${ }^{3 \mathrm{He}}$ has two protons and one neutron in its nucleus, and $4 \mathrm{He}$ has two protons and two neutrons in its nucleus.

The isotopic ratio of helium in a sample can be expressed as $\delta^{3} \mathrm{He}$ in units of percent:

$$
\delta^{3} \mathrm{He}=\left[\frac{\left({ }^{3} \mathrm{He} /{ }^{4} \mathrm{He}\right)_{\text {sample }}}{\left({ }^{3} \mathrm{He} /{ }^{4} \mathrm{He}\right)_{\text {air }}}-1\right] \times 100
$$

A tritium unit (TU) is equal to 3.19 picocuries per liter.

Concentrations of gases in water are given in several units:

pptv, volume of gas per volume of dry air, in parts per trillion.

$\mathrm{mmol} / \mathrm{L}$, millimoles of gas per liter of water.

$\mathrm{mmol} / \mathrm{kg}$, millimoles of gas per kilogram of water.

$\mu \mathrm{mol} / \mathrm{L}$, micromoles of gas per liter of water.

$\mathrm{nmol} / \mathrm{kg}$, nanomoles of gas per kilogram of water.

$\mathrm{pmol} / \mathrm{kg}$, picomoles of gas per kilogram of water.

$\mathrm{fmol} / \mathrm{kg}$, femtomoles of gas per kilogram of water.

$\mathrm{mg} / \mathrm{L}$, milligrams of gas per liter of water.

$\mathrm{cm}^{3} / \mathrm{g}$ or $\mathrm{cc} / \mathrm{g}$, cubic centimeters of gas at standard temperature and pressure (STP) per gram of water. of water.

$\mathrm{cm}^{3} / \mathrm{kg}$, cubic centimeters of gas at standard temperature and pressure per kilogram

\section{Abbreviations}

$\begin{array}{ll}\text { AEW } & \text { Air-equilibrated distilled water } \\ \text { CE } & \text { Closed-system equilibration } \\ \text { F } & \text { Fractionation } \\ \text { ID } & \text { Identification } \\ \text { PR } & \text { Partial re-equilibration } \\ \text { T } & \text { Temperature } \\ \text { UA } & \text { Unfractionated excess air } \\ \text { USGS } & \text { U.S. Geological Survey }\end{array}$




\section{CHEMICAL NAMES}

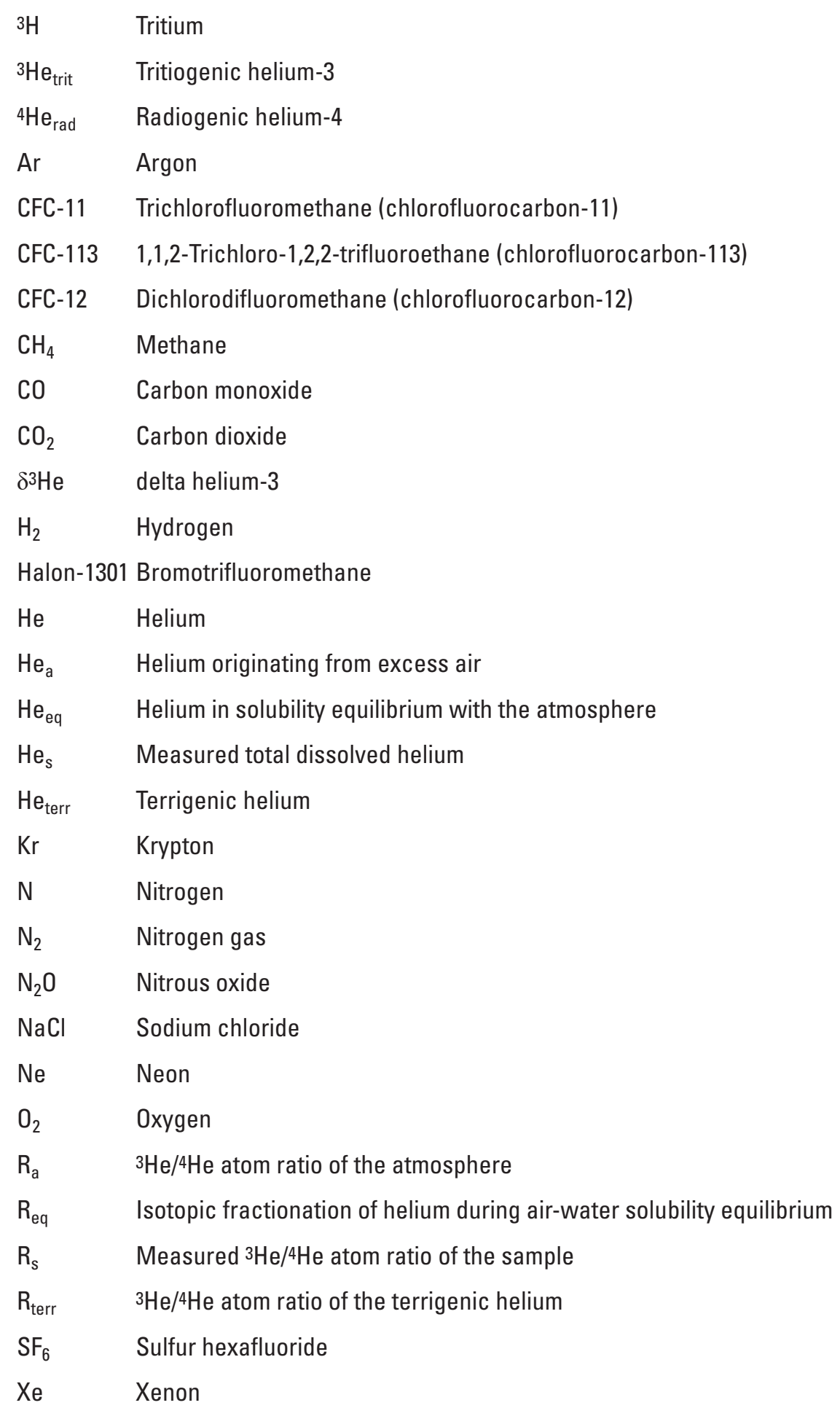




\title{
DGMETA (Version 1): Dissolved Gas Modeling and Environmental Tracer Analysis Computer Program
}

\author{
By Bryant C. Jurgens' ${ }^{1}$, J.K. Böhlke2, Karl Haase ${ }^{2}$, Eurybiades Busenberg², Andrew G. Hunt', and \\ Jeffrey A. Hansen1
}

\section{Abstract}

DGMETA (Dissolved Gas Modeling and Environmental Tracer Analysis) is a Microsoft Excel-based computer program that is used for modeling air-water equilibrium conditions from measurements of dissolved gases and for computing concentrations of environmental tracers that rely on air-water equilibrium model results. DGMETA can solve for the temperature, salinity, excess air, fractionation of gases, or pressure/elevation of water when it is equilibrated with the atmosphere. Models are calibrated inversely using one or more measurements of dissolved gases such as helium, neon, argon, krypton, xenon, and nitrogen. Excess nitrogen gas, originating from denitrification or other sources, also can be included as a fitted parameter or as a separate calculation from the dissolved gas modeling results. DGMETA uses the air-water equilibrium models to separate measured concentrations of gases and isotopes of gases into components that are used for tracing water in the environment. DGMETA calculates atmospheric dry-air mole fractions (mixing ratios) for transient atmospheric gas tracers such as chlorofluorocarbons, sulfur hexafluoride, and bromotrifluoromethane (Halon-1301); and concentrations of tritiogenic helium-3 and radiogenic helium-4, which accumulate from the decay of tritium in water and the decay of uranium and thorium in rocks, respectively.

Sample data can be graphed to identify applicable models of excess air, samples that contain excess nitrogen gas, or samples that have partially degassed, for example. Monte Carlo analysis of errors associated with dissolved gas equilibrium model results can be carried through computations of environmental tracer concentrations to provide robust estimates of error. In addition, graphical routines for separating helium sources using helium isotopes are included to refine estimates of tritiogenic helium- 3 when terrigenic helium from mantle or crustal sources is present

\footnotetext{
1U.S. Geological Survey, Placer Hall, 6000 J St., Sacramento, CA 95819, bjurgens@usgs.gov

${ }^{2}$ U.S. Geological Survey, 431 National Center, Reston, VA 20192

3U.S. Geological Survey, Denver Federal Center, Lakewood, CO, 80225
}

in samples. Environmental tracer concentrations and their errors computed from DGMETA can be used with other programs, such as TracerLPM (Jurgens and others, 2012), to determine groundwater ages and biogeochemical reaction rates. DGMETA also produces output files in a format that meets the U.S. Geological Survey open data requirements for documentation of model inputs and outputs.

DGMETA is a versatile and adaptable program that allows users to add solubility data for new gases, modify the existing set of gas solubility data, modify the default set of gases used for modeling, choose calculations based on real (non-ideal) gas behavior, and select various concentration units for data entry and results to match laboratory reports and study objectives. DGMETA comes with a set of gases widely used in hydrology and oceanography and many gases include multiple solubilities from previous work. Seventeen dissolved gases are included in the default version of the program: noble gases (helium, neon, argon, krypton, and xenon), reactive gases (nitrogen, oxygen, methane, carbon dioxide, carbon monoxide, hydrogen, and nitrous oxide), and environmental tracers (chlorofluorocarbon-11, chlorofluorocarbon-12, chlorofluorocarbon-113, sulfur hexafluoride, and Halon-1301).

\section{Introduction}

Analysis of dissolved gases in water is common in oceanographic and terrestrial hydrologic studies. Various combinations of dissolved gases can provide records of environmental change and a deeper understanding of groundwater flow systems (Heaton and Vogel, 1981; Heaton and others, 1983; Stute and others, 1995; Aeschbach-Hertig and others, 1999; Ballentine and Hall, 1999; Cey and others, 2008; Cartwright and others, 2017), groundwater discharges to surface water (Heilweil and others, 2015; Sanford and others, 2015; Gilmore and others, 2016), ocean circulation patterns and mixing (Schlosser and Winckler, 2002; Stanley and Jenkins, 2013; Loose and Jenkins, 2014), and emission rates of greenhouse gases from parts of the hydrosphere (Matthews and Fung, 1987; Dalal and Allen, 2008; Jeffrey and others, 2018). 
Dissolved gases with constant atmospheric abundances like the inert noble gases helium (He), neon $(\mathrm{Ne})$, argon (Ar), krypton (Kr), xenon (Xe; fig. $1 A$ ) or the reactive gas nitrogen $\left(\mathrm{N}_{2}\right.$; fig. $\left.1 B\right)$ are commonly used to evaluate the conditions (temperature or excess air, for example) of water when it is equilibrated with the atmosphere. Reactive gases such as $\mathrm{N}_{2}$, oxygen $\left(\mathrm{O}_{2}\right)$, carbon dioxide $\left(\mathrm{CO}_{2}\right)$, methane $\left(\mathrm{CH}_{4}\right)$, carbon monoxide $(\mathrm{CO})$, hydrogen $\left(\mathrm{H}_{2}\right)$, and nitrous oxide $\left(\mathrm{N}_{2} \mathrm{O}\right.$; fig. $\left.1 B\right)$ can be used to evaluate biogeochemical processes. Relatively stable, but transient (time-varying) atmospheric trace gases like sulfur hexafluoride $\left(\mathrm{SF}_{6}\right)$, chlorofluorocarbon-11 (CFC-11), chlorofluorocarbon-12 (CFC-12), chlorofluorocarbon-113 (CFC-113), and bromotrifluoromethane (Halon-1301) are commonly used to trace water in the environment (fig. 1C). Transient atmospheric gases and the isotopes of helium (helium-3/helium- $4,{ }^{3} \mathrm{He} /{ }^{4} \mathrm{He}$; or the delta helium-3, $\left.\delta^{3} \mathrm{He}\right)$ - tritiogenic helium-3 $\left({ }^{3} \mathrm{He}_{\text {trit }}\right)$ and radiogenic helium-4 $\left({ }^{4} \mathrm{He}_{\mathrm{rad}}\right)$ - are commonly known as "environmental tracers" and are frequently used to evaluate residence times of water and groundwater. Tritiogenic helium-3 can accumulate in water from the decay of tritium $\left({ }^{3} \mathrm{H}\right)$ in water and ${ }^{4} \mathrm{He}_{\mathrm{rad}}$ can accumulate in water from uranium and thorium in subsurface rocks.

The measured concentrations of reactive gases, transient atmospheric gases, and $\mathrm{He}$ with $\mathrm{He}$ isotopes are not typically meaningful because the concentration that was gained or lost from biogeochemical reactions or the concentration used for age-dating water, like the dry-air mole fraction or the amount of He produced from the decay of tritium $\left({ }^{3} \mathrm{He}_{\text {trit }}\right)$, are calculated quantities that are dependent on the air-water equilibration conditions when the water was last in contact with the atmosphere. The air-water equilibration conditions such as temperature and excess air contribution may be estimated or, more frequently, they are determined by inverse modeling of noble gases or Ar- $\mathrm{N}_{2}$. Consequently, samples for the noble gases (with He isotopes), reactive gases, and transient atmospheric tracers are increasingly collected together to gain a more complete analysis of gases in water.

Different sets of dissolved gases commonly are sampled in separate containers, analyzed at different laboratories, and may be interpreted separately using software programs available publicly, in literature, or provided by the laboratories. Noble90 (Aeschbach-Hertig and others, 1999, 2000; Peeters and others, 2003), NOBLEBOOK (Aeschbach-Hertig and others, 1999, 2000), and PANGA (Jung and Aeschbach-Hertig, 2018) are programs available for modeling air-water equilibrium conditions from noble gases. Noble 90 also can be used to calculate He components from model results. These programs rely on a limited set of gas solubility equations that are widely used but cannot be changed or updated without a substantial alteration of the program. In addition, no single program is available that can compute a wide range of commonly sampled environmental tracers, such as CFCs, $\mathrm{SF}_{6}$, and Halon-1301, or provide a way to interactively compute $\mathrm{He}$ components $\left({ }^{3} \mathrm{He}_{\mathrm{trit}},{ }^{4} \mathrm{He}_{\mathrm{rad}}\right)$ in the context of local conditions through graphical inspection and manipulation of dependent terms. Because environmental tracer interpretations are dependent on dissolved gas model results, and different combinations of gases may be included in various studies, a single program that is capable of simultaneously and consistently interpreting the full range of dissolved gases and environmental tracers is desirable.

The purpose of this report is to document the program DGMETA: Dissolved Gas Modeling and Environmental Tracer Analysis is a Microsoft Excel-based program that is compatible with Excel Office versions 2007 or later. DGMETA can be used for inverse modeling of air-water equilibrium conditions (temperature, excess air, gas fractionation, and pressure/elevation) from stable atmospheric dissolved gases ( $\mathrm{He}, \mathrm{Ne}, \mathrm{Ar}, \mathrm{Kr}, \mathrm{Xe}$, and $\mathrm{N}_{2}$ ); for evaluating environmental tracers of relatively stable, but transient atmospheric trace gases (such as the CFCs, $\mathrm{SF}_{6}$, and Halon-1301); and for evaluating environmental tracers produced within the subsurface from the decay of tritium in water, like ${ }^{3} \mathrm{He}_{\text {trit, }}$, or from the decay of uranium and thorium in rocks such as ${ }^{4} \mathrm{He}_{\mathrm{rad}}$. DGMETA can be used to model air-water equilibrium conditions assuming that excess air is unfractionated (UA; Heaton and Vogel, 1981), fractionated following the partial re-equilibration model (PR; Stute and others, 1995) of excess air, or fractionated following the closed-system equilibration model (CE; Aeschbach-Hertig and others, 2000) of entrapped air. Gases that are transient or biologically reactive also are included. These gases can be used to identify $\mathrm{O}_{2}$ and nitrate reduction, $\mathrm{CH}_{4}$ production, and other biogeochemical processes. Finally, DGMETA has the added capability for users to modify or add to the set of gas solubility equations included in DGMETA's solubility database, including atmospheric gas tracers. These modifications allow DGMETA to grow as new tracers are identified or as solubility equations are revised.

This report contains three sections: Methods, Program Description, and Examples. The "Methods" section describes the theoretical and empirical basis for the dissolved gas and tracer models and the computational methods used by DGMETA. The "Program Description" section describes the contents of the worksheets in DGMETA, the input data required for operation of the software, and how to use the functions provided in the DGMETA Excel ribbon. The "Examples" section includes five examples of using DGMETA to process dissolved gas data of different types. 
$\boldsymbol{A}$

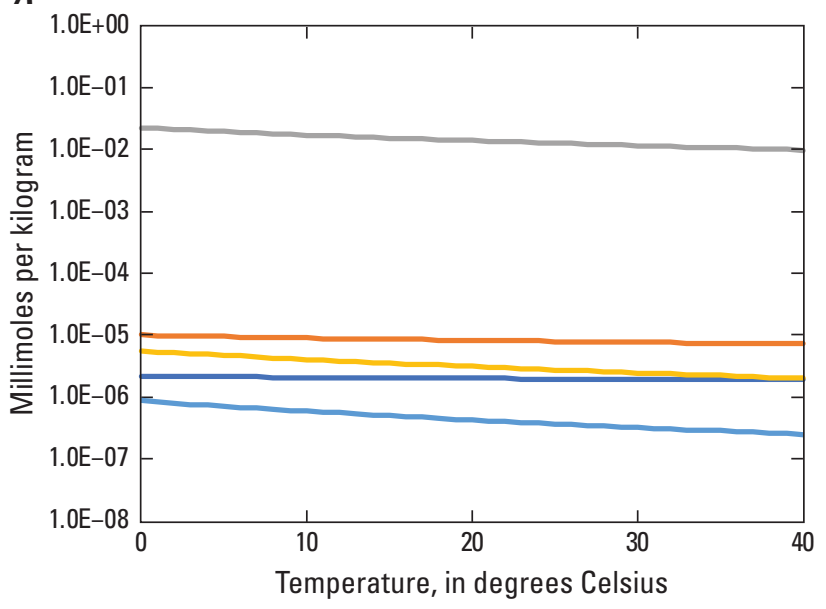

EXPLANATION

- He_Weiss - Ar_Weiss - Xe_Clur

C
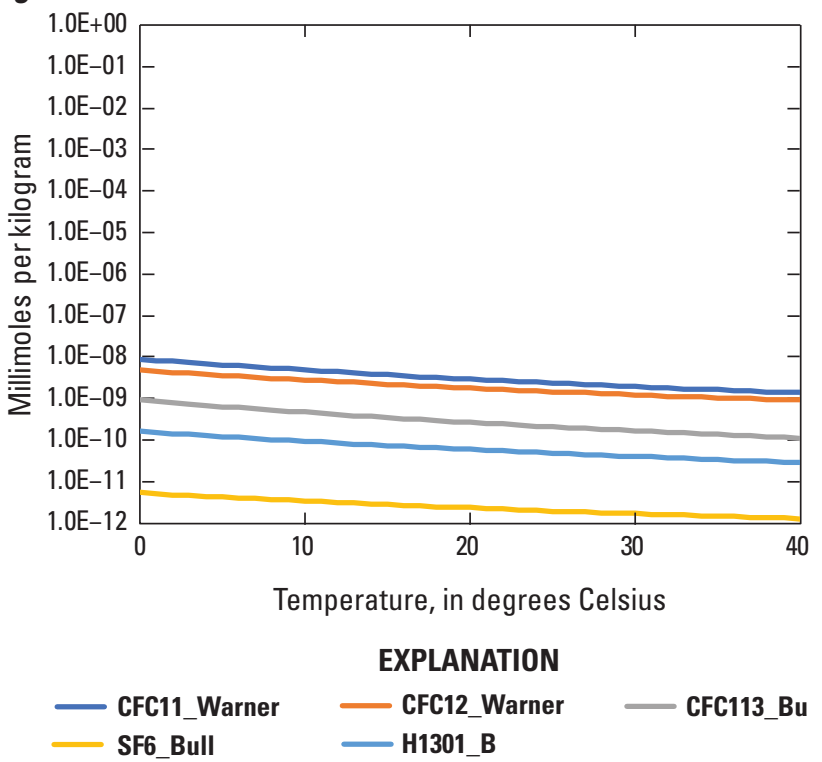

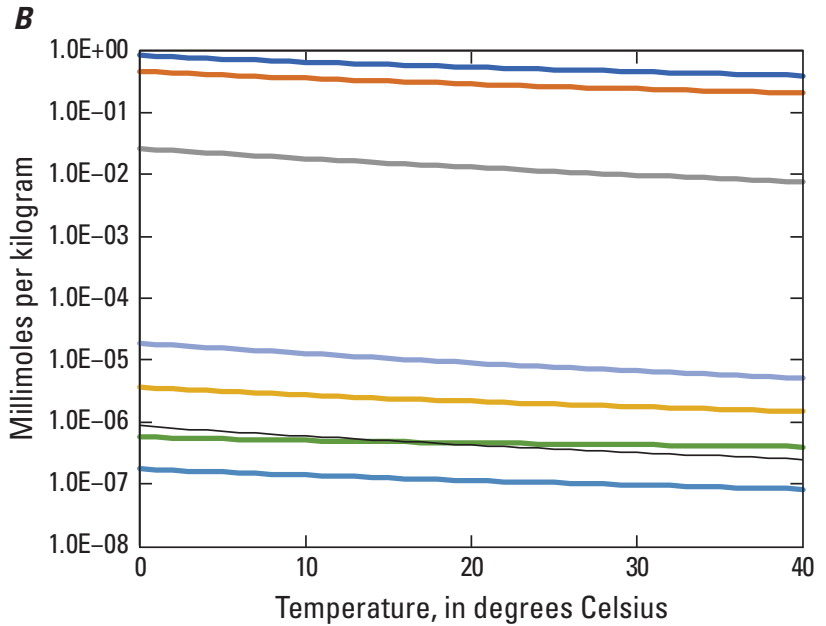

EXPLANATION

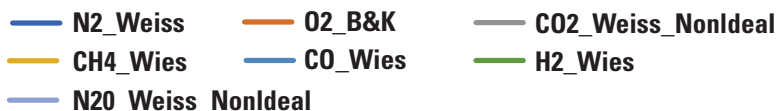

D

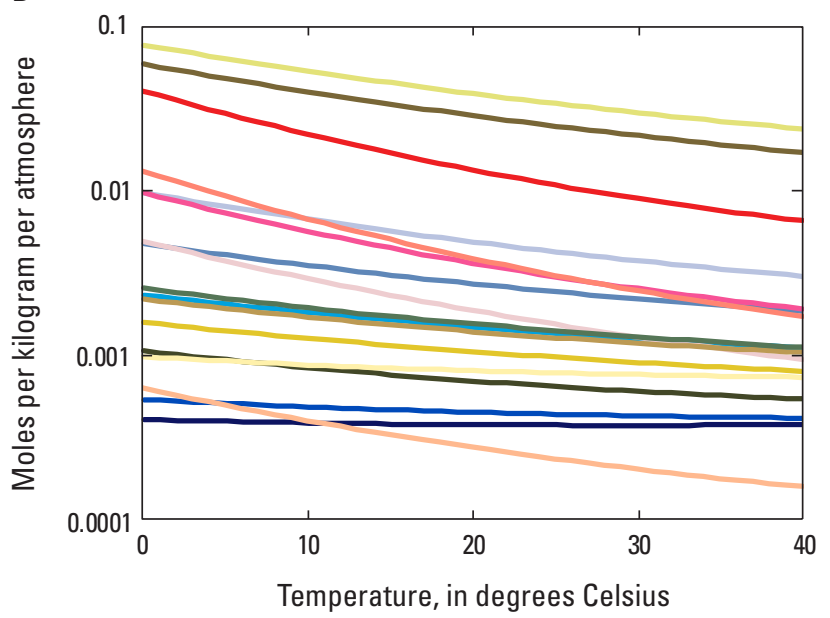

EXPLANATION

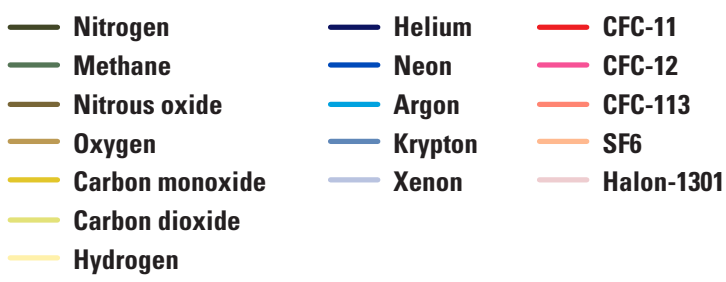

Figure 1. A, air-water solubility equilibrium concentration of inert (non-reactive) noble gases helium (He), neon ( $\mathrm{Ne})$, argon ( $\mathrm{Ar}$ ), krypton $(\mathrm{Kr})$, and xenon $(\mathrm{Xe})$ in water that are commonly used for modeling air-water equilibrium conditions; $B$, air-water solubility equilibrium concentration of the biogeochemically reactive gases nitrogen $\left(\mathrm{N}_{2}\right)$, oxygen $\left(\mathrm{O}_{2}\right)$, carbon dioxide $\left(\mathrm{CO}_{2}\right)$, methane $\left(\mathrm{CH}_{4}\right)$, carbon monoxide $(\mathrm{CO})$, hydrogen $\left(\mathrm{H}_{2}\right)$, and nitrous oxide $\left(\mathrm{N}_{2} \mathrm{O}\right) ; \mathrm{C}$, air-water solubility equilibrium concentration of environmental tracers chlorofluorocarbon-11, -12, -113 (CFC-11, CFC-12, CFC-113), sulfur hexafluoride $\left(\mathrm{SF}_{6}\right)$, and bromotrifluoromethane (halon-1301) that are commonly used for determining residence times of water; and $D$, Henry solubility constant of noble gases, reactive gases, and environmental tracers. Solubility concentration of the gases were determined for freshwater (salinity $=0$ per mil) over the temperature range of $0-40$ degrees Celsius at sea level (atmospheric pressure $=1$ standard atmosphere). The names of the lines consist of the name of the gas and a descriptor of the reference for the sources of the gas solubility data; and they are unique identifiers for the gas solubility data used by Dissolved Gas Modeling and Environmental Tracer Analysis (DGMETA; see the Database worksheet of DGMETA). 


\section{Methods}

The dissolved concentration of a gas, $C_{t}$, in water includes three major components: (1) the concentration of dissolved gas attributable to its solubility equilibrium with the atmosphere, $C_{e q}$; (2) an amount of gas in excess of solubility equilibrium resulting from the dissolution of air bubbles, $C_{a}$; and (3) an amount of gas that is produced or consumed in situ, either in an ocean, aquifer, surface water, or streambed, $C_{i s}$.

$$
C_{t}=C_{e q}+C_{a}+C_{i s}
$$

For some gases, the in situ production in water is zero or negligible. For other gases, the in situ production may be from biological processes $\left(\mathrm{N}_{2}\right.$; Heaton and others, 1983), radioactive decay of aquifer materials $\left({ }^{4} \mathrm{He}_{\mathrm{rad}}\right.$; Andrews and Lee, 1979), the decay of tritium in water $\left({ }^{3} \mathrm{He}_{\text {trit }}\right.$; Tolstikhin and Kamensky, 1969), or upwards migration of deep crustal or mantle fluids (Craig and others, 1978). Some gases can be consumed by biological processes that result in negative in situ concentration (for example, $\mathrm{O}_{2}$ reduction). Because the noble gases ( $\mathrm{He}, \mathrm{Ne}, \mathrm{Ar}, \mathrm{Kr}$, and $\mathrm{Xe}$ ) are chemically non-reactive, have stable concentrations in the atmosphere, and (except for $\mathrm{He}$ ) have in situ production rates that are often negligible, they provide the best tool for determining the temperature and excess air component of water when it equilibrated with the atmosphere (Kipfer and others, 2002).

Relatively stable, transient atmospheric trace gases, such as CFCs, $\mathrm{SF}_{6}$, and Halon-1301, are often used to determine the residence time of reservoirs of water because their concentrations in the atmosphere have changed since the 1930s (Gammon and others, 1982; Bullister and Weiss, 1983; Bullister, 1984; Bullister and Weiss, 1988; Busenberg and Plummer, 1992; Bu and Warner, 1995; Busenberg and Plummer, 2000; Bullister and others, 2002; Deeds, 2008; Beyer and others, 2014, 2015, 2017). To determine residence time, it is necessary to compute the atmospheric mole fraction (of dry air) of the gas when the water equilibrated with the atmosphere. Because the air-water equilibrium conditions are often unknown, it is common to measure noble gases (and nitrogen; N) along with $\mathrm{CFCs}_{2} \mathrm{SF}_{6}$, or Halon-1301 to provide the best estimate of air-water equilibrium conditions. The dry-air mole fraction of a $\mathrm{CFC}, \mathrm{SF}_{6}$, or Halon-1301 in water can be compared to the time-varying record of dry-air mole fractions in the atmospheric record to determine the year or range of years in which the water could have entered a reservoir of water. These methods also can apply to other more chemically reactive gases or transient gases to understand reaction rates and climate change records or deviations from non-equilibrium conditions.

\section{Gas Solubilities}

The solubility equilibrium concentration of a gas in water, $C_{e q}$, is governed by Henry's law, which says that the concentration of a gas dissolved in water is proportional to the partial pressure of the gas, $p$, above the water; this proportional relationship is defined as the Henry solubility constant: $K_{c p}=\frac{C_{e q}}{p}$ (commonly referred to as “ $K$ "). Henry's law also is frequently defined as a volatility constant, $K_{p c}$ (commonly known as " $K_{H}$ "), which is the inverse of $K_{c p}$ or $K_{p c}=1 / K_{c p}$; as this name implies, it is often used for expressing the volatility of sparsely soluble organic compounds from water. Henry's law also can be defined as a dimensionless molar ratio, $H$, that represents the molar concentration of the gas in water to the molar concentration of the gas in air. The Henry solubility constant, volatility constant, and dimensionless Henry constant are related by $H=R T K_{c p}=R T / K_{p c}$, where $R$ is the universal gas constant [82.056 cubic centimeters $\left(\mathrm{cm}^{3}\right)$-atm per mol per Kelvin] and $T$ is the temperature in Kelvin. For solubility studies of the atmospheric gases, the Henry solubility constant, $K_{c p}$, is the most commonly used form of Henry's law, and this form is adopted by DGMETA.

The concentration of a dissolved gas in equilibrium with the atmosphere is calculated using the following formula:

$$
C_{e q}=x\left(P_{h}-e_{w}\right) G_{(T, S)} \times \text { correction factors }
$$

where

$C_{e q} \quad$ is the solubility concentration in equilibrium with the atmosphere and may be computed in volumetric $\left(\mathrm{cm}^{3} / \mathrm{g}\right.$ ), mass (milligrams per liter; $\mathrm{mg} / \mathrm{L}$ ), molar (millimole per L; $\mathrm{mmol} / \mathrm{L}$ ), or molal (mmol/kilogram; kg) concentration units,

$x \quad$ is the dry-air mole fraction of the gas in the atmosphere in mole fraction,

$P_{h} \quad$ is the local total atmospheric pressure in atm,

$e_{w} \quad$ is the water vapor pressure (or saturation vapor pressure of water) in atm,

$G_{(T, S)} \quad$ is the generalized Henry solubility constant of a gas in water and is a function of temperature, $T$, and salinity, $S$, and may be expressed in any concentration units per atm,

$T \quad$ is the temperature of water in Kelvin, $S \quad$ is the salinity of water in parts per thousand (per mil) or g per kg (equivalent to 1 part dissolved solute per 1,000 parts of water), and

correction factors (for example, $P_{c}, R_{c}, U_{C}$, are defined in equations 7-12) are used as needed, depending on the form and units of $G_{(S, T)}$. 
Equation 2 is the general equation used by the program for computing the solubility of a gas in water and it is a function of the partial pressure of a gas $\left[x\left(P_{h}-e_{w}\right)\right]$ and the solubility function $G_{(T, S)}$. As written, $G_{(T, S)}$ is equal to the Henry's law solubility constant, $K_{c p}$, and is a function of temperature and salinity in any concentration units per atm. Equation 2 has been generalized to account for different definitions, formulations, and units of the solubility function, $G_{(T, S)}$, that was derived in the original solubility study of a gas. DGMETA builds specific forms of equation 2 in a modular fashion, such that the dry-air mole fraction, correction factors, and conversion terms can be added or removed based on the form of the solubility function, $G_{(T, S)}$. By default, DGMETA converts all gas concentrations to $\mathrm{cm}^{3} / \mathrm{g}$ of water-see the "Unit Conversions" section below. For gases that have transient dry-air mole fractions $(x)$, the equilibrium concentration of the gas will depend on the year in which the water was last in contact with the atmosphere. For such gases, the dry-air mole fractions can be manually adjusted from the Database worksheet by entering a different mole fraction from the atmospheric record for a particular year of interest.

DGMETA includes solubility equations for several gases: $\mathrm{He}, \mathrm{Ne}, \mathrm{Ar}, \mathrm{Kr}, \mathrm{Xe}, \mathrm{N}_{2}, \mathrm{CO}_{2}, \mathrm{H}_{2}, \mathrm{O}_{2}, \mathrm{CH}_{4}, \mathrm{~N}_{2} \mathrm{O}, \mathrm{CO}, \mathrm{CFC}-11$, CFC-12, CFC-113, $\mathrm{SF}_{6}$, and Halon-1301. This list can be expanded to suit user needs by entering gas solubility data and properties into the Database worksheet. The solubility equations were primarily derived to compute gas concentrations in fresh water and seawater over the salinity range of $0-35$ per mil (\%o or $\mathrm{g} / \mathrm{kg})$, temperature range of $0-40$ degrees Celsius $\left({ }^{\circ} \mathrm{C}\right)$, and pressure range of 0.5-1.0 atm, which corresponds to altitudes between sea level (1 atm) and 6,000 meters (m) above sea level, approximately.

\section{Approximations for Local Pressure, Water Vapor Pressure, and Salinity}

DGMETA uses the U.S. Standard Atmosphere (National Aeronautics and Space Administration , 1976) and barometric formula to approximate local atmospheric pressure based on an elevation specified by the user. The elevation may be based on the site location or the elevation where water enters an aquifer as recharge. DGMETA calculates pressure for the base level U.S. Standard Atmosphere only. The following calculation is valid for elevations less than $11,000 \mathrm{~m}$ :

$$
P_{h}=P_{o}\left[\frac{T_{b}}{T_{b}+L_{b}\left(h-h_{0}\right)}\right]^{\frac{g_{0} M_{a}}{R^{*} L_{b}}}
$$

where

$P_{h} \quad$ is the local atmospheric pressure in atm,

$P_{o} \quad$ is the sea level standard atmospheric pressure in $\mathrm{atm}(1 \mathrm{~atm}=1013.25$ millibars $)$,

$T_{b} \quad$ is the standard temperature, 288.15 Kelvin,

$L_{b} \quad$ is the standard lapse rate, -0.0065 Kelvin per m,

$h$ is the elevation in $m$ above sea level,

$h_{0} \quad$ is the elevation of the bottom layer, $0 \mathrm{~m}$ above sea level,

$g_{0} \quad$ is the gravitational acceleration, $9.80665 \mathrm{~m}$ per second squared,

$M_{a} \quad$ is the molar mass of air, $0.0289644 \mathrm{~kg}$ per mol, and

$R^{*} \quad$ is the universal gas constant, defined as 8.3144598 joules (J) per mol per Kelvin by the U.S. Standard

Atmosphere.

DGMETA approximates the water vapor pressure using the equation from Weiss and Price (1980):

$$
e_{w}=\exp \left[24.4543-\frac{6745.09}{T}-4.8489 \ln \left(\frac{T}{100}\right)-0.000544 S\right]
$$

where

$e_{w} \quad$ is the water vapor pressure (or saturation vapor pressure of water) in atm,

$T \quad$ is the temperature of water in Kelvin, and

$S \quad$ is salinity in per mil or $\mathrm{g} / \mathrm{kg}$.

When direct measurements of salinity or total dissolved solids are not available, salinity, $S$, can be approximated from measurements of specific conductance (SC) using an equation taken from Pickering (1981):

$$
S(\text { permilorg } / \mathrm{kg})=5.572 \times 10^{-4}(S C)+2.02 \times 10^{-9}(S C)^{2}
$$

where

$S \quad$ is salinity in per mil or $\mathrm{g} / \mathrm{kg}$, and

$S C \quad$ is the specific conductance in microsiemens per centimeter $(\mu \mathrm{S} / \mathrm{cm})$. 
Salinity is dependent on the ionic composition of water; therefore, relations between $S$ and $S C$ can vary for different environmental settings. Equation 5 was derived from more complex equations published in Standard Methods (American Public Health Association, 2005) with the assumption that the dissolved ions in water are identical to those in seawater. Differences between the predictions of equation 5 and the equations from Standard Methods typically result in less than a 0.1 percent change in the salinity factor over a wide range of temperature $\left(0-40^{\circ} \mathrm{C}\right)$ and specific conductance $(0-67,000 \mu \mathrm{S} / \mathrm{cm})$ values (U.S. Geological Survey, 2011). Consequently, this equation provides a reasonable approximation for most study objectives and applications.

\section{Forms of Solubility Equations}

As written in equation 2, $G_{(T, S)}$ is equal to the Henry's law solubility constant, $K_{c p}$, and is a function of temperature and pressure and is usually expressed in volumetric or gravimetric concentrations per atm. Equation 2 has been generalized to account for different definitions, formulations, and units of the solubility function, $G_{(T, S)}$, that was derived in the original solubility study of a gas. In general, two forms of $G_{(T, S)}$ are most often used for reporting solubility results. In one form, $G_{(T, S)}$ is a function for the solubility constant $\left(K_{c p}\right)$, Bunsen solubility constant $(\beta$; Weiss, 1970), mole fraction $(X$; Clever, 1979a; Smith and Kennedy, 1983), solubility constants that require a modified form of equation 2 for real gas behavior, such as $K_{o}$ (Weiss, 1974; Weiss and Price, 1980), or that approximate real gas behavior at pressures near $1 \mathrm{~atm}$, such as $K^{\prime}$ ' Warner and Weiss, 1985; Bu and Warner, 1995). In these cases, the corrections applied to equation 2 may only require conversion to different units - see the "Unit Conversions" section or correction for real gas behavior. The other form of $G_{(T, S)}$ that is frequently used is the moist-air solubility, which is the volume or concentration of a gas in water at equilibrium with water saturated air at a total pressure of $1 \mathrm{~atm}$. In other words, this is the volume or concentration of a gas expected to be dissolved in seawater or freshwater at sea level. This form is noted as $C^{*}$ (Weiss, 1970) and it includes the partial pressure of the gas at sea level in the solubility expression $\left[x\left(P_{0}-e_{w}\right)\right]$. It is, therefore, necessary to remove the pressure term from equation 2 to compute the solubility concentration at other elevations (or pressures) - see the "Correction" sections below. Similar to $C^{*}$, Weiss and Price (1980) and Benson and Krause (1984) derived equations that included the effects of real gas behavior for moist-air solubility concentrations in seawater or freshwater at sea level. To use their equations in equation 2, the pressure terms and non-ideality terms at 1 atm must be corrected in order to compute the solubility concentration at other elevations (pressure) - see the "Correction" sections below.

The solubility function, $G_{(T, S)}$, is usually a two- or three-part polynomial with coefficients that express the temperature and salinity dependence of the gas in water at $1 \mathrm{~atm}$. Most often the solubility equation is based on the integrated van 't Hoff equation and the Setchénow relation for salinity. The coefficients of the polynomial are found by fitting experimental solubility data to the function. The concentration units of $G_{(T, S)}$ are, therefore, dependent on the concentrations used in the experiment. DGMETA accepts most concentration units expressed as volumetric, gravimetric, molar, or molal units per atm. DGMETA will convert the concentrations internally to a common unit of $\mathrm{cm}^{3} / \mathrm{g}$ and can output concentrations in either $\mathrm{cm}^{3} / \mathrm{g}$, $\mathrm{mmol} / \mathrm{L}$, $\mathrm{mmol} / \mathrm{kg}$, or $\mathrm{mg} / \mathrm{L}$ — see the "Unit Conversions" section.

Below is a list of solubility equations that can be used to compute dissolved gas concentrations in water:

$$
\begin{gathered}
\ln C^{*} \text { or } \ln \beta=A_{1}+A_{2}\left(\frac{100}{T}\right)+A_{3} \ln \left(\frac{T}{100}\right)+A_{4}\left(\frac{T}{100}\right)+S\left[B_{1}+B_{2}\left(\frac{T}{100}\right)+B_{3}\left(\frac{T}{100}\right)^{2}\right] \\
\ln K_{o}, \ln K^{\prime}, \operatorname{orln} F^{*}=A_{1}+A_{2}\left(\frac{100}{T}\right)+A_{3} \ln \left(\frac{T}{100}\right)+A_{4}\left(\frac{T}{100}\right)^{2}+S\left[B_{1}+B_{2}\left(\frac{T}{100}\right)+B_{3}\left(\frac{T}{100}\right)^{2}\right] \\
\ln X=A_{1}+A_{2}\left(\frac{100}{T}\right)+A_{3} \ln \left(\frac{T}{100}\right)-N a C l\left[B_{1}+B_{2}\left(\frac{100}{T}\right)+B_{3} \ln \left(\frac{T}{100}\right)^{2}\right] \\
\ln C^{*}=A_{1}+\frac{A_{2}}{T}+\frac{A_{3}}{T^{2}}+\frac{A_{4}}{T^{3}}+\frac{A_{5}}{T^{4}}+S\left[B_{1}+\frac{B_{2}}{T}+\frac{B_{3}}{T^{2}}\right] \\
\ln C^{*}=A_{1}+\frac{A_{2}}{T_{s}}+\frac{A_{3}}{T_{s}^{2}}+\frac{A_{4}}{T_{s}^{3}}+\frac{A_{5}}{T_{s}^{4}}+\frac{A_{6}}{T_{s}^{5}}+S\left[B_{1}+\frac{B_{2}}{T_{s}}+\frac{B_{3}}{T_{s}^{2}}+\frac{B_{4}}{T_{s}^{3}}\right]+C_{1} S^{2} \\
\ln C^{*}=A_{1}+A_{2}\left(\frac{100}{T}\right)+A_{3} \ln \left(\frac{T}{100}\right)+A_{4}\left(\frac{T}{100}\right)+S\left[B_{1}+B_{2}\left(\frac{T}{100}\right)+B_{3}\left(\frac{T}{100}\right)^{2}\right]+C_{1} S^{2}
\end{gathered}
$$


where

In is the natural logarithm, a logarithm to base $e$ (a mathematical constant approximated as 2.71828),

$C^{*} \quad$ is the moist-air solubility concentration and is the volume or concentration of a gas in water at equilibrium with water saturated air at a total pressure of $1 \mathrm{~atm}$,

$\beta \quad$ is the Bunsen coefficient and is the volume of gas at standard temperature and pressure (STP) that partitions into the aqueous phase per unit volume of water at the temperature of the measurement when the partial pressure of the gas is 1 atm in milliliters $(\mathrm{mL})$ of gas per L of water,

$A_{j} \quad$ is the gas temperature coefficient for the $j$-th term $(1-6)$,

$B_{j} \quad$ is the gas salinity coefficient for the $j$-th term (1-4),

$C_{1}$ is the gas salinity coefficient for certain formulations,

$S \quad$ is the salinity of the water in per mil or $\mathrm{g} / \mathrm{kg}$,

$T$ is the water temperature in Kelvin for equations $\mathrm{G}_{1}, \mathrm{G}_{2}, \mathrm{G}_{3}$, and $\mathrm{G}_{6}$,

$T_{S} \quad$ is the scaled temperature of water, unitless, for equations $\mathrm{G}_{4}$ and $\mathrm{G}_{5}$, calculated as $\ln \left(\frac{298.15-t}{273.15+t}\right)$, where $t$ is temperature in ${ }^{\circ} \mathrm{C}$,

$K_{o} \quad$ is the fugacity solubility constant in mol per kg per atm (Weiss and Price, 1980; Warner and Weiss, 1985),

$\mathrm{K}^{\prime} \quad$ is the partial pressure equilibrium solubility constant in mol per $\mathrm{kg}$ of water per atm (Warner and Weiss, 1985),

$F^{*} \quad$ is moist-air solubility concentration adjusted for real gas behavior (Weiss and Price, 1980; Warner and Weiss, 1985),

$X \quad$ is the mole fraction solubility concentration (Clever 1979a, b, 1980; Smith and Kennedy, 1983), and

$\mathrm{NaCl}$ is the sodium chloride concentration in mol per $\mathrm{L}$ and is calculated following Aeschbach-Hertig and others (1999) as equation 6 below.

$$
N a C l=\frac{S}{M_{N a C l}} \rho_{(t, S)} / 1000
$$

where

$\mathrm{M}_{\mathrm{NaCl}} \quad$ is the molar mass of sodium chloride, $58.443 \mathrm{~g} / \mathrm{mol}$, and $\rho_{(t, S)} \quad$ is the density of water as function of temperature and salinity in $\mathrm{kg}$ per cubic meter $\left(\mathrm{m}^{3}\right)$ - see the "Unit Conversions" section for the calculation.

Equation $\mathrm{G}_{1}$ was used by Weiss $(1970,1971)$ to compute solubilities for dissolved $\mathrm{N}, \mathrm{O}_{2}$, and $\mathrm{Ar}$ (Weiss, 1970), for He and $\mathrm{Ne}$ (Weiss, 1971), and for $\mathrm{CH}_{4}, \mathrm{CO}$, and $\mathrm{H}_{2}$ (Wiesenburg and Guinasso, 1979) in fresh water and seawater. This equation is formulated with the integrated van 't Hoff equation for temperature and the Setchénow relation for salinity and can be used to compute gas solubilities from Bunsen constants $(\beta)$ or as moist air solubilities $\left(C^{*}\right)$. Weiss and Price (1980) used equation $\mathrm{G}_{2}$ to compute the fugacity solubility coefficient $\left(K_{0}\right)$ and fugacity adjusted moist-air solubility $\left(F^{*}\right)$ for $\mathrm{N}_{2} \mathrm{O}$ and $\mathrm{CO}_{2}$. Equation $\mathrm{G}_{3}$ is from Clever $(1979 \mathrm{a}, \mathrm{b})$ and Smith and Kennedy (1983) and was used to compute solubilities of the noble gases in fresh water and seawater. Equation $\mathrm{G}_{4}$ was used by Benson and Krause (1984) to compute dissolved $\mathrm{O}_{2}$ concentrations in fresh water and seawater. Equation $\mathrm{G}_{5}$ was used by Garcia and Gordon $(1992,1993)$ to compute dissolved $\mathrm{O}_{2}$ solubility and later was used by Hamme and Emerson (2004) for $\mathrm{Ne}, \mathrm{Ar}$, and $\mathrm{N}$ in fresh water and seawater. Equation $\mathrm{G}_{6}$ was used by Jenkins and others (2019) to fit noble gas solubility data in water and seawater.

\section{Pressure Corrections}

Some expressions of gas solubility were derived for moist air at sea level (total pressure is $1 \mathrm{~atm}$, adjusted for water saturated air) to facilitate use in oceanographic studies. These solubility forms are often noted as $C^{*}$ or $F^{*}$ (eqs. $\mathrm{G}_{1}$, $\mathrm{G}_{4}, \mathrm{G}_{5}$, and $\mathrm{G}_{6}$ ), and these forms need pressure corrections to be used at other elevations (pressures; Benson and Krause, 1984; Kipfer and others, 2002). DGMETA will apply the following correction term when the value of the "Use pressure correction, $P_{c}$ " field is "Yes" on the Database worksheet:

$$
P_{c}=\frac{1}{P_{o}-e_{w}}
$$

where

$P_{c} \quad$ is an optional pressure correction for water vapor when the solubility constant $\mathrm{G}_{(S, T)}$ is normalized to moist air at $1 \mathrm{~atm}$,

$P_{o} \quad$ is the sea level standard atmospheric pressure in $\operatorname{atm}(1 \mathrm{~atm}=1013.25$ millibars $)$, and

$e_{w} \quad$ is the water vapor pressure (or saturation vapor pressure of water) in atm. 


\section{Real Gas Corrections}

Two methods for dealing with non-ideal behavior of real gases are included in the program. DGMETA will compute additional gas corrections for non-ideal behavior when the value in the "Treat non-ideal" field is "Yes" on the Database worksheet. Some gases can deviate from ideal behavior, and these deviations may limit the accuracy of the solubility computations. For many gases this deviation is small at total pressures near $1 \mathrm{~atm}$ in comparison to solubility measurements (Weiss and Price, 1980; Warner and Weiss, 1985). Benson and others (1979) and Benson and Krause (1984) used the second virial coefficient to correct $\mathrm{O}_{2}$ for real gas behavior. Similarly, Weiss and Price (1980) derived a relationship for the second virial and cross virial coefficient to correct $\mathrm{N}_{2} \mathrm{O}$ and $\mathrm{CO}_{2}$ for real gas behavior:

Benson and others (1979) and Benson and Krause (1984):

$$
R_{c}=\frac{1-\theta P_{h}}{1-\theta}
$$

where

$$
\begin{aligned}
& R_{c} \quad \text { is the local real gas correction, in atm, } \\
& \theta \text { is a polynomial function for the second virial } \\
& \text { coefficient between oxygen and air (eq. } 22 \\
& \text { in Benson and others, 1979), and } \\
& P_{h} \quad \text { is the local atmospheric pressure in atm. }
\end{aligned}
$$

Weiss and Price (1980):

$R_{c}=\exp \left[P_{h}\left(\frac{B+2 \delta}{R T}\right)+\bar{v}\left(\frac{1-P_{h}}{R T}\right)\right]=\exp \left[P_{h} B^{*}+\bar{v}\left(\frac{1-P_{h}}{R T}\right)\right]$

where

$$
\begin{aligned}
& \begin{array}{c}
R_{c} \\
P_{h}
\end{array} \text { is the real gas correction, } \\
& B^{*} \quad \text { is a polynomial function (eq. } 11 \text { in Weiss and } \\
& \text { Price, 1980) relating the quantity } \frac{B+2 \delta}{R T}, \\
& \text { where } B \text { is the second virial coefficient and } \\
& \delta \text { is the cross-virial coefficient between the } \\
& \text { trace gas and air, } \\
& \bar{v} \quad \text { is the partial molal volume in } \mathrm{cm}^{3} \text { per mol, } \\
& R \quad \text { is the gas constant (82.056 } \mathrm{cm}^{3} \text {-atm per mol } \\
& \text { per Kelvin), and } \\
& T \quad \text { is the temperature in Kelvin. }
\end{aligned}
$$

For $\mathrm{CO}_{2}$, Weiss (1974) did not define the expansion series, $B^{*}$, like was done for $\mathrm{N}_{2} \mathrm{O}$ (Weiss and Price, 1980). To facilitate the use of equation 9 with $\mathrm{CO}_{2}$, the function $B^{*}$ (eq. 11 in Weiss and Price, 1980) was fitted to the quantity $\frac{B+2 \delta}{R T}$ based on equations for the second virial coefficient and cross-virial coefficient given by Weiss (1974). For formulations in moist air at sea level, $F^{*}$, the real gas correction at sea level must be removed to apply it at other elevations. This is done by dividing the real gas correction (eq. 9) by the real gas correction at sea level, $\exp \left(B^{*}\right)$.

\section{Unit Conversions}

Solubilities can be reported in gravimetric, volumetric, molar, or molal concentration units or mole fractions, $X$. By default, DGMETA automatically converts all gas solubilities internally from the units specified in the "Units of solubility constants" field on the Database worksheet to cubic centimeters of gas at an STP per gram of water, which is the most common unit of measurement of the noble gases. Most units can be converted using the density of water, molar gas volume, and molar mass of each gas. In general, conversion to and from cubic centimeters per gram use the molar volumes of each gas defined on the Database worksheet rather than the molar volume of an ideal gas $\left(M_{I}=R T \approx 22.414\right)$. The default molar volumes are computed by dividing the molar mass by the molar density. It is possible that the original solubility study used $M_{I}$ for conversions, and therefore, in some cases the $M_{I}$ may be more appropriate than the individual molar gas volumes used by default. Solubilities as mole fractions (Clever, 1979a, b, 1980; Smith and Kennedy, 1983) are converted to cubic centimeters per gram following Aeschbach-Hertig and others (1999). All dissolved gas modeling results report gas concentrations of each model component in $\mathrm{cm}^{3} / \mathrm{g}, \mathrm{mmol} / \mathrm{L}$, and $\mathrm{mg} / \mathrm{L}: \mathrm{mmol} / \mathrm{L}$ to $\mathrm{cm}^{3} / \mathrm{g}$ :

$$
U_{c}=\frac{V}{\rho_{(t, S)}}
$$

$\mathrm{mg} / \mathrm{L}$ to $\mathrm{cm}^{3} / \mathrm{g}$ :

$$
U_{c}=\frac{V}{M \rho_{(t, S)}}
$$

mole fraction to $\mathrm{cm}^{3} / \mathrm{g}$ :

$$
U_{c}=\frac{V}{M_{H 2 O}}\left(\frac{X}{1-X}\right) \frac{\rho_{(t, S=0)}}{\rho_{(t, S)}}
$$

Bunsen solubility $\left(\mathrm{cm}^{3} / \mathrm{mL}\right)$ to $\mathrm{cm}^{3} / \mathrm{g}$ :

$$
U_{c}=\frac{1}{\rho_{(t, S)}}
$$

where

$V \quad$ is the molar volume of a gas in mols per $\mathrm{cm}^{3}$ (molar mass in $\mathrm{g} / \mathrm{mol}$ divided by molar density in $\mathrm{g} / \mathrm{cm}^{3}$ ),

$\rho_{(t, S)} \quad$ is the density of water as function of temperature and salinity in $\mathrm{kg} / \mathrm{m}^{3}$ - see the "Unit Conversions" section for the calculation,

$M \quad$ is the molar mass of a gas in $\mathrm{g}$ per mol,

$X \quad$ is the mole fraction of a gas in water, in mol of gas per mol of water, and

$M_{H 2 O} \quad$ is the molar mass of water (18.016 $\mathrm{g}$ per mol). 
The density of water, $\rho_{(t, S)}$, in $\mathrm{kg}$ per cubic meter $\left(\mathrm{m}^{3}\right)$, is computed from the equations derived by Bigg $(1967 \mathrm{a}, \mathrm{b})$ and Millero and Poisson (1981). It is computed in two parts:

$$
\rho_{(t, S)}=\rho_{(t)}+A S+B S^{\frac{3}{2}}+C S
$$

where

$$
\rho_{(t)}=999.842594+6.793952 \times 10^{-2} t-9.09529 \times 10^{-3} t^{2}+1.001685 \times 10^{-4} t^{3}-1.120083 \times 10^{-6} t^{4}+6.536336 \times 10^{-9} t^{5}
$$

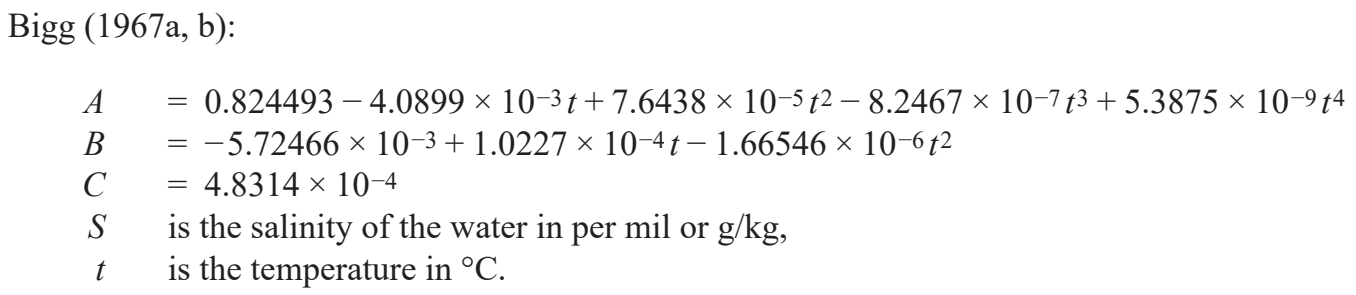

\section{Models of Excess Air}

DGMETA can be used to model air-water equilibrium conditions under different theories of the presence and partitioning of excess air, represented as $C_{a}$ in equation 1. Excess air $(A)$ is a phenomenon in which dissolved gas concentrations exceed the concentrations attributable to equilibrium in the atmosphere (Heaton and Vogel, 1981). The composition of the excess air is similar to the composition of the atmosphere, hence the name "excess air." This extra amount of air is from air-bubbles entrained in water that may be partially or completely dissolved into solution. Excess air may form in groundwater from water-table fluctuations during recharge or in ocean and surface-water bodies from wave action.

Dissolved gas concentrations of excess air can be unfractionated or fractionated relative to the atmospheric composition. Excess air will be unfractionated (UA) when air bubbles are completely dissolved into a solution (Heaton and Vogel, 1981; eq. 15). Fractionated excess air can occur from the diffusion of gases across a water table or by incomplete dissolution of entrapped air bubbles $\left(A_{e}\right)$. Stute and others (1995) proposed a partial re-equilibration (PR) model of fractionated excess air that describes a process where water loses its excess air component through progressive re-equilibration with the atmosphere via diffusion of gases across a water table or water surface (eq. 16). Because lighter gases will diffuse more quickly than heavier ones, the water is depleted in lighter gases relative to the heavier gases. The fractionation parameter, $F$, used in the PR model is the degree to which the gases have fractionated and may range from zero (unfractionated amount of excess air) to infinity (zero excess air). Excess air also can be fractionated if entrapped air-bubbles are only partially dissolved into a solution. Aeschbach-Hertig and others (2000) proposed a closed-system equilibration (CE) model of fractionated excess air that results from a gas phase (entrapped air-bubble), $A_{e}$, that is partially dissolved into a solution due to increased hydrostatic pressure (eq. 17). The fractionation of the gases dissolved into a solution is governed by the solubilities of the gases, which again tends to fractionate the lighter gases with lower solubilities relative to the heavier gases with higher solubilities (fig. 1D). Thus, water following this model will be enriched in heavier gases as compared to the lighter gases. For the CE model, the $F$ parameter relates the final and initial gas volumes of the entrapped air, such that $F=\frac{V_{b}}{V_{a}}$; where $V_{a}$ and $V_{b}$ are the initial and final gas volumes. Commonly, the final volume of the gas phase is smaller than the initial volume such that the $F$ parameter typically ranges from zero (complete dissolution of entrapped air into solution and excess air is unfractionated) to 1 (no excess air formed). A unique feature of this model is that it also can describe degassing or the formation of a gas phase (air bubble) in water. In this case, a drop in the total gas pressure could lead to the formation of a bubble such that the final volume is greater than the initial volume. In this case, the $F$ parameter is greater than 1 - see example 5. 
DGMETA uses the following equations for the excess air concentration in water:
UA model:
$C_{a}=x A$

PR model:

$$
C_{a}=x A \exp \left(-F \frac{D}{D_{N e}}\right)
$$

CE model:

$$
C_{a}=\frac{x A_{e}(1-F)}{1+\frac{x A_{e} F}{C_{e q}}}
$$

where

$$
\begin{aligned}
& C_{a} \quad \text { is the dissolved concentration of a gas in } \\
& \text { excess of air-water equilibrium from the } \\
& \text { entrainment of air in water in } \mathrm{cm}^{3} \text { (STP) } \\
& \text { per } g \text { of water, } \\
& x \quad \text { is the dry-air mole fraction of the gas in the } \\
& \text { atm in mole fraction, } \\
& A \quad \text { is the amount of air dissolved in water in } \mathrm{cm}^{3} \\
& \text { (STP) per g of water, } \\
& D \quad \text { is the molecular diffusion coefficient } \\
& \text { of the gas, } \\
& D_{N e} \quad \text { is the molecular diffusion coefficient of } \mathrm{Ne} \text {, } \\
& A_{e} \quad \text { is the amount of entrapped air as a gas phase } \\
& \text { in water in } \mathrm{cm}^{3} \text { (STP) of air per } \mathrm{g} \text { of water, } \\
& F \quad \text { is the fractionation parameter that describes } \\
& \text { the degree of diffusive fractionation when }
\end{aligned}
$$

Diffusion coefficients $(D)$ for gases are computed from the Arrhenius equation:

$$
D=B \exp \left(\frac{E_{a}}{R T}\right)
$$

where

$$
\begin{gathered}
B \quad \begin{array}{l}
\text { is the diffusion coefficient when the } \\
\text { temperature goes to infinity, in square } \\
\text { meters per second }\left(\mathrm{m}^{2} / \mathrm{s}\right),
\end{array} \\
E_{a} \quad \text { is the activation energy in J per mol, } \\
R \quad \text { is the gas constant (8.3143 J per mol per } \\
\text { Kelvin), and } \\
T \quad \text { is the temperature in Kelvin. }
\end{gathered}
$$

Diffusion coefficients were compiled for $\mathrm{He}, \mathrm{Ne}$, $\mathrm{Kr}, \mathrm{Xe}, \mathrm{CO}_{2}$, and $\mathrm{CH}_{4}$ from Jähne and others (1987); for
Ar from Holocher and others (2002); for $\mathrm{N}_{2}$ and $\mathrm{O}_{2}$ from Ferrell and Himmelblau (1967); for chlorofluorocarbons-11, -12 from Zheng and others (1998); and $\mathrm{SF}_{6}$ from King and Saltzman (1995).

\section{Inverse Modeling of Dissolved Gases}

DGMETA can compute best-fit parameter estimates for temperature, salinity, elevation (pressure), excess air (or entrapped air), fractionation of gases, and excess $\mathrm{N}_{2}$ for different models of excess air and solubility equations. Best-fit parameters are determined from inverse methods that solve equation 1 repeatedly until the error between modeled and measured concentrations, relative to the measurement error, is minimized.

DGMETA uses an inverse modeling method similar to that described by Ballentine and Hall (1999) and Aeschbach-Hertig and others (1999). More specifically, DGMETA uses a weighted, nonlinear least-squares parameter-estimation routine that was originally developed from the Gauss-Newton method (with scaling parameter) described by Johnson and Faunt (1992) and modified to allow for constrained parameters. The Jacobian matrix is numerically estimated using the five-point Lagrange differentiation. Standard errors of the fitted parameters are from the diagonal terms of the variance-covariance matrix.

Model fits are computed by minimizing the chi-square test statistic between measured and modeled gas concentrations relative to the gas concentration error:

$$
\chi^{2}=\sum_{l=1}^{n} \frac{\left(O_{i}-M_{i}\right) 2}{\sigma_{i}^{2}}
$$

where

$$
\begin{gathered}
n \quad \begin{array}{c}
\text { is the number of modeled gases, } \\
O_{i}
\end{array} \text { is the observed (measured) concentration of } \\
\text { the i-th gas, } \\
M_{i} \quad \begin{array}{r}
\text { is the modeled total gas concentration (eq. 1) } \\
\text { of the i-th gas, and }
\end{array} \\
\sigma_{i} \quad \text { is the standard error of the observed } \\
\text { (measured) concentration of the i-th gas. }
\end{gathered}
$$

The chi-square probability is calculated using the chi-square distribution and the degrees of freedom (number of gases minus the number of model-fit parameters). Chi-square probabilities are only calculated for models having a degree of freedom greater than zero.

Temperature is constrained to the range of $0-100{ }^{\circ} \mathrm{C}$. Excess air/entrapped air is constrained to the range of $0-250 \mathrm{~cm}^{3} / \mathrm{kg}$. Salinity is constrained to the range of 0-50 per mil (or $\mathrm{g} / \mathrm{kg}$ ). Pressure is constrained by elevation and can range from $-2,000$ to $10,000 \mathrm{~m}$ above sea level, which corresponds to about $1.2-0.26 \mathrm{~atm}$. Fractionation is constrained to the range of $0-5$. Excess $\mathrm{N}_{2}$ is constrained to the range of $0-500 \mathrm{mg} / \mathrm{L}$ as $\mathrm{N}$. 


\section{Monte Carlo Simulations}

Monte Carlo simulations are included in this program to provide better estimates of the parameter uncertainty for dissolved gas models. For some models, like the CE model, parameter uncertainties can be larger than the computed parameter estimates. This can occur when the $F$ parameter in the $\mathrm{CE}$ model approaches the inflection point at 1 (0.8 less than $F$ less than 1.2) or when gas samples appear to have more than one model solution or have large entrapped air values (less than $50 \mathrm{~cm}^{3} / \mathrm{kg}$ ) — see Jung and Aeschbach-Hertig (2018) for a more complete description. In cases where the parameter uncertainty is as large or larger than the parameter estimates, the results of the CE model are ambiguous. These large uncertainties become problematic with computing tracer concentrations because the large uncertainties in model parameters produce large uncertainties in computed tracer concentrations. This situation can be less of an issue with more precise gas measurements that have uncertainties of less than 0.5 percent. Uncertainties of gas measurements determined from existing methods are typically between 1 and 5 percent.

One method to assess the error around the best-fit parameters is to compute Monte Carlo simulations. PANGA (Jung and Aeschbach-Hertig, 2018) provides an interactive Monte Carlo method for exploring the individual cases listed above and potentially refining the model estimates in cases where there are multiple solutions. DGMETA also can be used to generate Monte Carlo simulations and store the results in a worksheet, but DGMETA does not provide automated graphical tools to explore the distribution of simulations for patterns. As an alternative, DGMETA can compute parameter uncertainties more locally around the best-fit parameter estimates computed from the inverse modeling method. Calculations of tracer concentrations from these error estimates have lower tracer uncertainties (see example 4).

Monte Carlo simulations are performed by generating random sets of gas concentrations from a normal distribution using the measured gas and error concentration for a sample and then solving for the best-fit model parameters. This process is repeated many times in order to produce a large population of simulations that can provide estimates of the possible solution space and parameter uncertainty in the model. The number of simulations is typically repeated until the variance of the parameter values asymptotically approach a stable value. The number of Monte Carlo simulations needed to give uncertainty estimates is typically greater than 500, but less than 10,000. By default, DGMETA uses 5,000 simulations. The random gas samples and Monte Carlo simulation results can be output to a separate worksheet if needed.

Random sets of gas samples can be generated by one of two options: (1) by assuming the gases are positively correlated and not independent or (2) by assuming complete independence. The default used by DGMETA is to compute random gas concentrations using option 1. For this option, gas concentrations are computed using a single random number to generate the entire set of gas concentrations. This will produce sets of gases with concentrations that are higher or lower than the original set of concentrations, but within the error of each gas. Alternatively, completely independent sets of gases can be generated. This approach computes a random number for each gas, such that the set of gases produced from this method are truly random. Unfortunately, that approach can generate parameter errors that are as large as the parameters themselves and hence do not improve the model confidence. In these cases, Jung and Aeschbach-Hertig (2018) recommend a more detailed analysis of the Monte Carlo results using PANGA. Alternatively, it is possible to compute parameter uncertainties that are more local to the best-fit parameters using sets of gas concentrations that increase and decrease in unison (option 1). Parameter estimates and their uncertainties computed using these dependent sets of gases tend to more strongly adhere to the best-fit parameter values based on the original gas data in comparison to results obtained from completely independent sets of gas concentrations. Users can choose either Monte Carlo simulation option.

\section{Environmental Tracer Calculations}

Environmental tracers such as CFCs, $\mathrm{SF}_{6}$, Halon-1301, ${ }^{3} \mathrm{He}_{\text {trit }}$, and ${ }^{4} \mathrm{He}_{\text {rad }}$ can be used to determine the time elapsed since the water was last in contact with the atmosphere. The measured concentrations of these tracers are not typically meaningful because the concentration used for computing the age of water; like the dry-air mole fraction, the amount of He produced from the decay of tritium in water $\left({ }^{3} \mathrm{He}_{\text {trit }}\right)$, or from the decay of uranium and thorium in rocks $\left({ }^{4} \mathrm{He}_{\mathrm{rad}}\right)$; are calculated quantities that are dependent on the air-water equilibration conditions when the water was last in contact with the atmosphere. Because these conditions (temperature and excess air contribution) are often unknown, they may be estimated or, more frequently, they are determined by inverse modeling of noble gases or Ar- $\mathrm{N}_{2}$.

DGMETA can compute atmospheric dry-air mole fractions for transient atmospheric gases and concentrations of ${ }^{3} \mathrm{He}_{\text {trit }}$ and ${ }^{4} \mathrm{He}_{\mathrm{rad}}$ using air-water equilibration conditions determined from inverse modeling of dissolved gases. Computations of air-water equilibration conditions and environmental tracer concentrations using DGMETA provides a consistent treatment of data that may have been analyzed at different laboratories and reported in different units. In addition, the concentrations of tracers and their errors computed by DGMETA can be used in newer versions of TracerLPM (Jurgens and others, 2012) to compute water ages using the same error-weighted inverse modeling technique described in this report. 


\section{Transient Atmospheric Gases}

Trace atmospheric gases, such as $\mathrm{CFCs}_{2} \mathrm{SF}_{6}$, and Halon-1301, have dry-air mole fractions that have increased in the atmosphere over the last 100 years - though mole fractions for the CFCs have been declining since the 1990s. The dry-air mole fraction is computed by rearranging equation 1 and substituting the total concentration for the measured concentration of the gas and ignoring the in situ production term. Equations for the dry-air mole fraction depend on the model of excess air and are computed using the equations below:

UA model:

$$
x=\frac{C_{s}}{G_{(T, S)}\left(P_{h}-e_{w}\right)+\frac{A}{V}}
$$

PR model:

$$
x=\frac{C_{s}}{G_{(T, S)}\left(P_{h}-e_{w}\right)+\frac{A\left[\exp \left(-F_{D_{N}}^{D}\right)\right]}{V}}
$$

CE model:

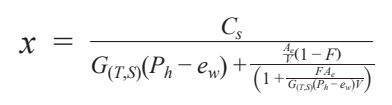

where
$x \quad$ is the dry-air mole fraction of the gas in the atmosphere in mole fraction,
$C_{s}$ is the sample concentration (measured value) of a gas tracer (CFC, $\mathrm{SF}_{6}$, or Halon-1301) in mols per $\mathrm{kg}$,
$\mathrm{G}_{(T, S)} \quad$ is the solubility function for the Henry solubility coefficient in mols per $\mathrm{kg}$,
$P_{h} \quad$ is the local atmospheric pressure in atm,
$e_{w} \quad$ is the water vapor pressure in atm,
$A$ is the excess air component in $\mathrm{cm}^{3}$ (standard temperature pressure) per $\mathrm{g}$ of water,
$V \quad$ is the molar volume of a gas in mol per $\mathrm{cm}^{3}$,
$F \quad$ is the fractionation parameter that describes the degree of diffusive fractionation when used with the PR model or the final to initial volume of entrapped air $\left(A_{e}\right)$ when used with the CE model,
$D \quad$ is the molecular diffusion coefficient of the gas,
$D_{\mathrm{Ne}} \quad$ is the molecular diffusion coefficient of $\mathrm{Ne}$, and
$A_{e} \quad$ is the entrapped air volume (volume of trapped air per volume of water) in $\mathrm{cm}^{3}$ (standard temperature pressure) per $g$ of water,

\section{Tritiogenic Helium-3 and Helium-4}

Tritiogenic helium-3 and terrigenic He components are computed from the mass balance of ${ }^{3} \mathrm{He}$ and ${ }^{4} \mathrm{He}$ and are described in more detail in Schlosser and others (1989), Solomon (2000), and Solomon and Cook (2000). Air-water equilibrium model results are used to determine the concentration of $\mathrm{He}$ in solubility equilibrium with the atmosphere $\left(\mathrm{He}_{\mathrm{eq}}\right)$ and the concentration of He originating from excess air $\left(\mathrm{He}_{\mathrm{a}}\right)$. The amount of terrigenic helium $\left(\mathrm{He}_{\text {terr }}\right)$ is calculated by subtracting the amount of $\mathrm{He}_{\mathrm{eq}}$ and $\mathrm{He}_{\mathrm{a}}$ from the measured total dissolved helium $\left(\mathrm{He}_{\mathrm{s}}\right)$ in each sample. Terrigenic helium includes He that accumulates in water from ${ }^{4} \mathrm{He}_{\mathrm{rad}}$ emitted from radioactive decay of uranium and thorium in aquifer materials and $\mathrm{He}$ from the Earth's mantle $\left(\mathrm{He}_{\mathrm{man}}\right)$ that has migrated upwards through faults or is released by weathering of volcanic sediments. Terrigenic helium that is dominated by radiogenic sources in the Earth's crust generally has a low ${ }^{3} \mathrm{He} /{ }^{4} \mathrm{He}$ ratio $\left(\mathrm{R}_{\text {terr }}\right)$ that is typically less than $5 \times 10^{-8}$, whereas $\mathrm{He}_{\text {terr }}$ that is dominated by mantle He generally has high $\mathrm{R}_{\text {terr }}$ that is typically greater than $5 \times 10^{-6}$. 
DGMETA determines $\mathrm{He}_{\mathrm{a}}$ from dissolved gas modeling results so the calculation of ${ }^{3} \mathrm{He}_{\text {trit }}$ (Schlosser and others, 1989) is in the equations below:

$$
{ }^{3} \mathrm{He} e_{\text {trit }}=H e_{s} R_{s}-\left(H e_{s}-H e_{\text {terr }}\right) R_{a}+H e_{e q} R_{a}(1-\alpha)-H e_{\text {terr }} R_{\text {terr }}
$$

where

${ }^{3} \mathrm{He}_{\text {trit }} \quad$ is the helium concentration from the decay of tritium in $\mathrm{cm}^{3}$ (STP) per $\mathrm{g}$ of water,

$\mathrm{He}_{s}$ is the helium concentration of the sample in $\mathrm{cm}^{3}$ (STP) per g of water,

$R_{S} \quad$ is the ${ }^{3} \mathrm{He} /{ }^{4} \mathrm{He}$ ratio of the sample corrected for the decay of tritium (half-life is equal to 12.32 years; Lucas and

Unterweger, 2000) for the time between the dates of sample collection and analysis,

$\mathrm{He}_{\text {terr }}$ is the helium concentration of terrigenic origin in $\mathrm{cm}^{3}$ (STP) per $\mathrm{g}$ of water,

$R_{a} \quad$ is the ${ }^{3} \mathrm{He} / 4 \mathrm{He}$ ratio of air $\left(\mathrm{R}_{\mathrm{a}}=1.384 \times 10^{-6}\right.$; Clarke and others, 1976),

$H_{e q}$ is the helium concentration in equilibrium with the atmosphere in $\mathrm{cm}^{3}$ (STP) per $\mathrm{g}$ of water,

$\alpha \quad$ is the isotopic fractionation factor of He during air-water solubility equilibrium, and

$R_{\text {terr }} \quad$ is the ${ }^{3} \mathrm{He} /{ }^{4} \mathrm{He}$ ratio of terrigenic helium.

$$
H e_{\text {terr }}=H e_{s}-H e_{e q}-H e_{a}
$$

where

$\mathrm{He}_{\text {terr }}$ is the helium concentration of terrigenic origin in $\mathrm{cm}^{3}$ (STP) per $\mathrm{g}$ of water,

$H_{s}$ is the helium concentration of the sample in $\mathrm{cm}^{3}$ (STP) per $\mathrm{g}$ of water,

$\mathrm{He}_{e q}$ is the helium concentration in equilibrium with the atmosphere in $\mathrm{cm}^{3}$ (STP) per $\mathrm{g}$ of water, and

$\mathrm{He}_{a}$ is the helium concentration of excess air in $\mathrm{cm}^{3}$ (STP) per $\mathrm{g}$ of water.

$$
\alpha=\exp \left[-\left(-0.0299645+\frac{19.8715}{T}+\frac{-1833.92}{T^{2}}\right)(1+0.000464 S)\right]
$$

where

$\alpha \quad$ is the isotopic fractionation factor of He during air-water solubility equilibrium,

$T \quad$ is the temperature of water in Kelvin, and

$S \quad$ is salinity in per mil or $\mathrm{g} / \mathrm{kg}$.

Samples that have $\mathrm{He}_{\mathrm{s}}$ less than $\mathrm{He}_{\mathrm{eq}}$ usually have experienced gas loss or the gases are fractionated. When $\mathrm{He}_{\mathrm{s}}$ is less than $\mathrm{He}_{\text {eq }}$, calculations of ${ }^{3} \mathrm{He}_{\text {trit }}$ using equation 23 will underestimate ${ }^{3} \mathrm{He}_{\text {trit }}$ concentrations in the sample. In these cases, DGMETA will compute ${ }^{3} \mathrm{He}_{\text {trit }}$ as the excess of solubility equilibrium, which is usually the largest component of He in samples without $\mathrm{He}_{\text {terr }}$ :

$$
{ }^{3} \mathrm{He} e_{\text {trit }}=H e_{s}\left(R_{s}-R_{e q}\right)
$$

where

${ }^{3} \mathrm{He}_{\text {trit }}$ is the helium concentration from the decay of tritium in $\mathrm{cm}^{3}$ (STP) per $\mathrm{g}$ of water,

$\mathrm{He}_{s}$ is the helium concentration of the sample in $\mathrm{cm}^{3}(\mathrm{STP})$ per $\mathrm{g}$ of water,

$R_{s} \quad$ is the ${ }^{3} \mathrm{He} /{ }^{4} \mathrm{He}$ ratio of the sample corrected for the decay of tritium (half-life is equal to 12.32 years; Lucas and

Unterweger, 2000) for the time between the dates of sample collection and analysis, and

$R_{e q} \quad$ is the ${ }^{3} \mathrm{He} / 4 \mathrm{He}$ ratio of helium in equilibrium with the atmosphere and is equal to the isotopic fractionation

factor times the ${ }^{3} \mathrm{He} / 4 \mathrm{He}$ ratio of air $\left(\alpha R_{a}\right)$. 
For many calculations of ${ }^{3} \mathrm{He}_{\text {trit }}$, the presence of $\mathrm{He}_{\text {terr }}$ in samples requires the $\mathrm{R}_{\text {terr }}$ value to be known or to be determined from an analysis of He isotope systematics. In these situations, the samples where ${ }^{3} \mathrm{H}$ is low or absent (tritium-dead) can be used to identify the source and appropriate $\mathrm{R}_{\text {terr }}$ value to apply to samples with ${ }^{3} \mathrm{H}$. The $\mathrm{R}_{\text {terr }}$ can often be identified using a modified Weise plot (Weise and Moser, 1987; Stute and others, 1992) where the ratio of $\mathrm{He}_{\text {terr }}$ normalized to the excess-air-corrected total $\mathrm{He}$ concentration, $\mathrm{He}_{\text {terr }} /\left(\mathrm{He}_{\mathrm{s}}-\mathrm{He}_{\mathrm{a}}\right)$, is plotted against the ratio of the excess-air-corrected $\mathrm{R}_{\mathrm{s}}$ to the $\mathrm{R}_{\mathrm{a}}$.

Figure 2 shows an example of the modified Weise plot with several lines that illustrate possible evolutionary paths for the accumulation of $\mathrm{He}$ in water from different sources of He. Water that enters a water body such as an aquifer, for example, will tend to follow a temporal process that starts on the left near the atmospheric equilibrium ratio of water, $R_{s} / R_{a},(0.983)$ and will generally evolve to the right as the water ages and accumulates $\mathrm{He}$ from terrigenic sources. In most groundwater systems, water will gain $\mathrm{He}_{\text {terr }}$ from the decay of uranium and thorium in sediments causing the $\mathrm{R}_{\mathrm{s}}$ to evolve along the lower dashed line showing a radiogenic source of $\mathrm{He}$ (dashed line in fig. 2). In some cases, for example, in basaltic rock aquifers or in areas of seismic activity that allow deep mantle gases to migrate upwards along faults (Craig and others, 1978; Plummer and others, 2000), the He in groundwater may be substantially influenced by a mantle-derived He source $\left(\mathrm{He}_{\mathrm{man}}\right)$ and cause $\mathrm{R}_{\mathrm{s}} / \mathrm{R}_{\mathrm{a}}$ end-member values greater than 5 (dotted line in fig. 2). In other cases, mantle He may be only a minor component caused by the weathering of small amounts of volcanic sediments in an aquifer (Jurgens and others, 2016), and the groundwater may show a mixed signature of mantle and radiogenic sources of $\mathrm{He}$ (dashed-dotted line in fig. 2). Tritiogenic helium-3 is another source of He. For water that entered a system after 1950, terrigenic sources of He may not be a substantial component of the total $\mathrm{He}$, so the resulting $\mathrm{R}_{\mathrm{s}} /$ $\mathrm{R}_{\mathrm{a}}$ will mainly reflect the contribution of ${ }^{3} \mathrm{He}$ from the decay of tritium. Samples that exemplify this process will contain ${ }^{3} \mathrm{H}$ and will plot along the red arrow in the upper left of figure 2. Samples with a mixture of post-1950s water and water older than 1,000 years will tend to have multiple sources of He. Samples that contain measurable levels of ${ }^{3} \mathrm{H}$ and substantial amounts of $\mathrm{He}_{\text {terr }}$ with a radiogenic source may plot above the dashed line on figure 2 .

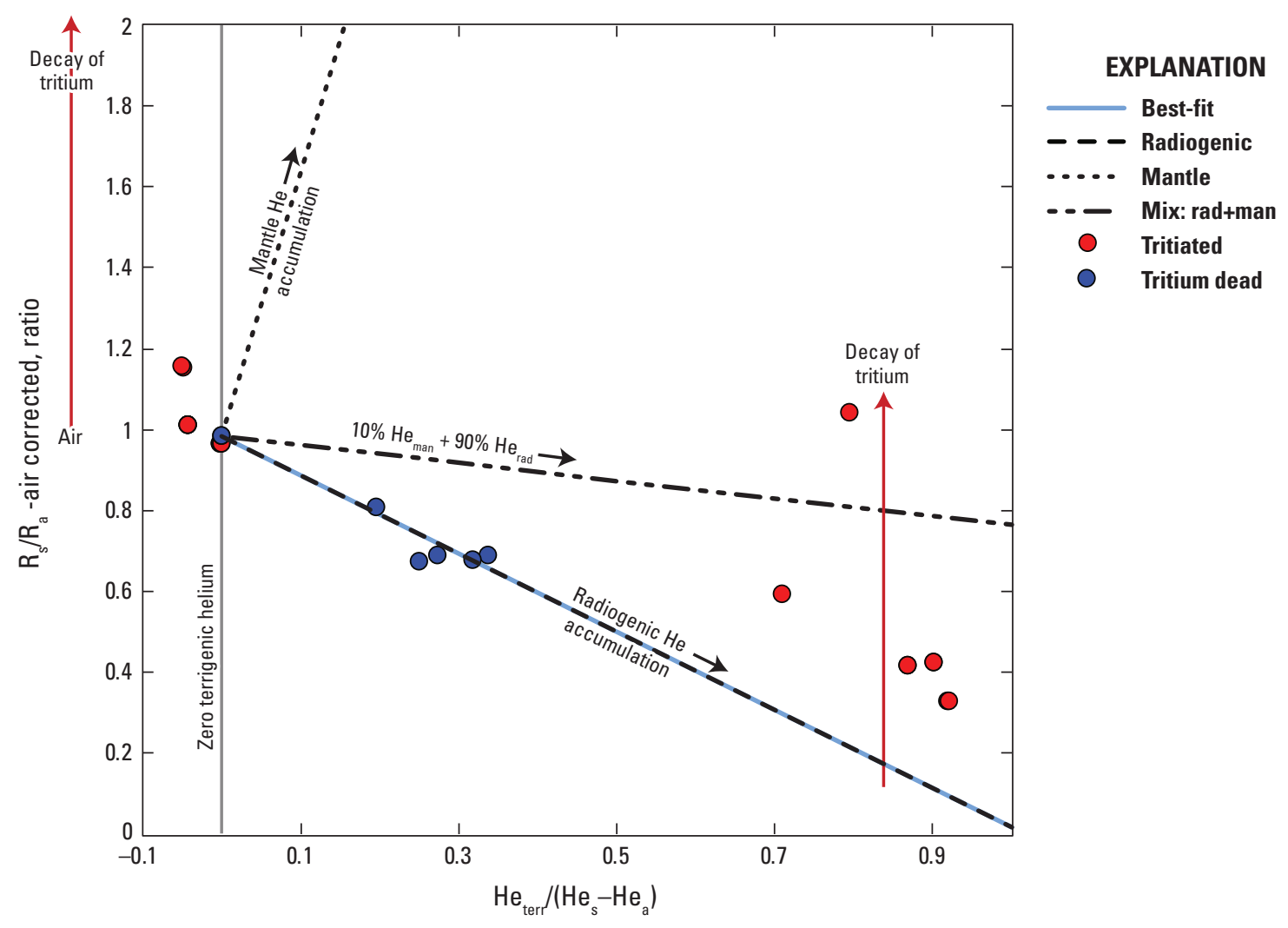

Figure 2. Excess air-corrected helium isotope ratio of the sample relative to air versus the concentration of terrigenic helium as a fraction of the total helium in the sample corrected for excess-air. 
To facilitate the He isotope analysis, samples are categorized as either "tritiated" or "tritium dead" using a tritium threshold value that is specified by the user (default is 0.5 tritium unit, TU). DGMETA automatically creates a graph like figure 2 and computes a best-fit line through all tritium-dead samples (blue circles). Those samples are expected to contain the largest proportion of $\mathrm{He}_{\text {terr }}$ and will usually indicate the $R_{s} / R_{a}$ value of the terrigenic source. For the blue samples on figure 2, a radiogenic He source appears to be the main source of $\mathrm{He}_{\text {terr }}$ and, therefore, the best-fit $\mathrm{R}_{\text {terr }}$ value is $2 \times 10^{-8}$. The best-fit line and $\mathrm{R}_{\text {terr }}$ value are determined from the equation below:

$$
Y=(1-x)\left(R_{e q}-R_{\text {terr }}+\frac{T_{b}}{H e_{e q}}\right)+R_{\text {terr }}
$$

where

$$
\begin{aligned}
& Y \quad \text { is the computed } R / R_{a} \text { value, } \\
& x \quad \text { is the excess air corrected value of terrigenic } \\
& \text { helium }\left(\mathrm{He}_{\text {terr }} / \mathrm{He}_{\mathrm{s}}-\mathrm{He}_{\mathrm{a}}\right) \text {, } \\
& R_{e q} \quad \text { is the }{ }^{3} \mathrm{He} / 4 \mathrm{He} \text { ratio of helium in equilibrium } \\
& \text { with the atmosphere and is equal to the } \\
& \text { isotopic fractionation factor times the } \\
& { }^{3} \mathrm{He} / 4 \mathrm{He} \text { ratio of air }\left(\alpha R_{a}\right) \text {, } \\
& R_{\text {terr }} \quad \text { is the }{ }^{3} \mathrm{He} / 4 \mathrm{He} \text { atom ratio of the } \\
& \text { terrigenic helium, } \\
& T_{b} \quad \text { is the background }{ }^{3} \mathrm{He}_{\text {trit }} \text { in water, and } \\
& H e_{e q} \text { is helium in solubility equilibrium } \\
& \text { with the atm. }
\end{aligned}
$$

The He isotope graph on the tracer calculation worksheet (“_TrcOut"; fig. 2) is controlled by variables listed in a table to the right of the figure. The table lists the best-fit $R_{\text {terr }}$ value computed by the program and this value is used as the default value to calculate ${ }^{3} \mathrm{He}_{\text {trit }}$ concentrations using equation $23-$ see example 4 . Changes to the $R_{\text {terr }}$ value will affect the graph and ${ }^{3} \mathrm{He}_{\text {trit }}$ calculations. The best-fit $\mathrm{R}_{\text {terr }}$ can be changed manually based on user-defined fits and also can be specified for each sample individually in the ${ }^{3} \mathrm{He} /{ }^{4} \mathrm{He}$ terr column of the Tracer Output worksheet. Users also can change the percentage of mantle $\mathrm{He}$ value and the ${ }^{3} \mathrm{He} /{ }^{4} \mathrm{He}$ ratio of mantle helium $\left(\mathrm{R}_{\mathrm{man}}\right)$ to explore different mixing lines of radiogenic and mantle He components on the graph (dash-dot-dot line). The default in the DGMETA program is set to 10 percent mantle He.

DGMETA is programmed to only report ${ }^{3} \mathrm{He}_{\text {trit }}$ concentrations for samples where the percentage of $\mathrm{He}_{\text {terr }}$ is less than 70 percent of the total He. Uncertainty in the ${ }^{3} \mathrm{He} /{ }^{4} \mathrm{He}$ ratio of the $\mathrm{He}_{\text {terr }}$ can lead to unreliable estimates of ${ }^{3} \mathrm{He}_{\text {trit }}$ for samples with large amounts of $\mathrm{He}_{\text {terr }}$. DGMETA computes ${ }^{3} \mathrm{He}_{\text {trit }}$ for all samples, but does not report it for samples with $\mathrm{He}_{\text {terr }}$ greater than 70 percent of the total He; instead, the output includes an additional column with a recommended ${ }^{3} \mathrm{He}_{\text {trit }}$ value to report. Tritiogenic helium is not reported for samples with $\mathrm{He}_{\text {terr }}$ greater than 70 percent of the total $\mathrm{He}$. In cases where the computed ${ }^{3} \mathrm{He}_{\text {trit }}$ is small or negative, but the ${ }^{3} \mathrm{H}$ concentration indicates that ${ }^{3} \mathrm{He}_{\text {trit }}$ should be present, DGMETA reports a value of less than $1 \mathrm{TU}$. In other cases, the concentration may not be reliably quantifiable.

\section{Program Description}

DGMETA includes an Excel ribbon tab that contains buttons to operate the program and four worksheets for entering sample data or gas solubility data. The DGMETA tab is in the Excel ribbon at the top of the Excel window (fig. 3). The worksheet called SuppInfo contains supporting information on and references to program implementation; models of excess air; equations of local pressure, water density, and vapor pressure; conversion factors; gas solubility formulations used by the program; and a set of sample calculations of pressure, salinity, model gas concentrations, and mole fractions of environmental tracers (fig. 4). The worksheet called Database is used for entering new or modifying existing gas solubility data and properties (fig. 5). The worksheet called Input_Gases is used for entering dissolved gas concentrations (fig. 6), and the worksheet called Input_Tracers is used for entering measurements of environmental tracers (fig. 7). The program is operated from buttons in the DGMETA ribbon menu that can be used to update gas solubility equations, create graphs, model dissolved gases, and calculate tracer concentrations. Some of the subroutines produce worksheets with graphs, model results, or tracer concentrations. Graphs of dissolved gas concentrations are output to a worksheet named by the user with the suffix “_Graphs" appended to the worksheet name. Dissolved gas modeling results are output to a worksheet with the suffix “_ModOut." Environmental tracer calculations are output to a worksheet with the suffix " TrcOut." The "Collapse Tracer Calculation" button will compute average tracer concentrations and results are output to a worksheet with the suffix “_AvgVal.” Flat files with a single-row header can be created for dissolved gas model output files ("_ModOut”), calculated tracer concentrations ("_TrcOut”). or average tracer concentrations (“_AvgVal”). 


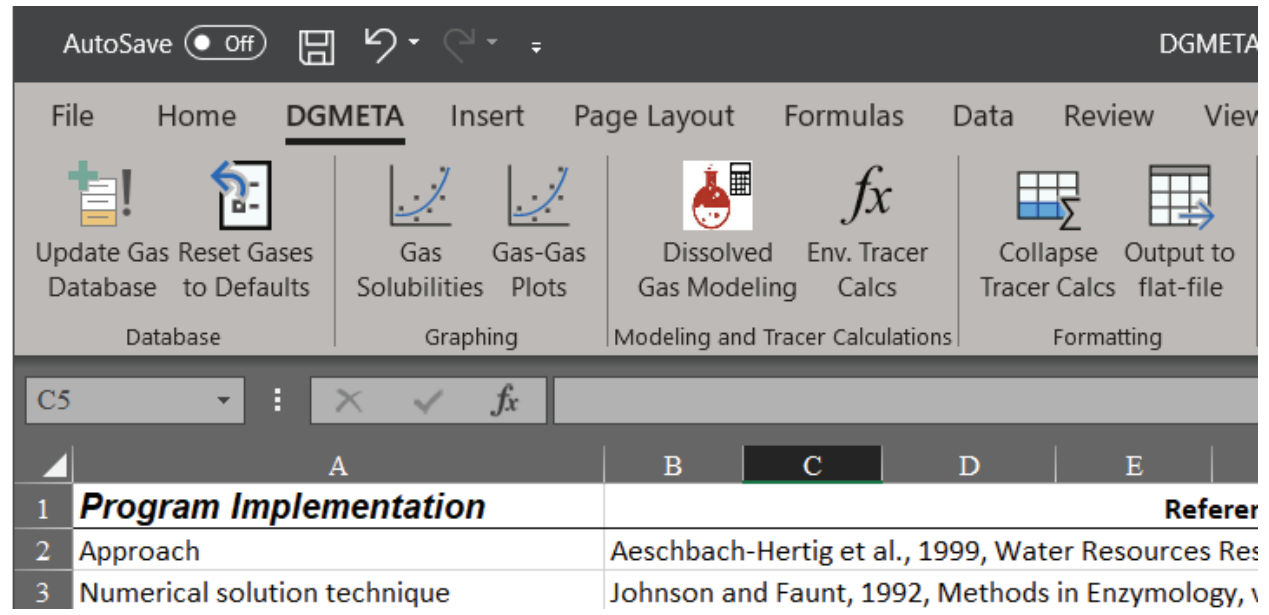

Figure 3. The Dissolved Gas Modeling and Environmental Tracer Analysis tab in the Excel ribbon.

\section{DGMETA Worksheets}

The following sections describe the function and purpose of four worksheets included in DGMETA: SuppInfo, Database, Input_Gases, and Input_Tracers. Worksheets colored gray (SuppInfo and Database) are mainly for reference, whereas worksheets colored blue are used for entering sample data.

\section{Supplnfo Worksheet}

The SuppInfo worksheet contains supporting information on and references to program implementation; models of excess air; equations of local pressure, water density, and vapor pressure; conversion factors; and gas solubility formulations used by the program (fig. 4). Two important pieces of information are codes used by the program to call up different models of excess air and for specifying the solubility equation of a gas. Worksheet functions are available to calculate total gas concentrations (eq. 1) and mole fractions of gases. These functions use the two-character short name of the excess air model to compute concentrations - see example 3. Examples of how to call up and use the worksheet functions are given at the bottom of the SuppInfo worksheet. When specifying new gas solubility data on the Database worksheet, the solubility equation used by the program is specified by an integer number that refers to one of the equations below the Dissolved Gas Solubility Formulations heading on the SuppInfo worksheet. Note that addition of new gas solubility data and other customizations of DGMETA do not require changes to the SuppInfo worksheet. A calculator for converting between pressure and elevation is provided at the bottom of the worksheet for convenience.

\section{Database Worksheet}

The Database worksheet contains a table of solubility coefficients, form of solubility equations, dry-air mole fractions, solubility units, molar volumes, diffusivities, and non-ideal behavior used to calculate the solubility concentration and diffusivity of gases in water. The table can be used for entering new or modifying existing gas solubilities and their formulations (fig. 5). References to source data are provided where applicable. There are comments associated with many fields at the top of the table that contain specific information on the values that can be entered in those fields.

The solubility table is loaded into memory when the program is first opened or when the button "Update Gas Database" is clicked from the DGMETA tab in the Excel ribbon. Users can change the primary solubility equations used for different gases to explore the effects of using different solubility equations on dissolved gas model results - see examples 1 and 2. A value of "Yes" next to the gas (column A) instructs the program to use that formulation for dissolved gas modeling and tracer concentration calculations. The default set of equations are the Weiss solubilities for $\mathrm{He}, \mathrm{Ne}, \mathrm{Ar}$, and $\mathrm{Kr}$ and the Clever solubility for Xe. The program can reset to the default set of gas solubilities using button "Reset Gases to Defaults" from the DGMETA tab in the Excel ribbon (fig. 3).

A unique name for each solubility equation must be specified when entering new gas solubility data on the Database worksheet. Worksheet functions are available to call up gas solubility concentrations for different solubility data. These worksheet functions use the unique name of the gas to call up the solubility formula listed in the solubility table - see example 1. 


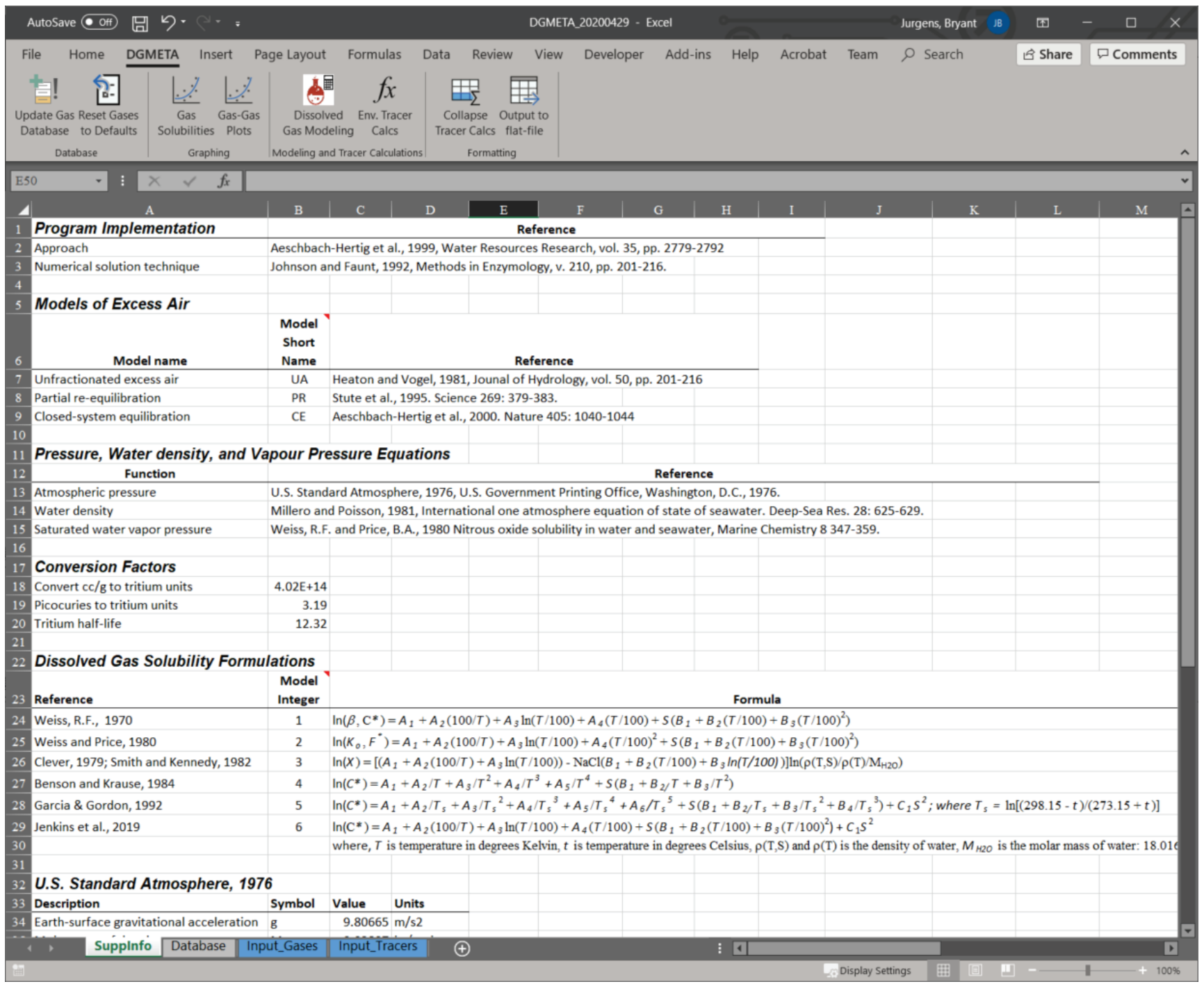

Figure 4. The SuppInfo worksheet, which contains supporting information on and references to program implementation; models of excess air; equations of local pressure, water density, and vapor pressure; conversion factors; gas solubility formulations used by the program; and a set of sample calculations of pressure, salinity, model gas concentrations, and mole fractions of environmental tracers. 


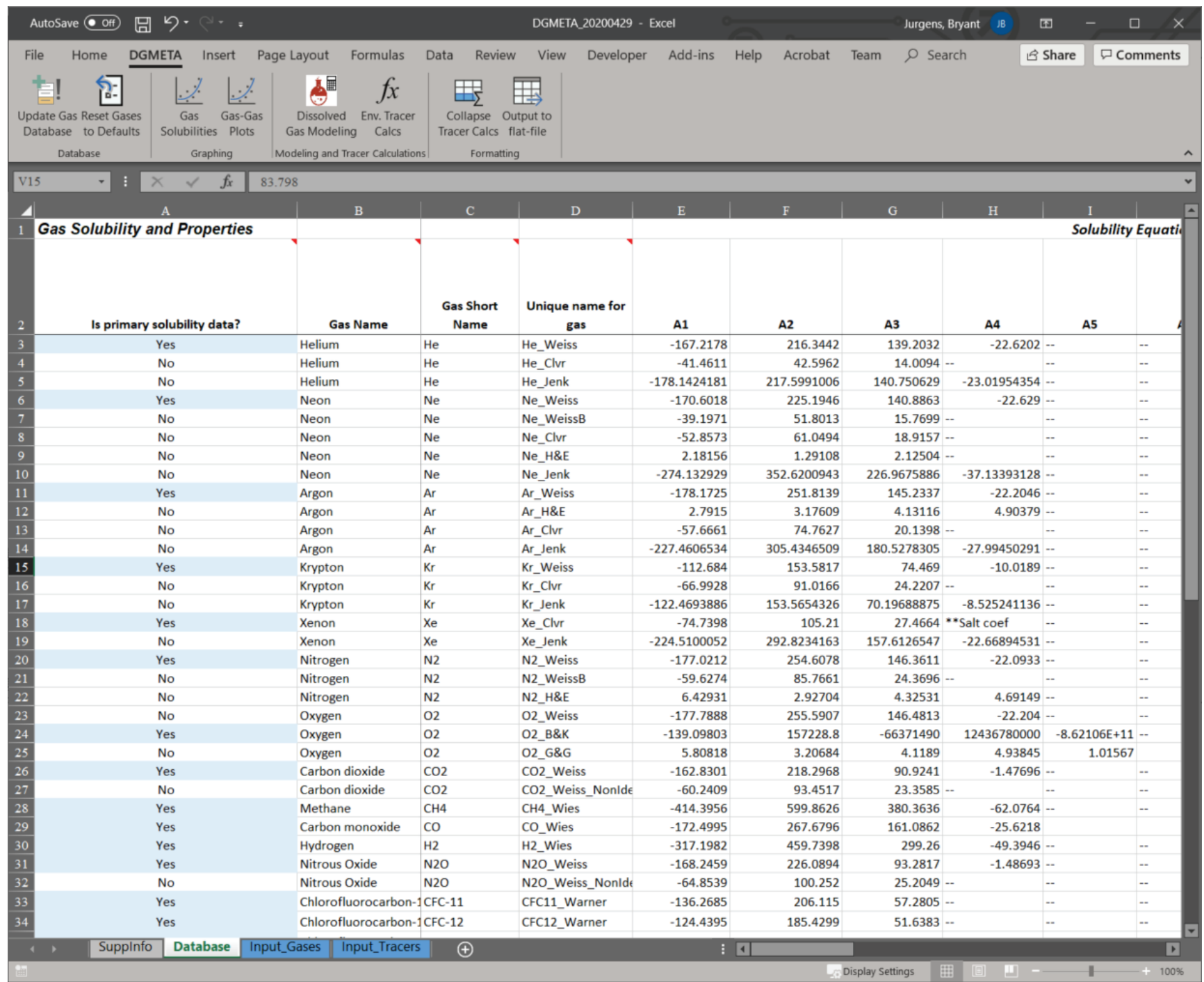

Figure 5. The Database worksheet. 


\section{Input_Gases Worksheet}

The Input_Gases worksheet is used to enter sample information, initial or fixed model values, and dissolved gas concentration data for water samples (fig. 6). Entries for Sample identification (ID), Sample Date, and values for the initial or fixed air-water model parameters are required fields for each sample. Values for the model parameters may be estimated initially and solved for later - see the "Dissolved Gas Modeling" section. Values for salinity and elevation (commonly referred to as the recharge elevation in groundwater studies), and excess air or entrapped air are needed for all models (UA, PR, and CE). The CE and PR models require a value for $\mathrm{F}$. Models that include $\mathrm{N}_{2}$ as a model constraint require a value for excess $\mathrm{N}_{2}$, which is most often set to zero unless there is evidence of denitrification or some other contribution of excess $\mathrm{N}_{2}$ in the sample. Parameter values are treated as initial starting values when those parameters are optimized during dissolved gas modeling. Parameter values are fixed if the model parameter is not chosen to be optimized. Commonly, salinity and elevation are not optimized so these values are often fixed using site estimates. Salinity can be estimated from measurements of total dissolved solids or from SC using equation 5 . The elevation is used to calculate the atmospheric pressure during air-water equilibrium. In groundwater studies, the elevation of air-water equilibrium occurs at the phreatic surface where recharge occurs. The elevation of the well or spring where the dissolved gas sample was collected is often used when the actual recharge elevation is unknown.

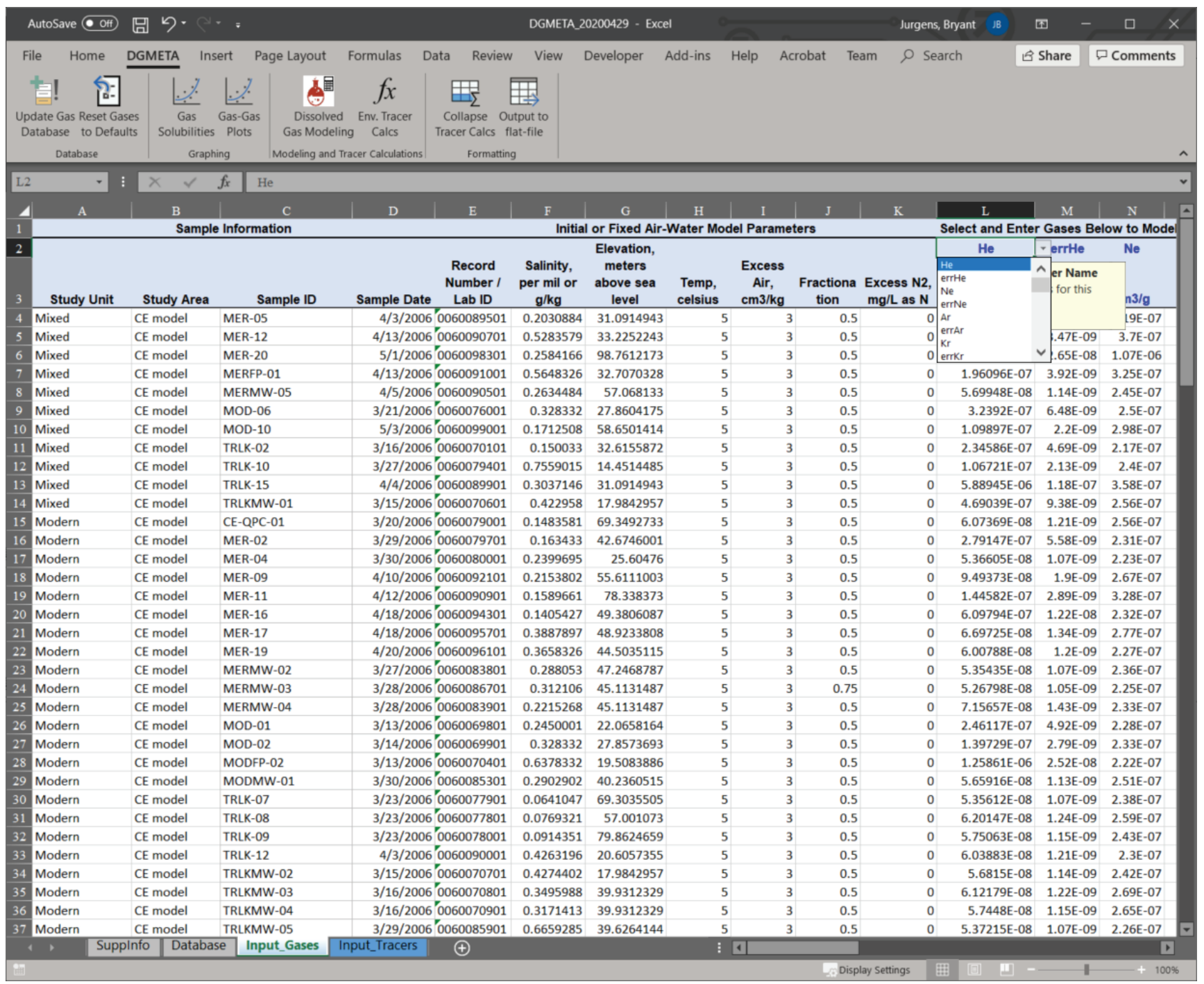

Figure 6. The Input_Gases worksheet and the Dissolved Gas Modeling and Environmental Tracer Analysis tab in the Excel ribbon. 
Dissolved gas concentrations and uncertainty for each sample are entered below the section "Select and Enter Gases Below to Model Air-Water Equilibrium Conditions or Graph." Each gas requires an estimate of the measurement uncertainty (usually 1 standard error) in order to find the best-fit solution to the data. Measurement uncertainty for dissolved gases can vary by gas and analytical method, but are typically between 1 and 5 percent of the measured value.

The list of gases in columns below the section "Select and Enter Gases Below to Model Air-Water Equilibrium Conditions or Graph" can be changed to different gases and different concentration units by the user. Worksheet cells that have blue text contain a drop-down list of gases or units (fig. 6). Row 2 contains a list of gases and row 3 contains a list of units that the program will accept. The list of gases in the drop-down menu is controlled by the list of gases entered on the Database worksheet. Adding new gases to the Database worksheet will expand the gases listed in the drop-down menus on the Input_Gases worksheet.

\section{Input_Tracers Worksheet}

The Input_Tracers worksheet is used to enter laboratory results for ${ }^{3} \mathrm{H}, \overline{\mathrm{H}}$ e isotopes, dissolved gas data, and transient atmospheric gas tracers (fig. 7). The program uses the tracer information on this worksheet to calculate environmental tracer concentrations of dry-air mole fractions and $\mathrm{He}$ components from dissolved gas model results listed in a dissolved gas modeling output worksheet, which is identified by the suffix "_ModOut." Dissolved gas model output is based on information entered on the Input_Gases worksheet so samples entered on the Input_Tracers worksheet should correspond to samples entered on the Input_Gases worksheet.

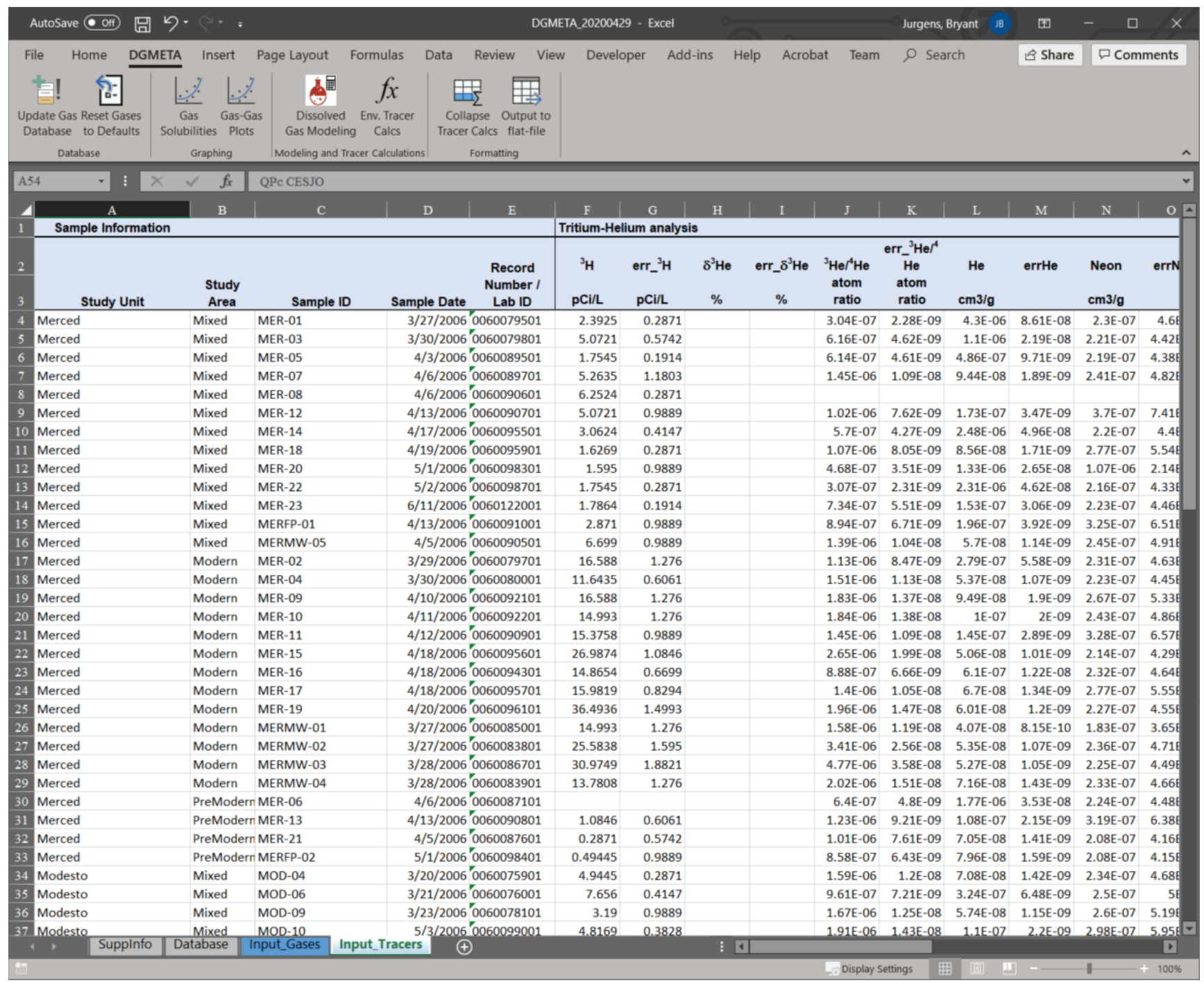

Figure 7. The Input_Tracers worksheet and the DGMETA (Dissolved Gas Modeling and Environmental Tracer Analysis) tab in the Excel ribbon. 
The first several columns of the Input Tracers worksheet pertain to sample information. The Sample ID and Sample Date are used to pair environmental tracer measurements on the Input_Tracers worksheet with samples listed in a dissolved gas modeling output worksheet. As such, multiple dissolved gas models and multiple rows of tracer measurements will produce multiple rows of calculated environmental tracer concentrations on the Environmental Tracer Output worksheet ("_TrcOut").

Measurements of ${ }^{3} \mathrm{H}$, isotopes of $\mathrm{He}\left({ }^{3} \mathrm{He} /{ }^{4} \mathrm{He}\right), \mathrm{He}$, and $\mathrm{Ne}$ are used to compute the concentration of He derived from the decay of tritium $\left({ }^{3} \mathrm{He}_{\text {trit }}\right)$ and the amount of $\mathrm{He}_{\text {terr }}$ in a sample. Measured concentrations of these constituents are entered below the column "Tritium-Helium analysis." Helium isotope concentrations and errors can be entered as $\delta^{3} \mathrm{He}$ or $\mathrm{R}_{\mathrm{s}}$. If the analysis date of the He isotope measurement is provided by the user, the isotopes will be corrected for the decay of tritium between the sample date and the analysis date. If the analysis date is unknown, the program will use a presumed analysis date that is 6 months after the sample date. The measurement uncertainty must also be entered or estimated for each measured value.

Atmospheric Gas Tracers are listed to the right of Tritium-Helium analysis (not shown in fig. 7). For each gas listed in the "Atmospheric Gas Tracers" section, the program will compute the dry-air mole fraction in the Environmental Tracer Output worksheet ( TrcOut). The list of gases can be modified by the user for cells with blue text. Worksheet cells that have blue text contain a drop-down list of gases or units. Row 2 contains a list of gases and row 3 contains a list of units that the program will accept. The list of gases in the drop-down menu is controlled by the list of gases entered in the Database worksheet. Adding new gases to the Database worksheet will expand the gases listed in the drop-down menus on the Input_Gases and Input_Tracers worksheets.

\section{DGMETA Operation}

The DGMETA tab is used to operate the program (fig. 3). The buttons on the tab are organized into four areas of program functionality: Database, Graphing, Modeling and Tracer Calculations, and Formatting.

\section{Database}

There are two buttons that cause the database, stored in memory, to change. The first button called "Update Gas
Database" is used when changes to the database table are made. Additional gases can be added to the database by following the formatting and conventions provided on the Database worksheet. The field comments at the top of the database table can contain specific information on the values that can be entered in those fields. The button "Update Gas Database" also will need to be clicked when changes to the existing gases are made. For example, many reactive gases, like $\mathrm{CO}_{2}$, have transient atmospheric mole fractions (mixing ratios) not just the environmental trace gases. As such, it may be necessary to adjust the mole fractions of these gases for calculating solubility and modeling biogeochemical reactions. In addition, the reactive gases can be included as tracers and their mole fractions can be derived from dissolved gas modeling results.

A common use of the Update Gas Database function is to test the fit of various solubility data to sample gas concentrations during dissolved gas modeling. Dissolved gas modeling fits are performed with the set of solubility data indicated with a "Yes" next to the gas name. To change the default set of solubility data, replace the "Yes" with a "No" for updated solubility data and replace the "No" with a "Yes" for the desired solubility data. For each gas, only one set of solubility data can be chosen as the primary solubility data. Example 2 tests the fit of different sets of solubility data to air-equilibrated and seawater samples. The second button, "Reset Gases to Defaults," will reset the primary solubility data values to the defaults. The set defaults are the Weiss solubilities for $\mathrm{He}, \mathrm{Ne}, \mathrm{Ar}$, and $\mathrm{Kr}$ and the Clever solubility (with salting coefficients from Smith and Kennedy, 1983) for Xe. These solubilities are the most commonly used for groundwater studies of past recharge temperatures and age dating (Aeschbach-Hertig and others, 1999; Kipfer and others, 2002; Aeschbach-Hertig and Solomon, 2013).

\section{Graphing}

Graphs are a simple way to aid the evaluation of dissolved gas models to fit sample data and to evaluate the behavior of gases under different conditions. DGMETA can create two types of interactive graphs: (1) graphs of the solubility of gases in water at equilibrium with the atm and (2) graphs of gas concentrations of samples with dissolved gas model output. Users are encouraged to explore the Graphs worksheet to see how built-in functions can be used to create custom graphs and functionality. 


\section{Gas Solubilities}

The solubility of a gas in water can be graphed using the "Gas Solubilities" button on the DGMETA tab (fig. 3). This button will display a form (fig. 8) that can be used to select gases and graph their solubility in water over a range of temperature, elevation (pressure), and salinity conditions (fig. 8). The list of gases displays the unique name entered in the database table. The user can specify which conditions to vary (temperature, elevation, or salinity values), the range of parameter values, the step increment, the values of fixed parameters (temperature, elevation, or salinity), and the units of the concentrations. Example 1 uses this routine to examine the solubility of $\mathrm{Ne}$ in water and seawater for different sets of Ne solubility data. Once the form is complete, the "CREATE

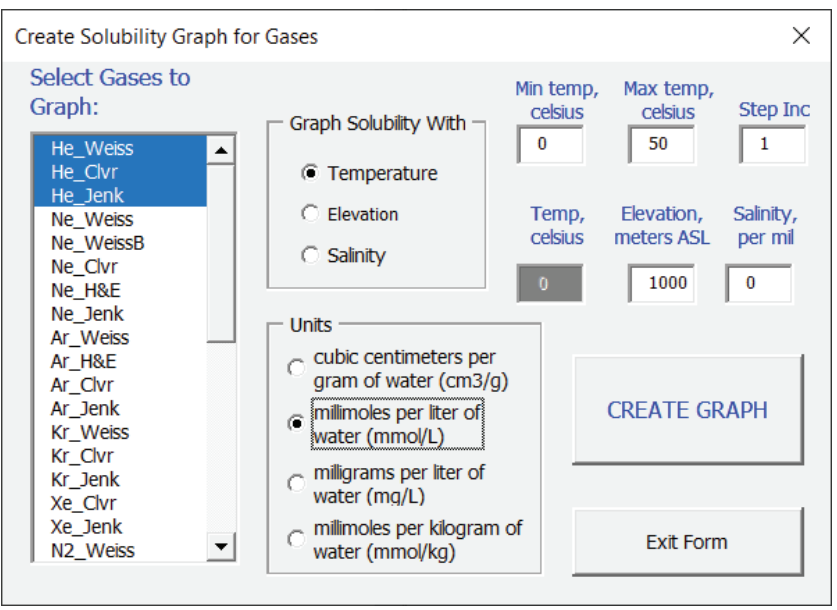

Figure 8. The form used for creating graphs of the solubility of a gas in water at equilibrium with the atmosphere.
GRAPH" button will create a new worksheet with a name specified by the user and a suffix of “_SolGph," and this new worksheet will contain a graph of the solubility concentration in water (fig. 9).

\section{_SolGph Worksheet}

The _SolGph worksheet is organized into three sections: (1) the graphical display of charts, (2) a set of control variables that can be adjusted to change the graph, and (3) a section below the control variables that contains formulas for calculating the dissolved gas concentration (fig. 9). The worksheet has a set of control variables that are initially populated by the program based on the values specified on the form by the user (fig. 8). The values on the worksheet can be changed to see how the solubility of a gas is affected.

\section{Gas-Gas Graphs}

Graphs of gas concentrations from samples and from model output can be created to evaluate different models of dissolved gas concentrations (UA and CE) that might explain measured concentrations in samples. The "Gas-Gas Plots" button will display a form named "Create Graphs" that can be used to select samples to graph from the Input_Gases worksheet or from the Output of Dissolved Gas Models (_ModOut) worksheet (fig. 10)—-see the "Dissolved Gas Modeling" section. Up to four graphs can be created, and graphs can include selected ratios of gases in addition to the gas concentrations. Samples can be plotted as groups according to their labels entered in the Study Area column on the Input_Gases or_ModOut worksheets; although these worksheets should be sorted by Study Area before plotting the samples as groups. 


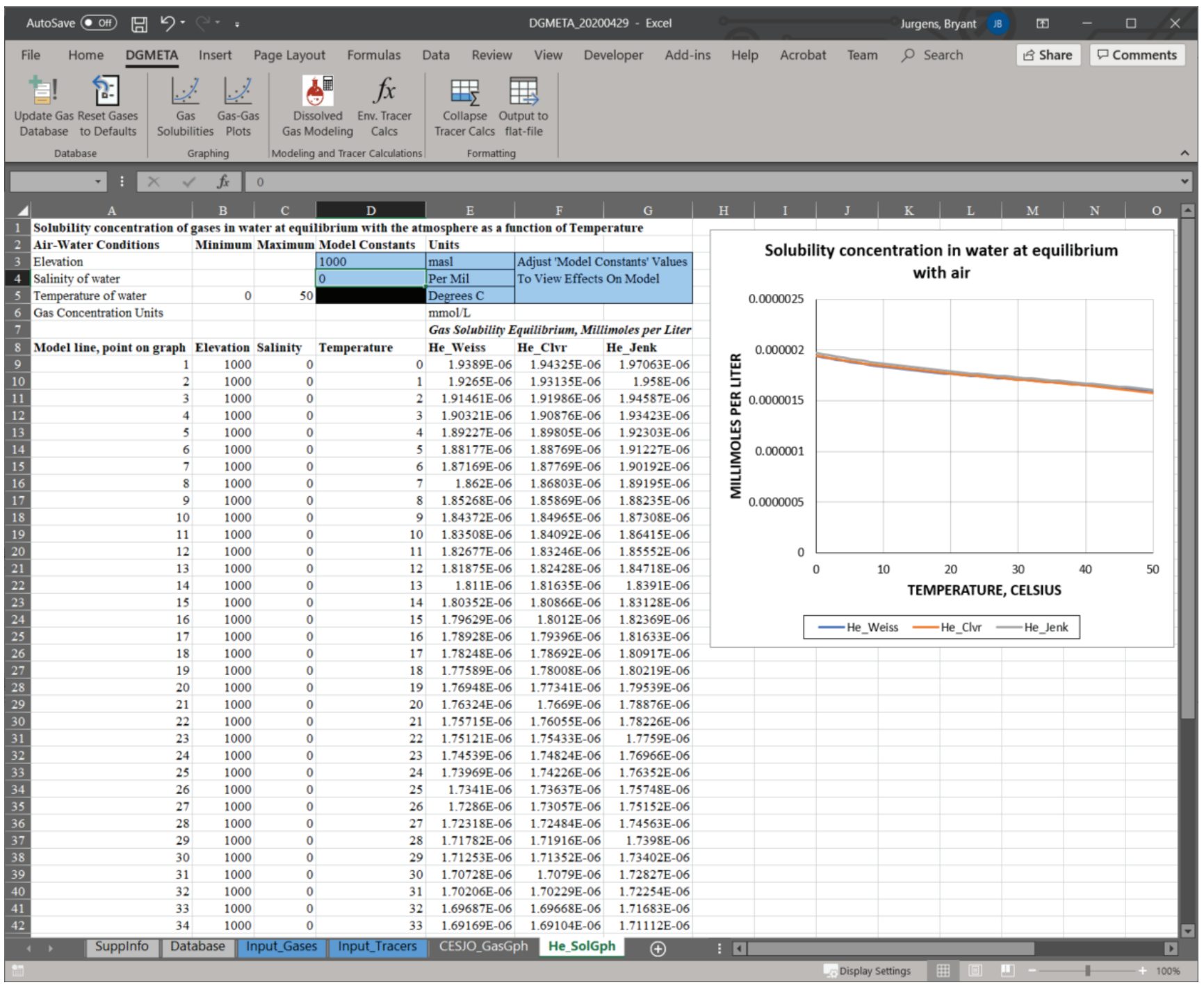

Figure 9. The _SolGph worksheet created by the program that is used to compute and graph the solubility of a gas in water with different temperature, elevation (pressure), and salinity conditions. 


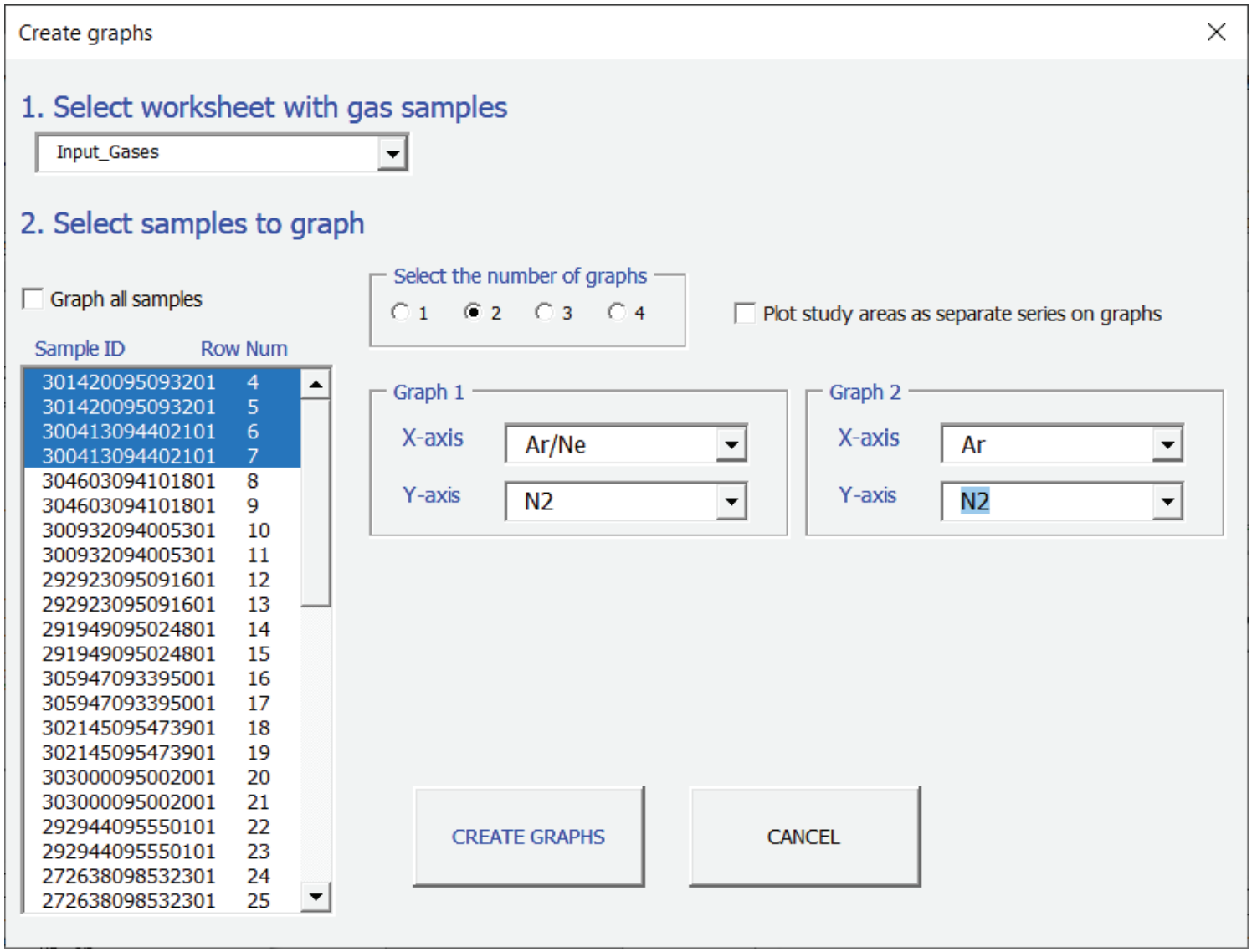

Figure 10. The form used for creating graphs of gas concentrations from samples and dissolved gas models.

\section{_GasGph Worksheet}

The Create Graphs program will create a new worksheet with a suffix of "GasGph" that contains interactive graphs with a set of control variables above each graph, which are used for exploring sample gas concentrations in relation to modeled dissolved gas concentrations from the UA and CE models (fig. 11). Each graph created on a_GasGph worksheet will have a set of black lines that correspond to a range in temperatures $\left(0-40^{\circ} \mathrm{C}\right)$ and amounts of UA $\left(0-10 \mathrm{~cm}^{3} / \mathrm{kg}\right)$. The black lines will generally bound most well-behaved samples. Samples that plot outside the black lines can indicate degassed samples (see example 5), extreme F of gases, and samples that have undergone in situ production of gases, such as radiogenic helium or denitrification (see examples 3 and 4).
Each graph also will include a green line of the UA model that spans across the bounded range of black lines and a red-dotted line of fractionated excess air (CE model) for various amounts of entrapped air (0-200 $\mathrm{cm}^{3} / \mathrm{kg}$; fig. 11). The position of the UA model (green line) and CE model will move based on changes to the temperature value set in the control variables above each graph. The CE model also will change shape based on changes to the F value. Graphs that include $\mathrm{N}_{2}$ gas concentrations will have an orange line that shows UA for various amounts of excess $\mathrm{N}_{2}$ gas $(0-10 \mathrm{mg} / \mathrm{L}$ as $\mathrm{N}$ ) that could be contributed by denitrification or deep fluids. The origin of the excess $\mathrm{N}_{2}$ gas line will intersect the UA model line by the value set in the "Init. excess air (UA), $\mathrm{cm}^{3} / \mathrm{kg}$ " field. 


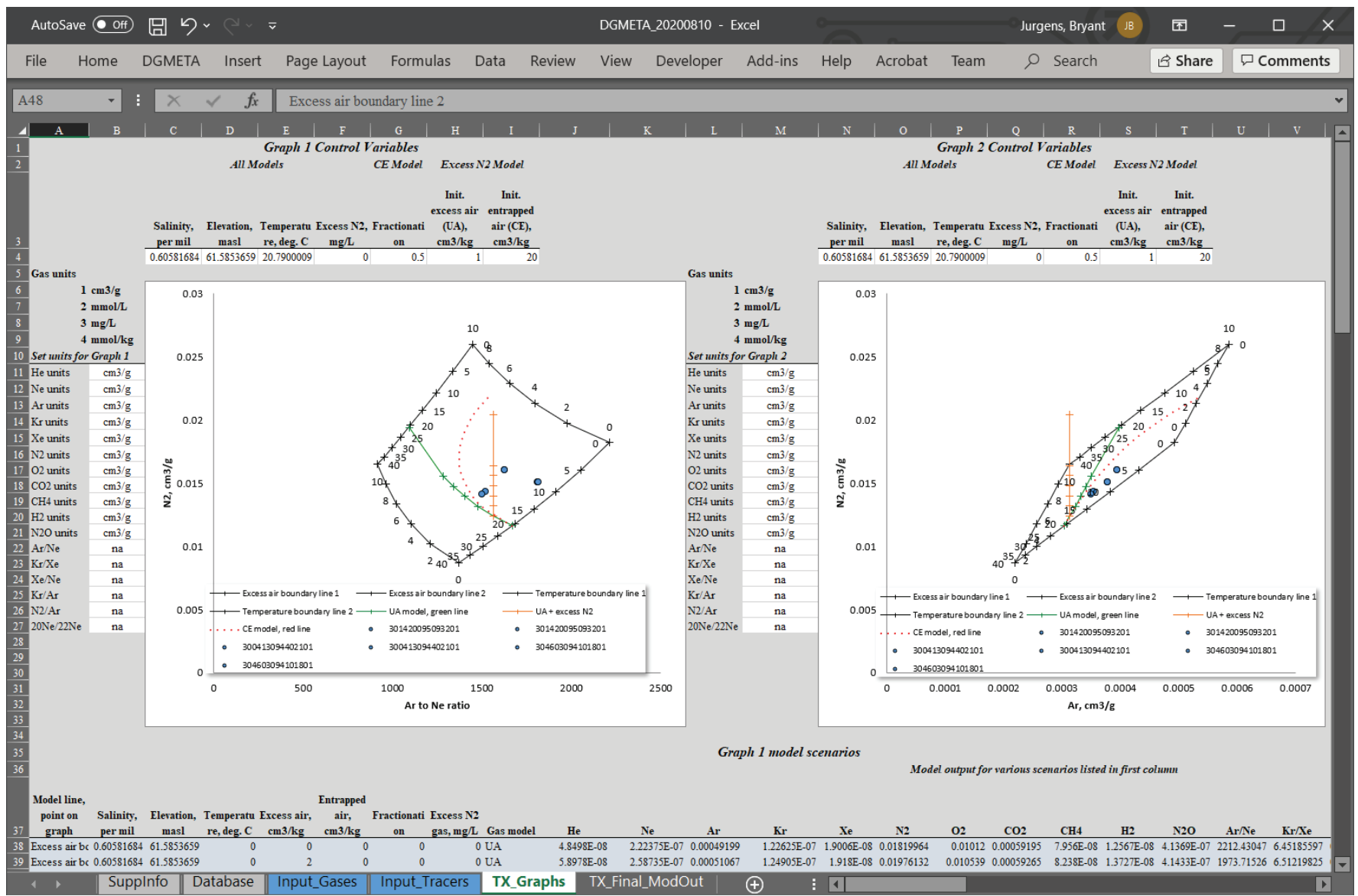

Figure 11. An example_GasGph worksheet created by the program to compute and graph gas concentrations for samples and models.

Above each graph is a set of variables that control the lines on each graph (fig. 11). The values are initially set by the program based on averages of the initial values on the Input_Gases worksheet or best-fit values from a_ModOut worksheet. The values for salinity and elevation affect the gas concentrations for all lines displayed. The value for temperature affects the lines for the UA model (green line), $\mathrm{CE}$ model (red-dotted line), and excess $\mathrm{N}_{2}$ (orange line). The "Init. excess air (UA), $\mathrm{cm}^{3} / \mathrm{kg}^{2}$ " field affects the position of the excess $\mathrm{N}_{2}$ line and the $\mathrm{F}$ value affects the $\mathrm{CE}$ model.

To the left of each graph is a set of controls for setting the units of gas concentrations (fig. 11). These can be changed to display gases in units of (1) $\mathrm{cm}^{3} / \mathrm{g}$, (2) $\mathrm{mmol} / \mathrm{L},(3) \mathrm{mg} / \mathrm{L}$, or (4) $\mathrm{mmol} / \mathrm{kg}$. Gas concentrations are converted to different units using equations $10-11$.

The GasGph worksheets also contain calculations for the different gas models and the sample concentrations converted to different units. These calculations call up custom Excel worksheet functions that can be manipulated and used to create custom calculations and graphs to suit user needs.

\section{Dissolved Gas Modeling}

DGMETA is used most often to compute dissolved gas models and environmental tracer concentrations; these tasks are completed in three steps: (1) enter dissolved gas measurements on the Input_Gases worksheet and environmental tracer measurements on the Input_Tracers worksheet, (2) compute dissolved gas models for samples listed on the Input_Gases worksheet, and (3) compute environmental tracer concentrations for samples listed on the Input_Tracers worksheet using the dissolved gas models computed from step 2. Dissolved gas models can be computed using the "Dissolved Gas Modeling" button in the DGMETA tab (fig. 3). This program will compute best-fit estimates of temperature, excess air, and other model parameters and will report the results in a program created output worksheet with the suffix “_ModOut." Environmental tracer concentrations can be computed using the "Env. Tracer Calcs" button in the DGMETA tab. For samples listed in the _ModOut worksheet, environmental tracer concentrations will be computed for every corresponding Sample ID and Date listed on the Input_Tracers worksheet. Tracer calculations will be reported on a worksheet created by the program with the suffix “_TrcOut." 
The program for modeling dissolved gases is initiated from the "Dissolved Gas Modeling" button in the DGMETA tab in the Excel ribbon (fig. 3). This button will display the Dissolved Gas Modeling form, which allows users to select one or more samples to model, gases to include in the model, parameters to optimize, and one or more models to evaluate (fig. 12). The user also has several model options that can be included. The first option enables the program to automatically rerun models with poor fits by removing the gas with the poorest fit in an attempt to look for an acceptable model solution for the sample. The program defines a poor fit as a model with a chi-square probability less than 1 percent or 0.01 - see example 4 . The second option enables the program to calculate excess $\mathrm{N}_{2}$ for samples where dissolved $\mathrm{N}$ was measured, but is not included as a model-fit parameter such that the dissolved gas model is based on measured gases other than N. For example, if noble gases and $\mathrm{N}$ were measured in a sample, a user could select $\mathrm{Ne}, \mathrm{Ar}, \mathrm{Kr}$, and $\mathrm{Xe}$ for modeling the temperature and excess air, and the program would subsequently calculate the amount of excess $\mathrm{N}_{2}$ using the model results and the dissolved $\mathrm{N}$ measurement. Alternatively, the user could include excess $\mathrm{N}_{2}$ as a model-fit parameter. The third option will run Monte Carlo simulations for models with acceptable probabilities in order to more accurately define the parameter errors. The user can choose the number of simulations and to output all the simulation results in a separate worksheet. The fourth option, Excess $\mathrm{N}_{2}$ for $\mathrm{Ar} / \mathrm{N}_{2}$ only, allows users to solve for excess $\mathrm{N}_{2}$ gas for a range of excess air values (see example 3 ) when only Ar and $\mathrm{N}_{2}$ were measured. This analysis computes a set of dissolved gas models by setting excess air to a constant value incrementally over a range of values and computing the best-fit recharge temperature and excess $\mathrm{N}_{2}$ value. If the $\mathrm{N}_{2}$ values are greater than or equal to zero, the model is accepted and the average and standard deviation of the set of accepted models are returned as the best-fit parameter and parameter error values.

\section{_ModOut Worksheet}

Results of dissolved gas modeling are output to a worksheet named by the user with the suffix "_ModOut" appended to the name (fig. 13). All sample information, initial model parameter values, dissolved gas modeling results, measured concentrations, modeled concentrations, and Monte Carlo results are written to the output worksheet. Results of dissolved gas modeling include the model-fit and optimal parameters and their uncertainty. If a parameter was not included in the best-fit parameter, but was required by the model, then the initial value was used ("init. val."). Only the $\mathrm{CE}$ and $\mathrm{PR}$ models require a value for $\mathrm{F}$, and only samples with dissolved $\mathrm{N}$ can be used to estimate excess $\mathrm{N}_{2}$; all other parameters are required. The gas with the highest contribution to the chi-square error, deviations between measured and modeled solubility concentrations, and generic comments about the gas concentrations and model results are provided to help evaluate the model results. Modeled gas solubility, excess air, and total gas concentrations are provided in $\mathrm{cm}^{3}$ at $\mathrm{STP}$ per $\mathrm{g}$ of water, $\mathrm{mmol} / \mathrm{L}$, and $\mathrm{mg} / \mathrm{L}$. If the $\mathrm{CE}$ model was used to find the best-fit parameter of entrapped air, then the equivalent excess air concentration for each gas is calculated and included in the output.

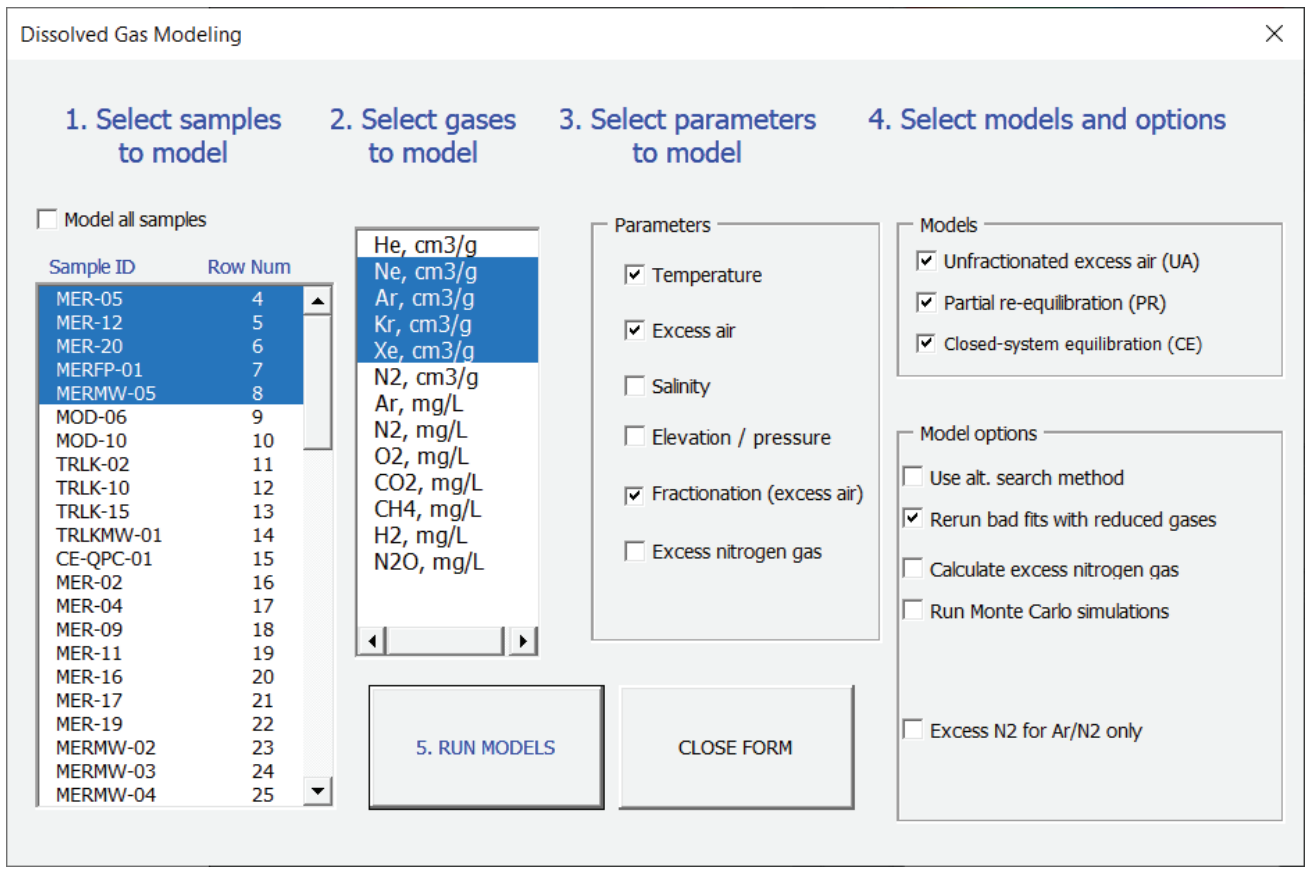

Figure 12. The form for modeling dissolved gases. 


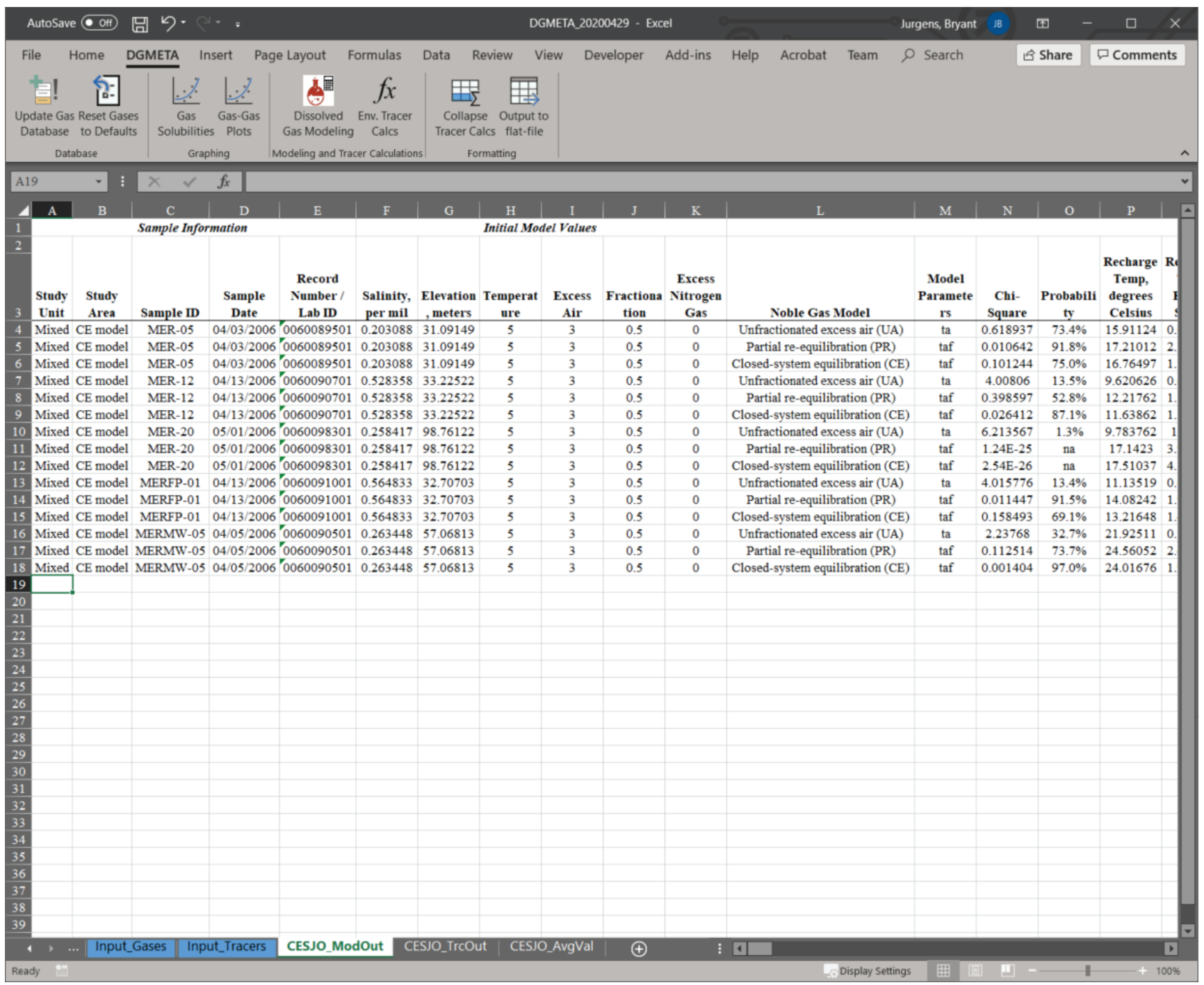

Figure 13. The _ModOut worksheet. There are more than 250 columns of values that are produced in the output, organized into groups that relate fields to sample information, initial model values, model results, measured concentrations and computations of model components and Monte Carlo results.

Monte Carlo simulation results are provided in the last set of columns in the worksheet and contain the results of the average and standard deviations of modeled simulations. When computing tracer concentrations from dissolved gas model results where Monte Carlo simulations were computed, the Monte Carlo parameter errors from these simulations will be automatically used for tracer calculations; these values are red in the _TrcOut worksheet—see example 4.

There are more than 250 columns of values that are produced in the output from the ModOut worksheet. Many of the fields are used for documenting the measured concentrations and internal calculations of model components so that results satisfy U.S. Geological Survey (USGS) open data requirements for models.

\section{Environmental Tracer Concentrations}

Environmental tracer concentrations can be calculated for every dissolved gas model listed in a ModOut worksheet. This requires that samples have been modeled using the dissolved gas modeling routines listed in the previous section. The tracer calculations are initiated by the "Env. Tracer Calcs" button in the DGMETA tab in the Excel ribbon (fig. 3). The user will be prompted to select a _ModOut worksheet (fig. 14A) to calculate tracer concentrations for each dissolved gas model that is listed in the worksheet. The program will match tracer measurements for each corresponding Sample ID and Sample Date listed in the _ModOut and Input_Tracers worksheets. Calculated tracer concentrations are output to a worksheet named by the user with the suffix " TrcOut" appended to it (fig. 15). 


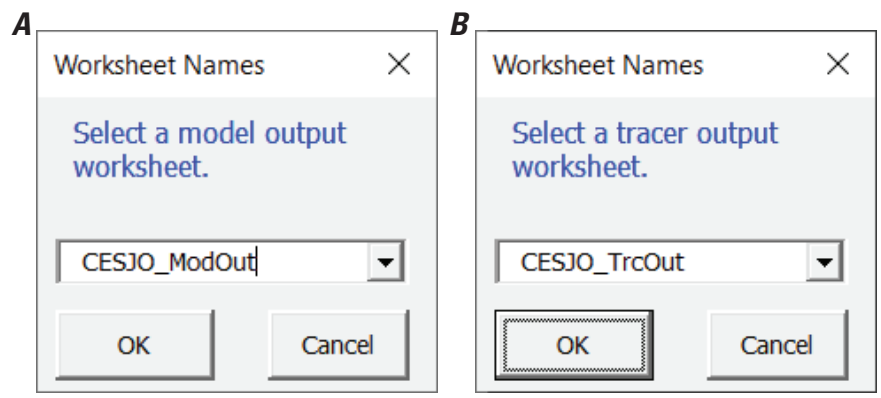

Figure 14. The forms $A$, for selecting a model output worksheet for computing tracer concentrations and $B$, for selecting a tracer output worksheet for computing average tracer concentrations (single row per Sample and Date).

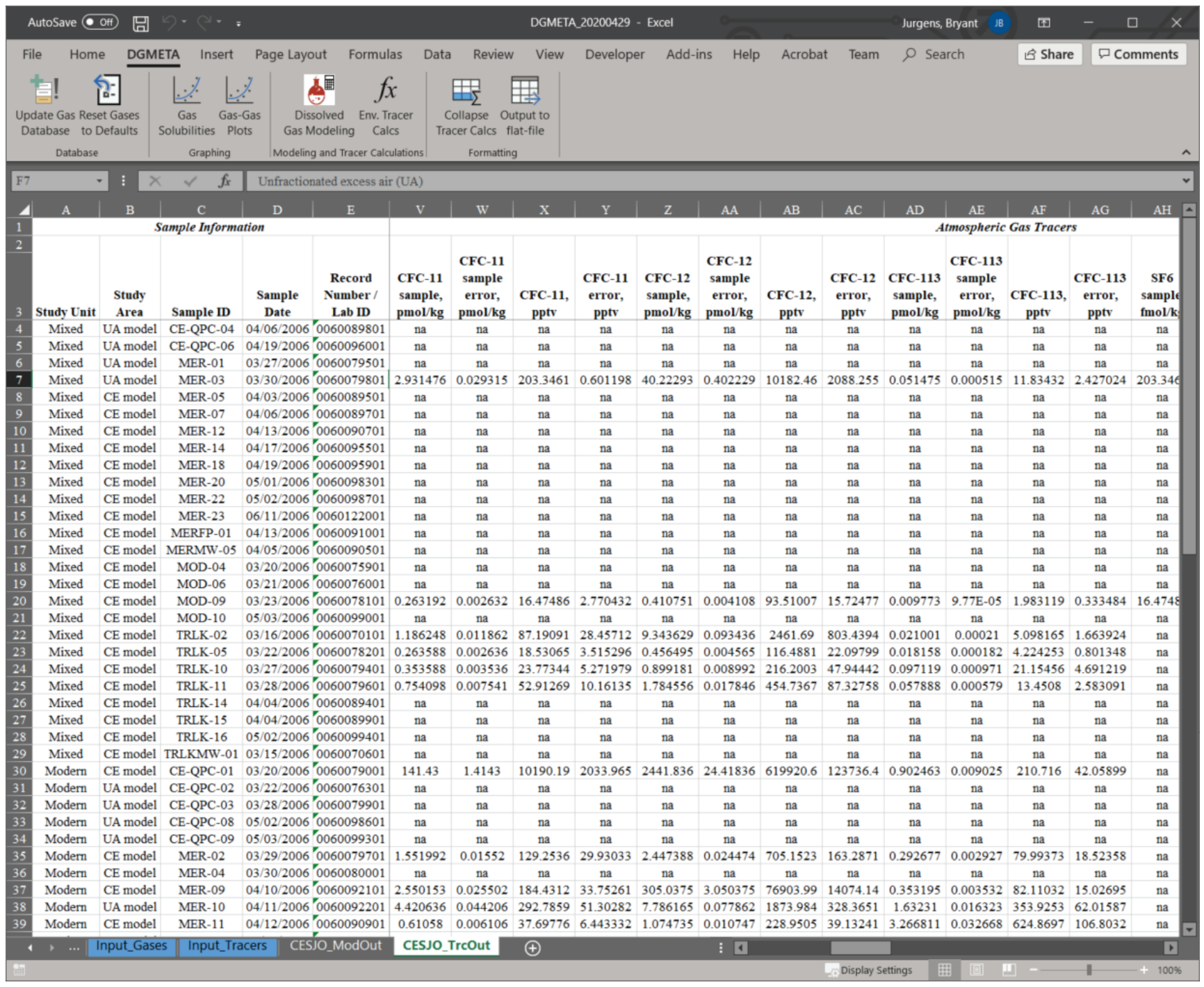

Figure 15. The _TrcOut worksheet, which contains calculations of atmospheric dry-air mole fractions and concentrations of tritium-helium-3 components. 


\section{_TrcOut Worksheet}

The TrcOut worksheet (fig. 15) contains the calculated dry-air mole fractions (mixing ratios) of atmospheric transient gas tracers and concentrations of ${ }^{3} \mathrm{H}-\mathrm{He}$ components for every model listed in the corresponding _ModOut worksheet. Parameter errors that are red are errors computed from Monte Carlo simulations reported in the _ModOut worksheet—see example 4. These errors can be preferred when parameter errors determined from dissolved gas model fits are of the same magnitude as the fitted parameters. In particular, the CE model can have large parameter errors when the $\mathrm{F}$ parameter approaches 1.

Details of the methods used for the calculations of tracer concentrations were given in the "Environmental Tracers" section. The ${ }^{3} \mathrm{He}_{\text {trit }}$ calculations are dependent on the $\mathrm{R}_{\text {terr }}$ and the TrcOut worksheet, which provides a graphical approach for evaluating different sources of $\mathrm{He}_{\text {terr }}$ and their effect on ${ }^{3} \mathrm{He}_{\text {trit }}$ concentrations. The calculated value of $\mathrm{R}_{\text {terr }}$ is to the right of the $\delta^{3} \mathrm{He}$ graph and is blue; that value should be evaluated using the graph (fig. 2) on the _TrcOut worksheet. The $\mathrm{R}_{\text {terr }}$ can be manually changed by entering a new value in the cell on the _TrcOut worksheet. These parts of the worksheet and functionality are demonstrated in examples 3 and 4 .

\section{Formatting}

There are two routines in the DGMETA tab that can be used to reformat worksheets created by DGMETA. The first routine, "Collapse Tracer Calcs" can collapse multiple tracer calculations for a single Sample ID and Sample Date, which can be useful for finalizing the reporting of results and transferring them to other programs. The second routine reformats the ModOut, TrcOut, and_AvgVal worksheets into a new worksheet with a single-row header that is useful for exporting the results into another program. This output worksheet is in a format that meets USGS model open data requirements for documentation of model inputs and outputs.

If there are multiple dissolved gas models in a ModOut worksheet or multiple tracer measurements in the Input Tracers worksheet for a single Sample ID and Sample Date, the _TrcOut worksheet can contain multiple rows of tracer results for the same Sample ID and Sample Date. Multiple models and tracer measurements may provide additional estimates of uncertainty for the calculated tracer concentrations or identify samples that may be contaminated, degraded, or were collected improperly. The "Collapse Tracer Calcs" button in the DGMETA tab can be used to collapse the multiple rows into a single row for each unique Sample ID and Sample Date. The program will prompt the user (fig. 14B) to select a TrcOut worksheet and create a new worksheet with a suffix "AvgVal" appended to the name. The worksheet is organized and formatted the same as the TrcOut worksheet, but the program will compute the average tracer concentration for multiple tracer results.

\section{AvgVal Worksheet}

This worksheet contains average dissolved gas model results and tracer concentrations for every unique Sample ID and Sample Date reported in the _TrcOut worksheet (fig. 16). The_AvgVal worksheet can be useful for collapsing multiple tracer measurements from different laboratories or for comparing the effect of different dissolved gas model results on tracer concentration calculations. The _AvgVal worksheet should not be used, however, as a sole source of results when reporting the model outcomes. In cases where the dissolved gas models or computed tracer concentrations are very different, the averaging of the results could be undesirable, so users are advised to look closely at the _TrcOut worksheet before averaging the results.

\section{_ModFlt,_TrcFlt, and_AvgFlt Worksheets}

Worksheets with the suffix _ModFlt,_TrcFlt, and _AvgFlt are reformatted versions of the _ModOut,_TrcOut, and_AvgVal worksheets (fig. 17). These worksheets are identical to the original worksheets, but contain a single-row header that enable the worksheets and results to be portable to other programs and graphing software. 


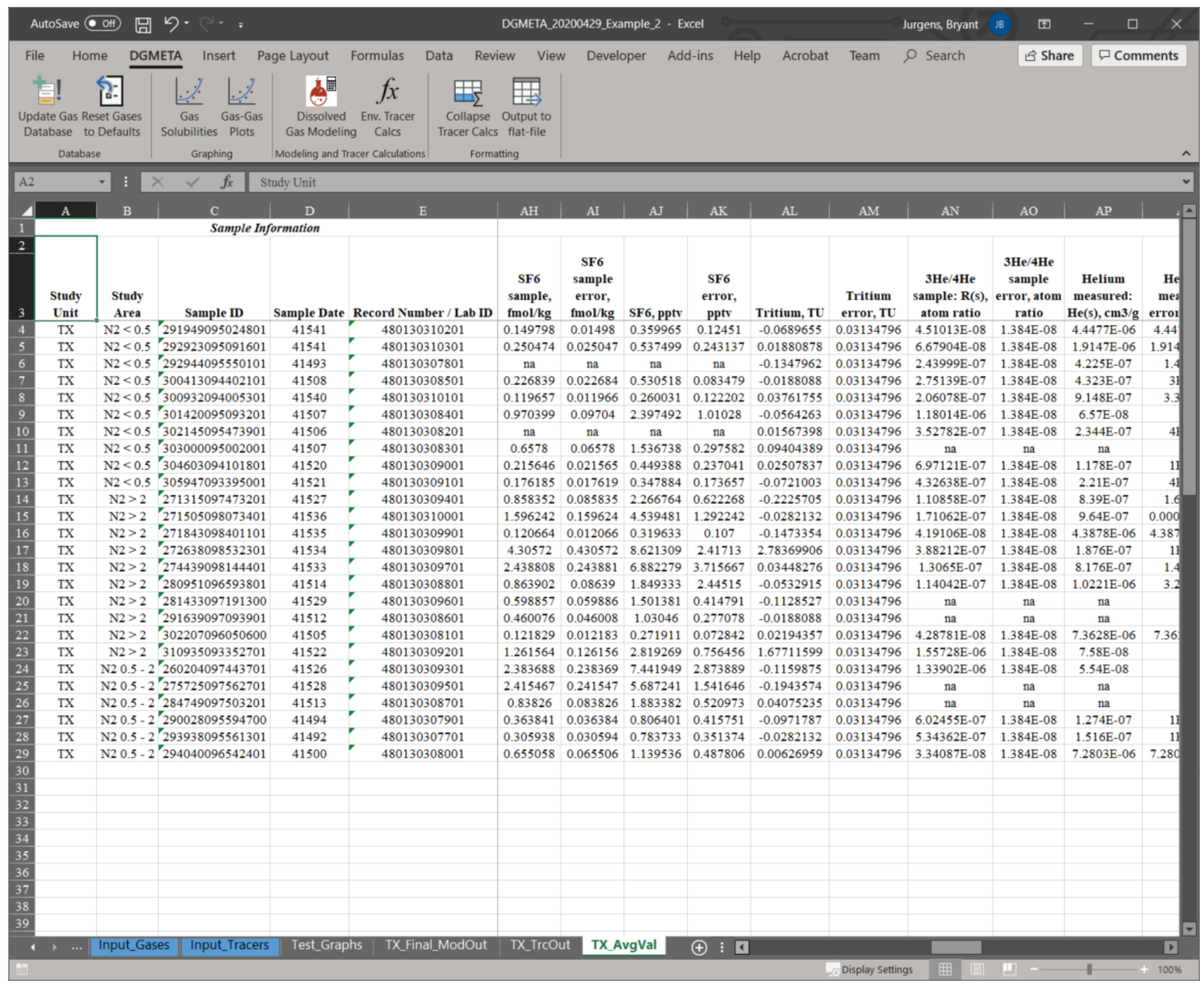

Figure 16. The_AvgVal worksheet, which contains average values of tracer concentrations for each sample and date listed on the _TrcOut worksheet. 


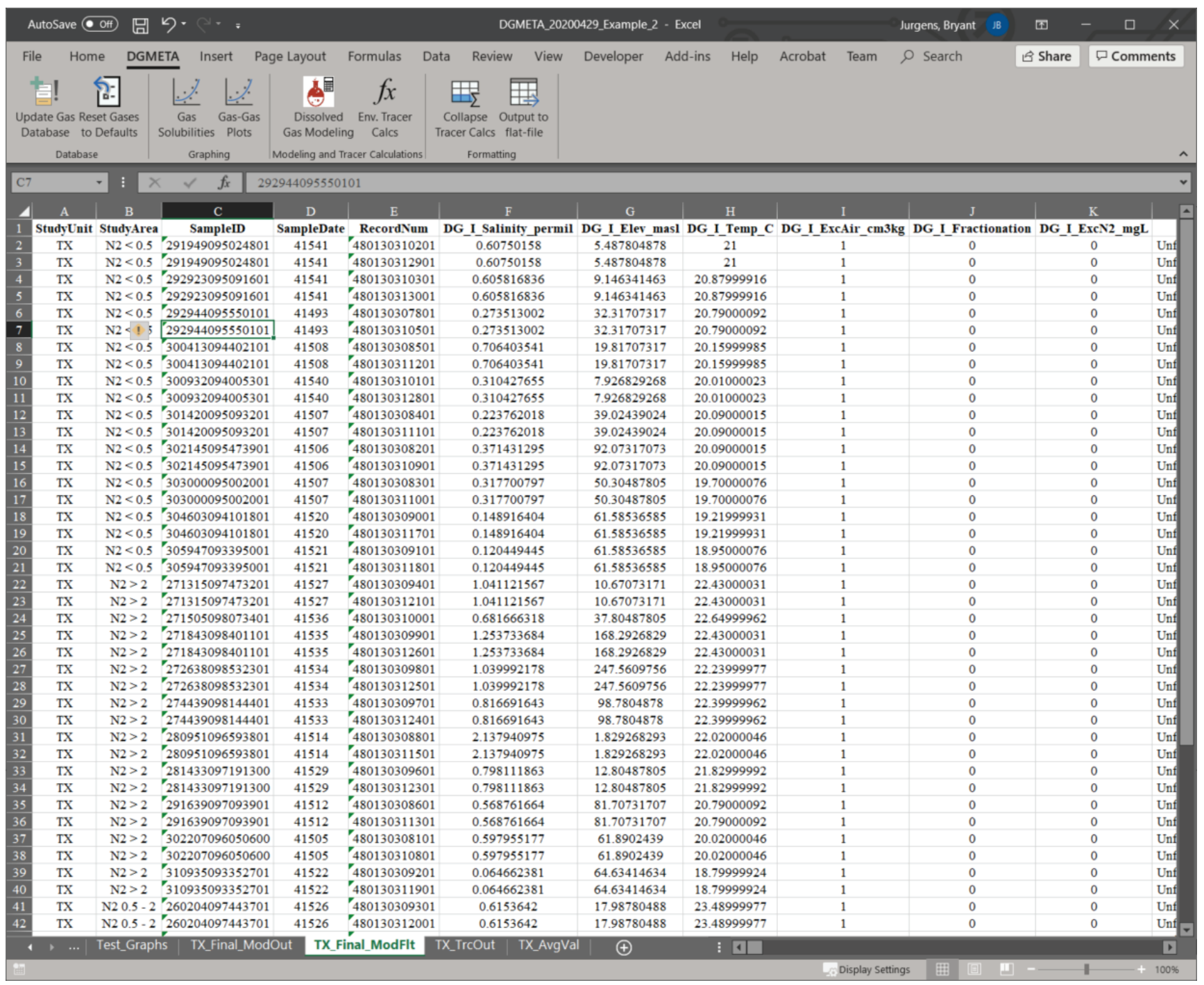

Figure 17. A_ModFlt worksheet, which is a single-row header version of a _ModOut, _TrcOut, or_AvgVal worksheet.

\section{Examples}

The following examples provide guidance for entering and comparing different solubility equations, strategies for modeling dissolved gas concentrations with a limited set of measured gases, the identification of mantle $\mathrm{He}$ in groundwater, and samples that have been degassed. This is not a comprehensive set of examples to show the full capability of the program. All figures included in the examples were created using the DGMETA workbooks that are included in the DGMETA installation package. Users are encouraged to use them while following the written examples below.

\section{Example 1-Comparison of Noble Gas Solubility Data in Freshwater and Seawater}

DGMETA includes multiple solubility data for each noble gas - see the Database worksheet for the list of gases. For most noble gases, the solubilities from different studies vary less than 1 percent over temperatures between 0 and $40^{\circ} \mathrm{C}$ and salinities between 0 and 35 per mil. However, the solubility of Ne among studies frequently varies by more than 1 percent over this range of temperature and salinity (fig. 18). 

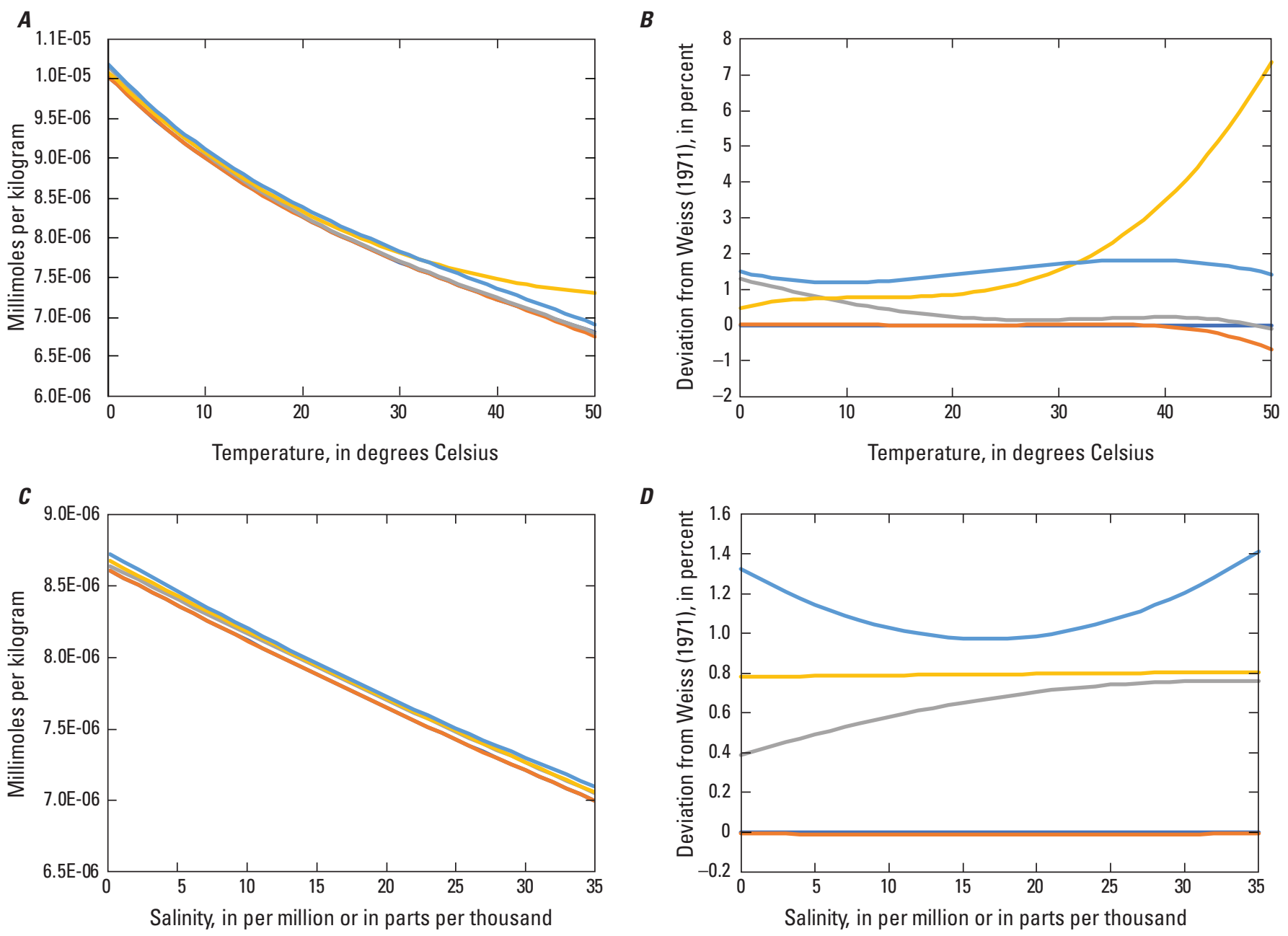

D

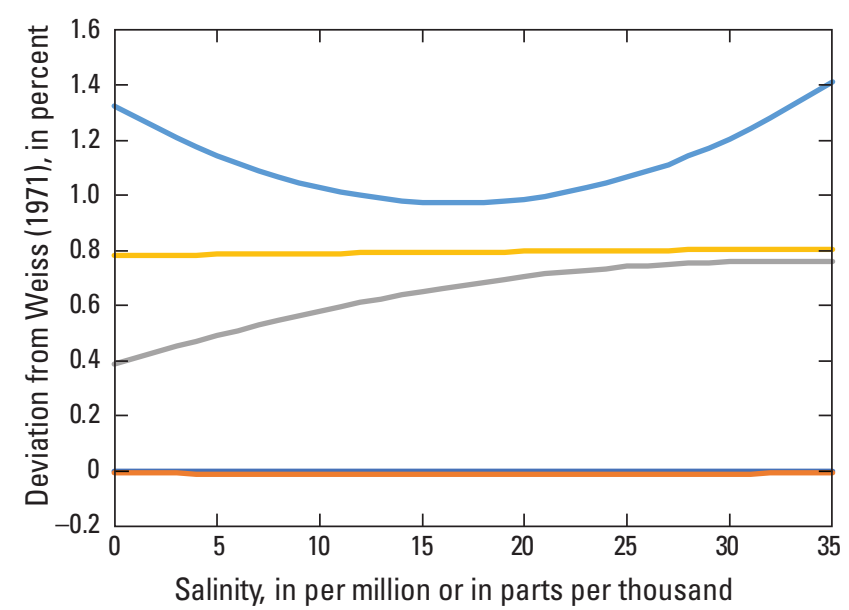

\section{EXPLANATION}

-Ne_Weiss $\quad$ Ne_WeissB Ne_Clvr $\longrightarrow$ Ne_H\&E Ne_Jenk

Figure 18. Neon ( $\mathrm{Ne}$ ) concentrations in freshwater and saltwater at equilibrium with air, based on solubility equations by Weiss (1971) that were expressed as the moist-air solubility (Ne_Weiss) and Bunsen solubility constant (Ne_WeissB), by Clever (1979a; Smith and Kennedy, 1983; Ne_Clvr), by Hamme and Emerson (2004; Ne_H\&E), and by Jenkins and others (2019; Ne_Jenk). $A$, variation in neon solubility concentrations in freshwater (salinity $=0$ per mil) over the temperature range of $0-50^{\circ} \mathrm{C}$; $B$, deviation of the solubility concentrations derived from all four equations compared to those derived from the gravimetric equation of Weiss (1971) as a function of temperature; $C$, variation of neon solubility concentrations at a temperature of $15^{\circ} \mathrm{C}$ over the salinity range of $0-35$ per mil; and $D$, deviation of the solubility equations from those of the gravimetric equation of Weiss (1971) as a function of salinity. The names of the lines consist of the name of the gas and a descriptor of the reference for the source of the gas solubility data and are unique identifiers for the gas solubility data used by DGMETA (see the Database worksheet of DGMETA).

DGMETA includes solubility data for Ne in freshwater and seawater from five studies. These solubility data were graphed using the "Gas Solubilities" routine in the DGMETA tab (fig. 3) and selecting the Ne solubilities listed in the Gas Solubilities form (fig. 8). In general, these studies measured the solubility of $\mathrm{Ne}$ in freshwater and seawater over a range of temperatures and fit polynomial equations to the experimental solubility data. The derived expressions provide a reasonable approximation of the solubility of the gas in water as a function of temperature and salinity for the conditions used in each experiment. Many of the studies used different methods and instruments to measure the solubility. The purpose of the analysis presented here is to compare the differences in solubility to evaluate their applicability over a range of environmental conditions rather than a detailed examination and comparison of the methods used to develop the solubility functions or to identify a "correct" set of solubility equations. 
Weiss (1971) provided two equations for the solubility of Ne: (1) one equation based on the moist-air solubility at $1 \mathrm{~atm}$ (Ne_Weiss) and (2) another equation for the Bunsen solubility (Ne_WeissB). Both equations used the van 't Hoff equation and Setchénow relation for solubility and salinity corrections $\left(G_{1}\right)$. Clever (1979a) determined the solubility of $\mathrm{Ne}$ in water in terms of the mole fraction solubility at standard pressure (1 atm) from a compilation of several solubility studies, and these solubility equations were combined with salting coefficients for solutions of $\mathrm{NaCl}(0.0-5.2 \mathrm{~mol} / \mathrm{L})$ computed by Smith and Kennedy $\left(1983 ; \mathrm{G}_{3}\right)$. Hamme and Emerson (2004) reexamined the solubility of $\mathrm{Ne}\left(\mathrm{G}_{5}\right)$ using the equations of Garcia and Gordon (1992; $\mathrm{G}_{5}$ ). Most recently, Jenkins and others (2019) performed solubility experiments for $\mathrm{Ne}$ in freshwater and seawater and reported their solubility using a modified version of the Weiss (1970) equation to include an additional salinity term introduced by Garcia and Gordon $\left(1992 ; \mathrm{G}_{6}\right)$. These five solubility equations can be easily compared in DGMETA by clicking the "Gas Solubility" button on the DGMETA tab (see the "Graphing" section).

The Weiss solubility equations are the default or primary solubility equations used by the program because the experiments used to derive the equations were done over a wide range of temperatures and salinities using the same or similar methods for each gas. The Weiss solubility for Ne was reported in terms of volumetric Bunsen coefficients (Ne_WeissB) and gravimetric moist air solubilities (Ne_Weiss). Deviations between the two forms are less than 0.04 percent over the temperature range of $0-40{ }^{\circ} \mathrm{C}$ (figs. $18 A, B$ ). The solubilities derived from the mole-fraction-based equations of Clever (1979a) for freshwater (Ne_Clvr) deviate from the Weiss solubilities usually less than 2 percent, whereas solubilities from Hamme and Emerson (2004; Ne_H\&E) are more than 0.5 percent higher than the Weiss solubilities over the entire temperature range (figs. 18A, B). The Jenkins (2019) solubilities for $\mathrm{Ne}$ in freshwater were more than 1 percent over the entire temperature range. At temperatures greater than $30^{\circ} \mathrm{C}$, Hamme and Emerson (2004) solubilities grow to more than 2 percent because their experiments were done for the temperature range of $0-25^{\circ} \mathrm{C}$ and seawater experiments for the temperature range of $0-30{ }^{\circ} \mathrm{C}$. Solubility equations determined by Clever (1979a, b, 1980) were fit to several reported sets of measured solubility equations over the temperature range of $5-66^{\circ} \mathrm{C}$. For temperatures less than $5{ }^{\circ} \mathrm{C}$, this may partly explain deviations between the Clever and Weiss solubilities. It should be noted that the Clever solubilities for $\mathrm{He}, \mathrm{Ar}$, and $\mathrm{Kr}$ were partly based on solubility data from Weiss; and therefore, the Clever solubilities can be similar to the Weiss solubilities.

These differences highlight the importance of choosing solubility equations best suited to the environmental conditions being studied. For freshwater terrestrial environments, the Weiss solubilities combined with Xe solubility from Clever (1979b) and Smith and Kennedy (1983) are commonly used. Newer solubility studies by Hamme and Emerson (2004) and Jenkins (2019) may be more common in oceanographic or saltwater studies.

Hamme and Emerson (2004) noted that small inaccuracies of the solubility equations can lead to large differences in biological fluxes of $\mathrm{O}_{2}$ production. In their study, they showed that the most commonly used solubility data for $\mathrm{Ne}$ in freshwater and seawater was most often lower, about 1 percent or more, than the solubility of Ne they determined (Ne_H\&E; figs. 18B, D). In particular, the Weiss solubilities had the highest deviations. Sano and Takahata (2005) measured equilibrium concentrations of noble gases in seawater for nine temperatures ranging from 1 to $29.6^{\circ} \mathrm{C}$. The measured $\mathrm{Ne}$ data were compared to $\mathrm{Ne}$ concentrations predicted from the Ne_Weiss, $\mathrm{Ne} \_\mathrm{Clvr}, \mathrm{Ne} \_\mathrm{H} \& \mathrm{E}$, and $\mathrm{Ne}$ Jenk solubilities. Figure 19 shows the percentage of deviation from the measured data reported by Sano and Takahata (2005). The Weiss solubility of Ne were lower than the measured data for the entire temperature range and were more than 1 percent lower for many temperatures. Almost all of the predicted $\mathrm{Ne}$ were lower than the measured $\mathrm{Ne}$ for temperatures greater than $15{ }^{\circ} \mathrm{C}$. Neon from Ne_H\&E, Ne_Clvr, and Ne_Jenk were most similar to the Ne data from Sano and Takahata (2005) and indicate that those solubilities may be better suited for oceanographic studies.

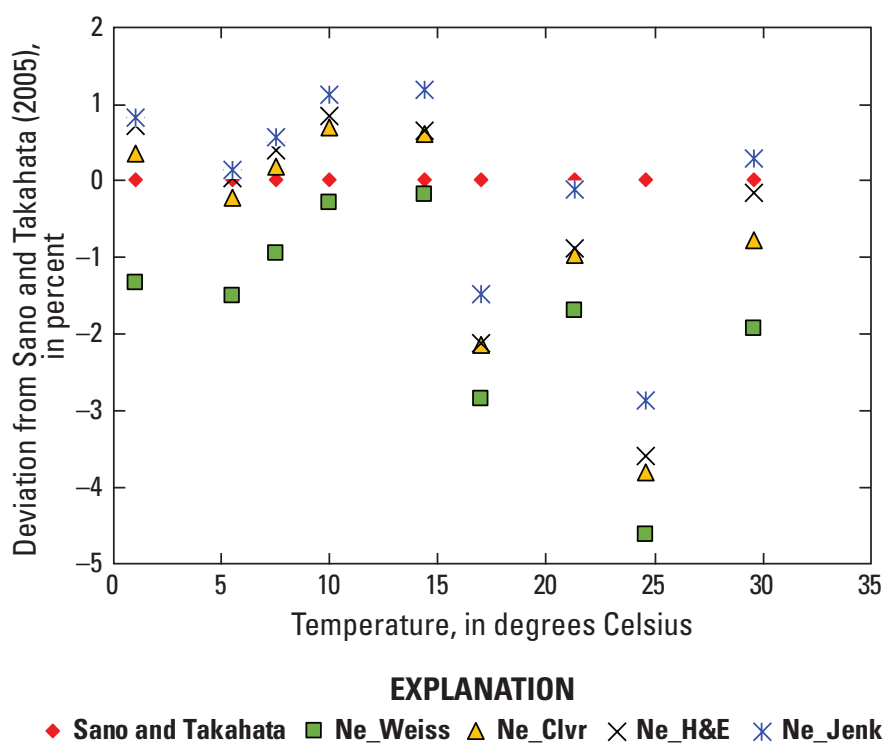

Figure 19. Percentage of deviation of neon (Ne) solubility from measured data reported by Sano and Takahata (2005) in seawater (salinity equals 34.2 per mil) for a range of temperatures. The names of the points consist of the name of the gas and a descriptor of the reference for the source of the gas solubility data and are unique identifiers for the gas solubility data used by Dissolved Gas Modeling and Environmental Tracer Analysis (DGMETA; see the Database worksheet of DGMETA). 
Despite the differences in Ne solubility, overall differences in gas solubilities are usually less than 1 percent among all types of water. Solubility equations can be chosen to maximize precision for specific temperature and salinity conditions. Most solubility equations are valid for temperatures between 0 and $40{ }^{\circ} \mathrm{C}$ and salinity from 0 to 35 per mil, although individual solubility equations may have broader or shorter temperature and salinity ranges based on the experimental data used to derive the solubility equation.

\section{Example 2-Inverse Modeling of Air-Equilibrated Freshwater and Seawater Samples}

A common application of measuring noble gases in water is to determine the temperature of the water when it equilibrated with the atmosphere. The temperature is determined by inverse modeling of the measured noble gas concentrations with modeled concentrations predicted by solubility. The noble gas concentrations reported by Sano and Takahata (2005) were from nine seawater samples equilibrated with air at different temperatures. Inverse modeling of the measured concentrations should, in theory, predict the air-water equilibration temperature of each sample in the experiment $(1,5.5,7.5,10,14.4,17,21.3,24.6$, and 29.6 $\left.{ }^{\circ} \mathrm{C}\right)$. Similarly, the USGS Noble Gas Laboratory in Denver, Colorado, routinely prepares air-equilibrated distilled-water (AEW) samples for laboratory quality-assurance purposes (Hunt, 2015). Between April 2016 and August 2017, the USGS Noble Gas Laboratory prepared 51 AEW samples that were equilibrated with room air at about $20^{\circ} \mathrm{C}$.

The temperatures of these air-equilibrated water and seawater samples were modeled using the full suite of measured noble gases using different sets of solubility. The default set used the Weiss solubilities for $\mathrm{He}, \mathrm{Ne}, \mathrm{Ar}$, and $\mathrm{Kr}$, and the solubility of Xe from Clever (1979b) and Smith and Kennedy (1983). The second set used the solubility equations from Clever (1979a, b, 1980) and Smith and Kennedy (1983). The third set used the solubility of Ar and Ne from Hamme and Emerson (2004), He from Weiss (1971), Kr from Weiss and Kyser (1978), and Xe from Clever (1979b) and Smith and Kennedy (1983). The fourth set used the solubility of noble gases reported by Jenkins and others (2019). The Dissolved Gas Modeling form was configured to find the temperature of AEW and seawater samples at air-water equilibrium for each set of noble gas solubilities (fig. 20). For the USGS Noble Gas Laboratory AEW samples, He was not modeled because a known source of excess atmospheric He at the USGS Noble Gas Laboratory contaminated the AEW samples.

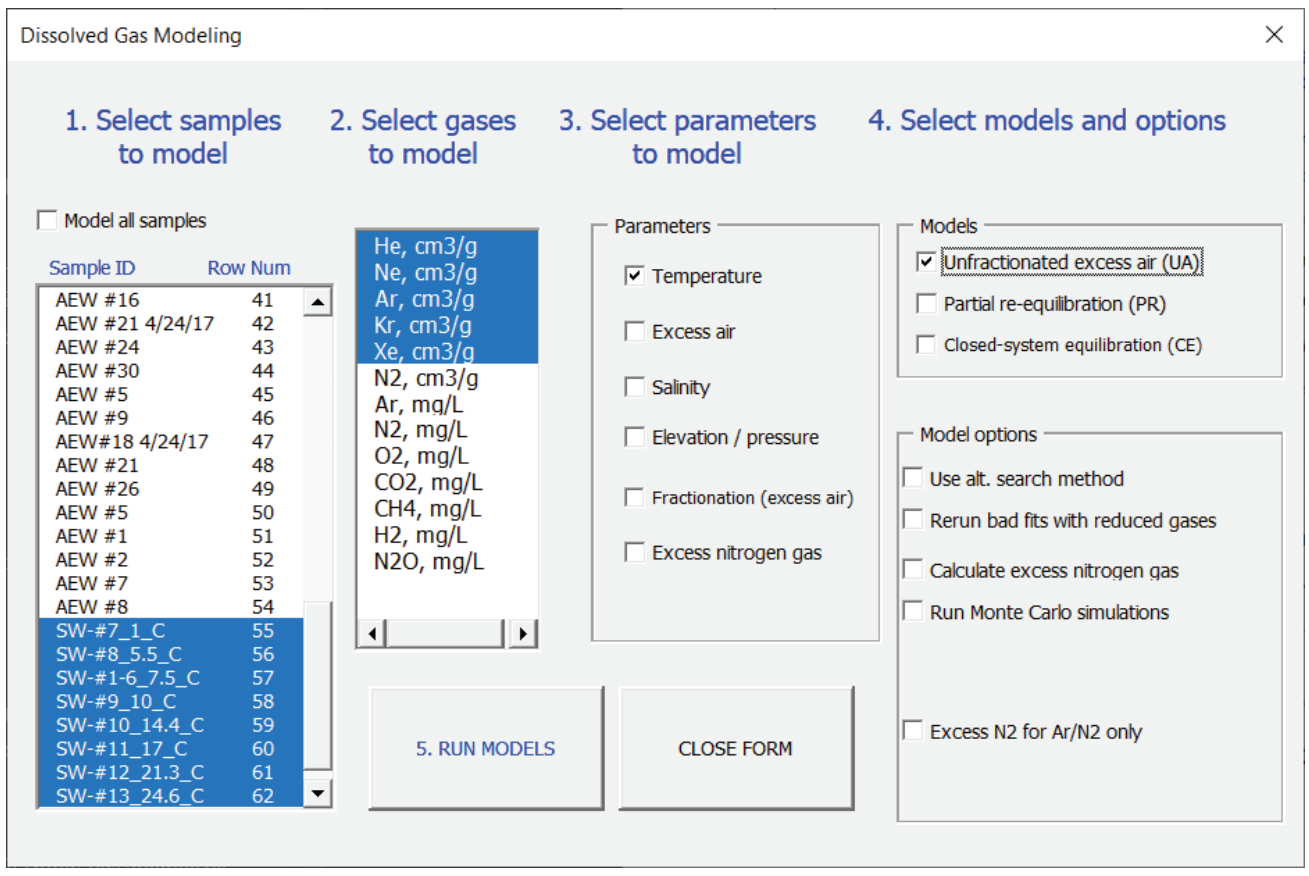

Figure 20. The Dissolved Gas Modeling form used to evaluate air-equilibrated samples prepared at the U.S. Geological Survey (USGS) Noble Gas Laboratory in Denver, Colorado, and seawater samples from Sano and Takahata (2005). Helium was not included in dissolved gas model fits for air-equilibrated, distilled-water samples from the USGS Denver Noble Gas Laboratory. 
Results of the dissolved gas modeling for seawater samples showed that none of the four sets of solubility data fit the seawater sample data well. It also was counterintuitive that the modeled temperature agreed more with the reported temperature for the sets of solubilities with poorer fits than for sets of solubilities with better fits. The median chi-square probabilities were $3.2,12,18.4$, and 14.5 percent for the Weiss, Clever, Hamme, and Jenkins solubilities, respectively. Temperature agreements, measured by the median of the percent deviation from the reported temperature, were -0.24 , $0.04,-1.5$, and -4.4 percent for the Weiss, Clever, Hamme, and Jenkins solubilities, respectively. Despite some poor fits to the data, the modeled temperatures were generally within $0.5^{\circ} \mathrm{C}$ of the reported equilibrated temperature.

Results of the dissolved gas modeling for AEW samples prepared by the USGS Noble Gas Laboratory showed that all sets of solubilities fit the measured data well. Unlike the seawater samples, the sets of solubilities with better fits also had better temperature agreement. The median chi-square probabilities were $80.8,77.8,76.5$, and 70.7 percent for the Weiss, Clever, Hamme, and Jenkins solubilities, respectively. Temperature agreements, measured by the median of the percent deviation from the equilibration temperature of $20^{\circ} \mathrm{C}$, were $-0.73,-0.76,-1.1$, and -2.9 percent for the Weiss, Clever, Hamme, and Jenkins solubilities, respectively. Temperature disagreements were within $0.5^{\circ} \mathrm{C}$ for most of the fits.

Overall, the solubility comparisons for AEW and seawater samples indicate that the Weiss and Clever solubilities may perform better than other solubilities when estimating air-water equilibration temperatures. These solubilities gave better fits to the measured freshwater AEW samples and had better temperature agreements than other solubilities. Although the Weiss and Clever solubilities gave poorer fits to the seawater samples than other solubilities, the Weiss and Clever solubilities gave better temperature agreement. This interesting result could reflect the complexities and difficulties in the preparation and measurement of gases in concentrated salt solutions. Although the analysis of modeled fits to AEW samples and seawater support the use of the Weiss data and the Clever data for Xe for most applications, the data used in this comparison were not rigorously assessed, and comparisons to other data or to data collected over a different range of temperatures may support other sets of solubility equations. Therefore, users are given the option to substitute different solubility equations and parameters to explore dissolved gas model fits and results for temperature and excess air.

\section{Example 3-Dissolved Gas Modeling with Neon, Argon, and Nitrogen or Argon and Nitrogen}

This example shows how data from different labs can be combined to model recharge temperatures and excess air in an aquifer where denitrification complicates the interpretation. Samples where denitrification has increased the amount of dissolved $\mathrm{N}_{2}$ gas can make it difficult to determine temperature and excess air from $\mathrm{Ar}$ and $\mathrm{N}_{2}$ concentrations alone or from $\mathrm{Ar}, \mathrm{N}_{2}$, and $\mathrm{Ne}$ concentrations. In this situation, the temperature, excess air, and excess $\mathrm{N}_{2}$ need to be determined; but in one case only two gases are available and in the other case $\mathrm{Ne} A r$, and $\mathrm{N}_{2}$ are available. This situation is best solved by working with samples that have $\mathrm{Ar}, \mathrm{N}_{2}$, and $\mathrm{Ne}$ data first to provide ranges of possible temperatures and excess air and then to use those estimates to inform the modeling of samples with $\mathrm{Ar}$ and $\mathrm{N}_{2}$ only.

Water samples for analysis of $\mathrm{N}_{2}$ and Ar were collected from 26 wells in the Texas coastal lowlands aquifer in August and September 2013. These samples were measured at the USGS Groundwater Dating Laboratory (Reston, Virginia) using gas chromatography (U.S. Geological Survey, 2020) and were reported in $\mathrm{mg}$ of gas per $\mathrm{L}$ of water. Samples from a subset of 19 wells were analyzed for $\mathrm{He}, \mathrm{Ne}$, and $\delta^{3} \mathrm{He}$ at the Lamont-Doherty Earth Observatory (Ekwurzel and others, 1994; Ludin and others, 1998). Five of the 19 samples were analyzed at the USGS Noble Gas Laboratory in Denver, Colorado (Hunt, 2015). Concentrations of He and Ne were reported in units of $\mathrm{cm}^{3}$ of gas at an STP per $\mathrm{g}$ of water.

DGMETA can handle gases reported in different units and can convert them to common units for graphical display of the data and for inverse modeling of recharge temperature, excess air, and excess $\mathrm{N}_{2}$.

Graphs of $\mathrm{N}_{2}$ concentration versus the Ar-to-Ne ratio and $\mathrm{N}_{2}$ versus Ar concentrations were made to identify patterns in temperature, excess air, and excess $\mathrm{N}_{2}$ that could be caused by denitrification in the aquifer (fig. 21). These graphs show that groundwater likely was recharged at temperatures between 10 and $20^{\circ} \mathrm{C}$ and had excess air values between 1 and $3 \mathrm{~cm}^{3} / \mathrm{kg}$. Samples that may have been affected by denitrification tend to plot above samples unaffected or less affected by denitrification. Samples affected by denitrification are orange and green on figure 21; samples that are green have excess $\mathrm{N}_{2}$ between 0.5 and $2 \mathrm{mg} / \mathrm{L}$ as $\mathrm{N}$, and samples that are orange have excess $\mathrm{N}_{2}$ greater than $2 \mathrm{mg} / \mathrm{L}$ as N. Samples that are blue on figure 21 have little to no excess $\mathrm{N}_{2}$ and plot near lower excess air concentrations, typically between 2 and $4 \mathrm{~cm}^{3} / \mathrm{kg}$. The temperature ranges and trends of samples are more consistent on the Ar- $\mathrm{N}_{2}$ graph than the $\mathrm{Ar} / \mathrm{Ne}-\mathrm{N}_{2}$ graph because the concentrations were measured from the sample bottle and used the same analytical method. 

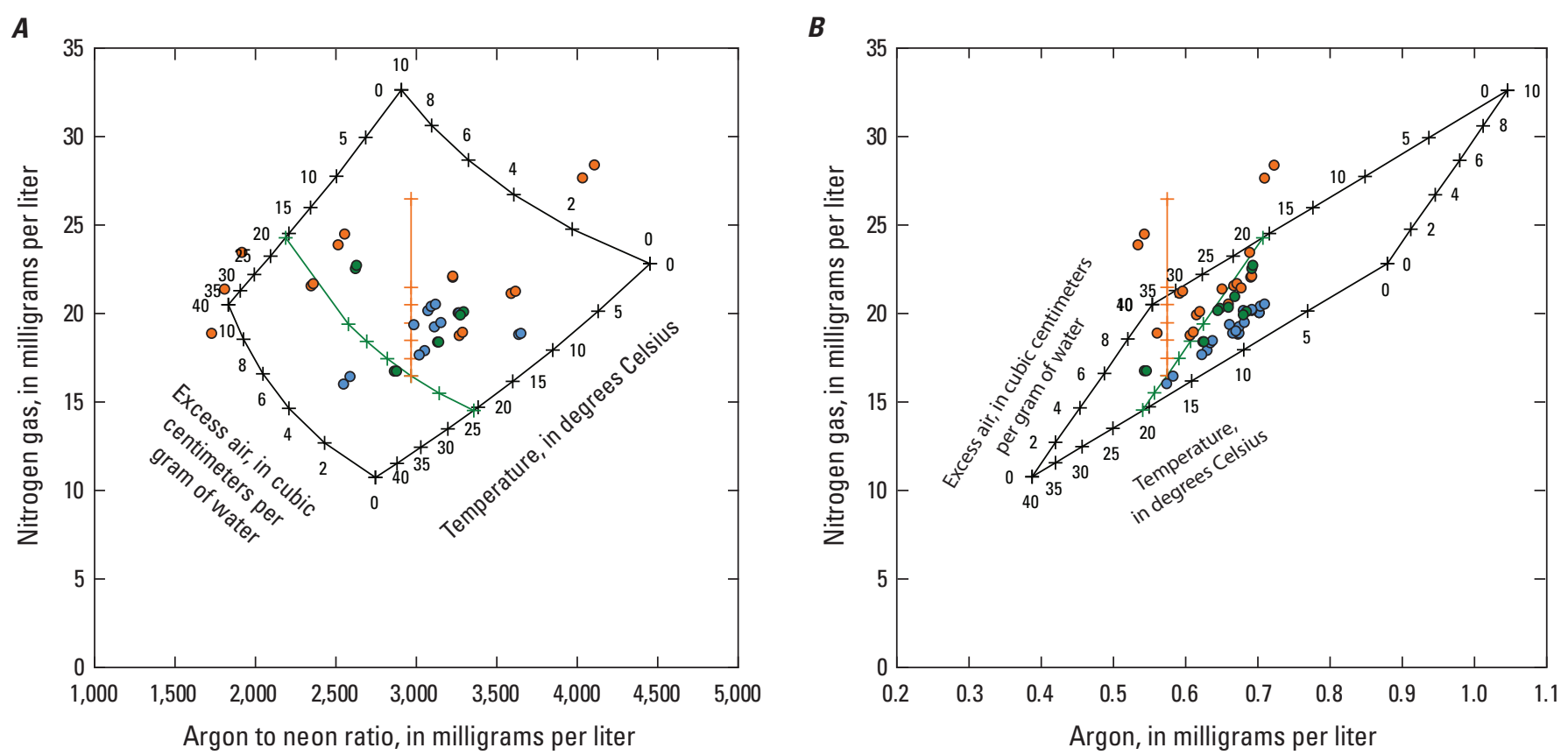

EXPLANATION

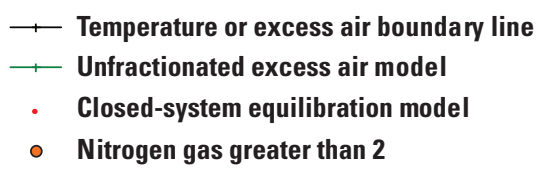

— Unfractionated excess air model, plus excess nitrogen gas

- Nitrogen gas less than $\mathbf{0 . 5}$

- Nitrogen gas 0.5-2

Figure 21. Concentrations of $A$, Nitrogen gas $\left(\mathrm{N}_{2}\right)$ and argon and neon ratio, and $B, \mathrm{~N}_{2}$ and argon only were measured in groundwater samples from the Texas coastal lowlands aquifer in 2013. Samples are color coded for the amount of excess $\mathrm{N}_{2}$ (presumably from denitrification; milligrams per liter as nitrogen) determined from graphical analysis and model fits to the data.

In order to assess the extent of potential denitrification, 19 sites with measured values of $\mathrm{Ne}, \mathrm{Ar}$, and $\mathrm{N}_{2}$ were modeled first using the UA model with fit parameters of temperature, excess air, and excess $\mathrm{N}_{2}$ (fig. 22). Model results indicate that most samples had temperatures around $16{ }^{\circ} \mathrm{C}$ (median of samples), excess air of about $2.5 \mathrm{~cm} 3 / \mathrm{kg}$, and denitrification of about $0.6 \mathrm{mg} / \mathrm{L}$. In some cases, modeled recharge temperatures were too low $\left(8^{\circ} \mathrm{C}\right)$ or too high $\left(42^{\circ} \mathrm{C}\right)$ because the Ne did not agree well with measured $\mathrm{Ar}$ and $\mathrm{N}_{2}$ results. These samples and other samples with near-zero excess air were reevaluated using $\mathrm{Ar}$ and $\mathrm{N}_{2}$ only. Recharge conditions from models that include $\mathrm{Ne}$ may differ from $\mathrm{Ar}-\mathrm{N}_{2}$ recharge conditions because of different sample collection techniques that lead to different chemistry of samples, or from denitrification, or biogenic- $\mathrm{CH}_{4}$ production that causes partial gas loss.

As a next step, all the samples were modeled again using $\mathrm{Ar}$ and $\mathrm{N}_{2}$ only, with fit parameters of temperature and excess nitrogen gas. The option "Excess $\mathrm{N}_{2}$ for $\mathrm{Ar} / \mathrm{N}_{2}$ only" will generate multiple models for a range of excess air values specified on the user form (fig. 23). For each model generated, the best-fit temperature and excess $\mathrm{N}_{2}$ values are computed and the average temperature, excess $\mathrm{N}_{2}$, and excess air value are reported. The median excess air concentration using $\mathrm{Ne}$, Ar, and $\mathrm{N}_{2}$ was $2.5 \mathrm{~cm}^{3} / \mathrm{kg}$ and most models with no excess or a minimal amount of excess $\mathrm{N}_{2}$ had excess air between 1.5 and $3.5 \mathrm{~cm}^{3} / \mathrm{kg}$. Consequently, a range of $1.5-3.5 \mathrm{~cm}^{3} / \mathrm{kg}$ was used as an estimate of excess air in groundwater that likely had undergone denitrification.

The option "Excess $\mathrm{N}_{2}$ for $\mathrm{Ar} / \mathrm{N}_{2}$ only" method works best when all samples are from the same aquifer and were recharged under similar conditions. If there are large differences in recharge conditions in an aquifer, this method may overestimate or underestimate the contribution of denitrification to samples. 


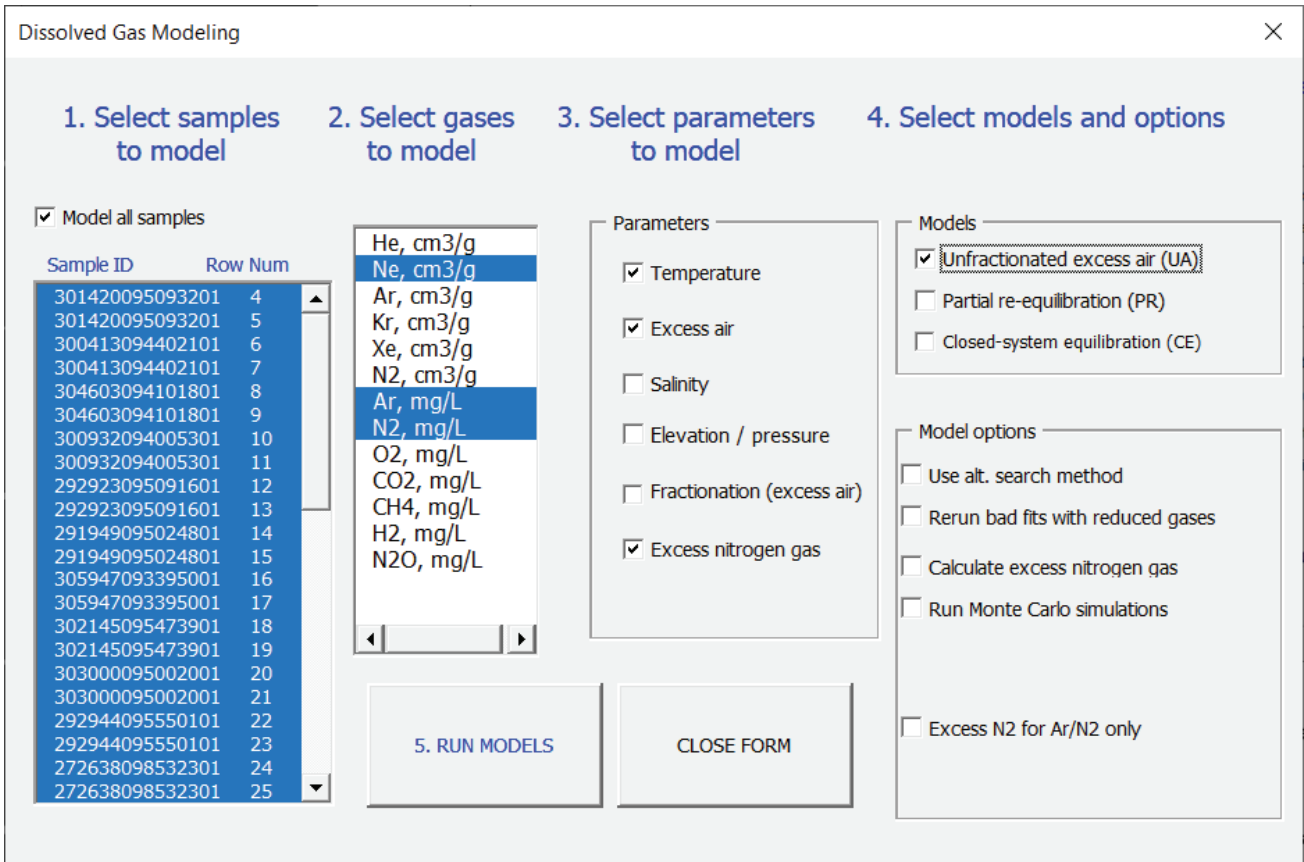

Figure 22. The form for Dissolved Gas Modeling for modeling recharge conditions and denitrification using neon (Ne), argon ( $\mathrm{Ar}$ ), and nitrogen gas $\left(\mathrm{N}_{2}\right)$ concentrations. In this example, all samples will be modeled using available $\mathrm{Ne}, \mathrm{Ar}$, and $\mathrm{N}_{2}$. Temperature, excess air, and excess $\mathrm{N}_{2}$ are the parameters to be used to fit the dissolved gas models to the sample data. Elevation and salinity will be specified from the Input_Gases worksheet.

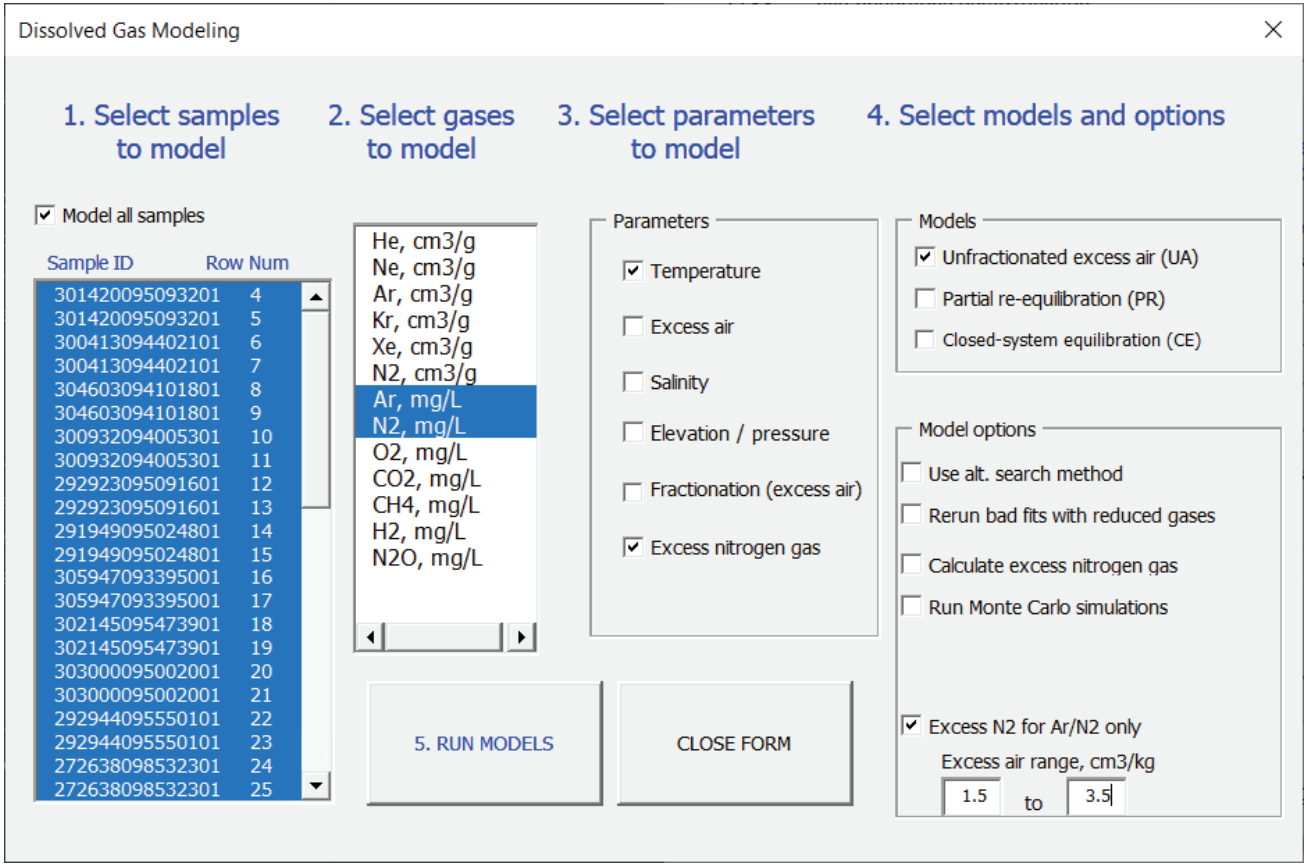

Figure 23. The form for Dissolved Gas Modeling for modeling recharge conditions with denitrification using argon (Ar) and nitrogen gases $\left(\mathrm{N}_{2}\right)$ only. The option "Excess $\mathrm{N}_{2}$ for $\mathrm{Ar} / \mathrm{N}_{2}$ only" will compile a list of models that have excess air values between the range specified by the user, 1.5-3.5 cubic meters per kilogram $\left(\mathrm{cm}^{3} / \mathrm{kg}\right)$ in this case, and will report the corresponding concentrations of excess $\mathrm{N}_{2}$ (presumably from denitrification). 
For samples with multiple models of dissolved gas results, the output from each model should be evaluated against one another to select a single dissolved gas model that best describes the set of measured gas concentrations. For this example, selected models are included in the example file and each sample was categorized in the study area column according to the excess $\mathrm{N}_{2}$ concentration of the chosen model. In general, models with $\mathrm{Ne}, \mathrm{Ar}$, and $\mathrm{N}_{2}$ were preferred over models that used only Ar and $\mathrm{N}_{2}$ when the excess air was greater than 1 or less than or equal to $6 \mathrm{mg} / \mathrm{L}$ as $\mathrm{N}$. In a few instances, the $\mathrm{Ne}$ was not useful for determining temperatures and excess air. The final set of models listed in the worksheet called TX_Final_ModOut (in the example workbook) was used to make graphs on figure 21. In this example, the dissolved gas models that were derived based on $\mathrm{Ne}, \mathrm{Ar}$, and $\mathrm{N}_{2}$, provided the range of likely recharge temperatures, excess air, and extent of denitrification in the aquifer. This information was then used to inform samples with $\mathrm{Ar}$ and $\mathrm{N}_{2}$ data only. Samples with larger excess air values than the range typical of samples with $\mathrm{Ne}, \mathrm{Ar}$, and N2 were likely to have excess $\mathrm{N}_{2}$ present. In these cases, the UA model was run with a different amount of excess N2 (entered on the Input_Gases worksheet) until the excess air or temperature ranges were similar to those determined using $\mathrm{Ne}, \mathrm{Ar}$, and $\mathrm{N}_{2}$.

Combining data from different sample collection types and analytical methods can highlight some of the sources of uncertainty in the laboratory results and the assumptions that underlie the models. Böhlke and others (2007) compared model results using $\mathrm{Ar}$ and $\mathrm{N}_{2}$ (only) with model results using $\mathrm{Ne}, \mathrm{Ar}$, and $\mathrm{N}_{2}$ for an aquifer in Nebraska receiving irrigation recharge. The modeling approach that included $\mathrm{Ne}$ data indicated variation in recharge temperature and excess air (assumed to be unfractionated, using the "UA" model). After accounting for those variations, oxic samples had a mean calculated excess $\mathrm{N}_{2}$ concentration of -6 plus or minus 9 micromoles per $\mathrm{L}(\mu \mathrm{mol} / \mathrm{L})$ as $\mathrm{N}(-0.1 \mathrm{mg} / \mathrm{L})$, indicating a minor bias that might have resulted from combining data from different sample collection types and analytical methods. Similar comparisons of calculated excess air in oxic samples for an aquifer in Long Island, New York (Böhlke and others, 2009), yielded a mean excess $\mathrm{N}_{2}$ value of -14 plus or minus $11 \mu \mathrm{mol} / \mathrm{L}$ as $\mathrm{N}(0.2 \mathrm{mg} / \mathrm{L})$ when calculated using all three gases. These negative values were interpreted as an indication of uncertainty in the estimation of excess $\mathrm{N}_{2}$ from such data.

Tracer concentrations for the Texas samples were computed for the final set of dissolved gas models listed in the TX_Final_ModOut worksheet. In this example, concentrations of $\mathrm{SF}_{6},{ }^{3} \mathrm{H}$, and ${ }^{3} \mathrm{He}_{\text {trit }}$ were calculated using the "Env. Tracer
Calcs" button in the toolbar. As part of the ${ }^{3} \mathrm{He}_{\text {trit }}$ computation, the ${ }^{3} \mathrm{He} /{ }^{4} \mathrm{He}$ ratio of $\mathrm{He}_{\text {terr }}$ was determined automatically by DGMETA. The calculated best-fit line explains the $\delta^{3} \mathrm{He}$ evolution of tritium-dead samples. In this example, the best-fit $\mathrm{R}_{\text {terr }}$ value was $4.43 \times 10^{-8}$ and is listed in the blue cell in the table to the right of the graph (fig. 24). This value is very similar to the radiogenic helium line $\left(2 \times 10^{-8}\right.$; black dashed line) but is slightly elevated probably because the amount of He in some samples appears to be overestimated from dissolved gas models that do not fit the He data well. In this case, the authors decided to replace the $\mathrm{R}_{\text {terr }}$ value in the blue cell to the right of the graph with $2 \times 10^{-8}$ and the best-fit value was ignored.

Average concentrations of the tracers and their errors can be computed as a final step using the "Collapse Tracer Calcs" button in the toolbar. In this study area, $\mathrm{SF}_{6}$ concentrations above 1.0 volume of gas per volume of dry air, in parts per trillion (pptv), in samples with low ${ }^{3} \mathrm{H}$ (less than $0.5 \mathrm{TU}$ ) indicate that $\mathrm{SF}_{6}$ was contaminated, likely by terrigenic sources or perhaps from atmospheric contamination during sample collection, storage, or shipping. The contamination bias can be identified from a graph of ${ }^{3} \mathrm{H}$ and $\mathrm{SF}_{6}$ (fig. 25). Because $\mathrm{SF}_{6}$ is a tracer of water that entered an aquifer after about 1975 or later, groundwater recharged after that date should contain $\mathrm{SF}_{6}$ concentrations between 0.5 and 9 pptv and have detectable levels of ${ }^{3} \mathrm{H}$ (greater than $0.5 \mathrm{TU}$ ). However, ${ }^{3} \mathrm{H}$ concentrations in most samples were less than $0.1 \mathrm{TU}$, which indicates most of the groundwater was recharged before about 1950, such that all $\mathrm{SF}_{6}$ concentrations of environmental origin should be below about $0.5 \mathrm{pptv}$ (gray-shaded area in fig. 25). Assuming the laboratory analyses were reliable and sample collection procedures were followed correctly, groundwater samples with $\mathrm{SF}_{6}$ concentrations above 0.5 pptv and ${ }^{3} \mathrm{H}$ concentrations less than $0.1 \mathrm{TU}$ indicate the introduction of $\mathrm{SF}_{6}$ from a terrigenic source of $\mathrm{SF}_{6}$ diffused from igneous or volcanic rocks (Busenberg and Plummer, 2000; red-shaded area in fig. 25). On the other hand, contamination from exposure to atmospheric sources of $\mathrm{SF}_{6}$ during sample collection, storage, or shipping could be another explanation. By comparison, the atmospheric mole fraction concentration of $\mathrm{SF}_{6}$ is about $10 \mathrm{pptv}$.

Sulfur hexafluoride concentrations substantially above the atmospheric levels would indicate a terrigenic source was more likely. Unfortunately, the presence of terrigenic $\mathrm{SF}_{6}$ can limit the utility of $\mathrm{SF}_{6}$ for dating water because it may not be possible to tell if the $\mathrm{SF}_{6}$ was derived from terrigenic or atmospheric sources even when the concentrations are at expected environmental levels. 
$\boldsymbol{A}$

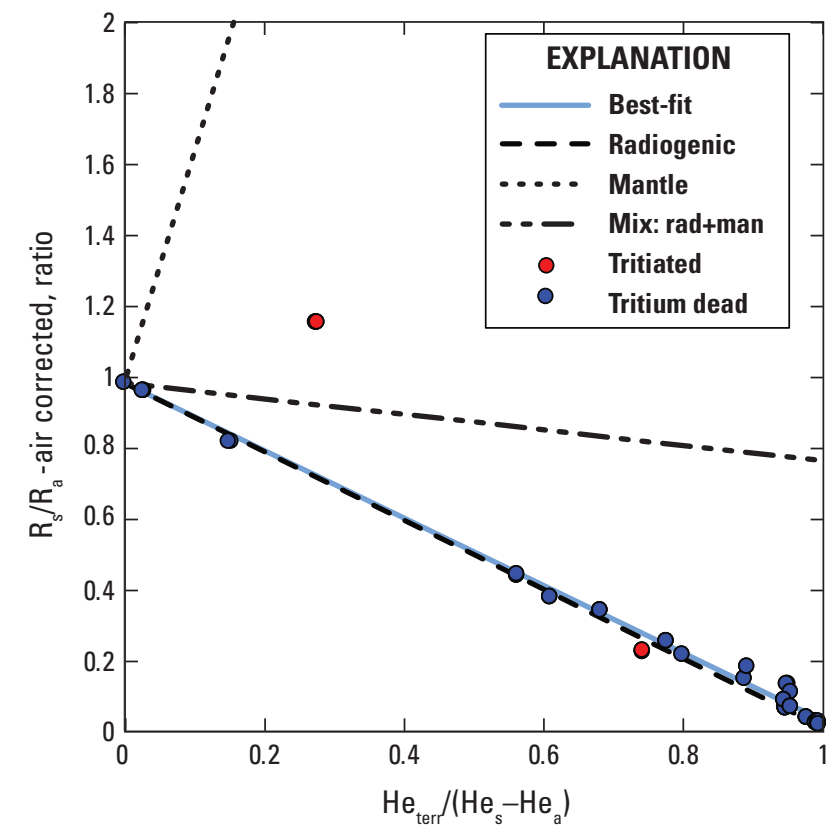

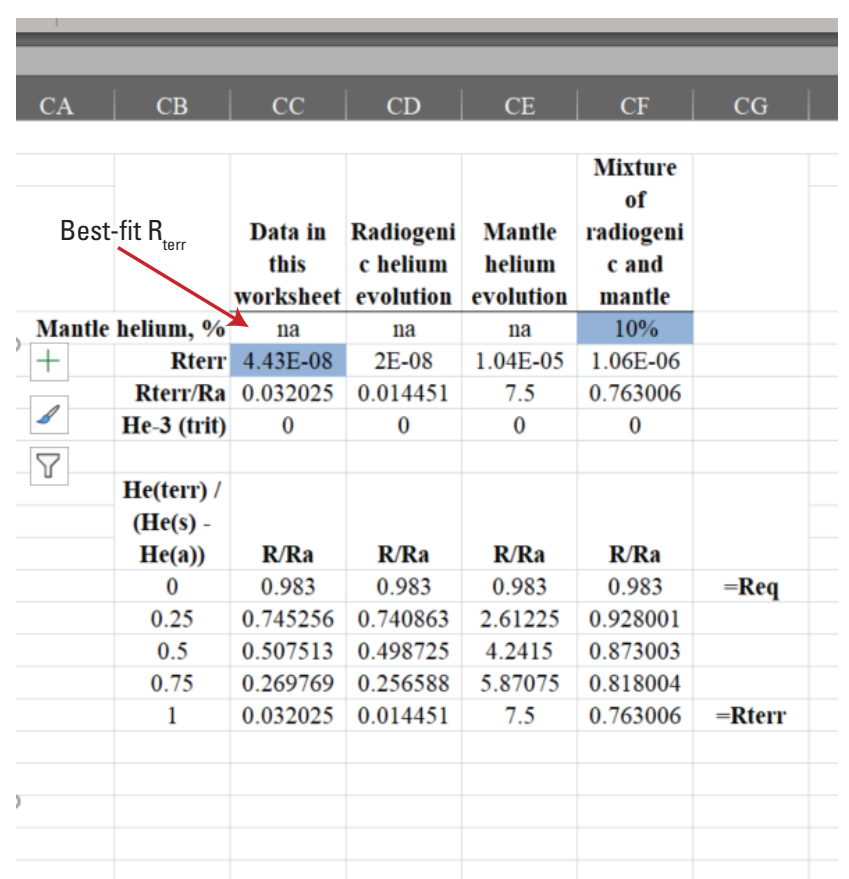

Figure 24. The $A$, helium isotope separation plot and $B$, table of helium isotope control variables on the TX_Final_Trc0ut worksheet. Dissolved Gas Modeling and Environmental Tracer Analysis automatically calculates a best-fit line for samples with tritium less than 0.5 tritium unit in order to compute the helium-3/helium-4 of terrigenic helium $\left(R_{\text {terr }}\right)$, which is output in the blue cell to the right of the graph on the _TrcOut worksheet.

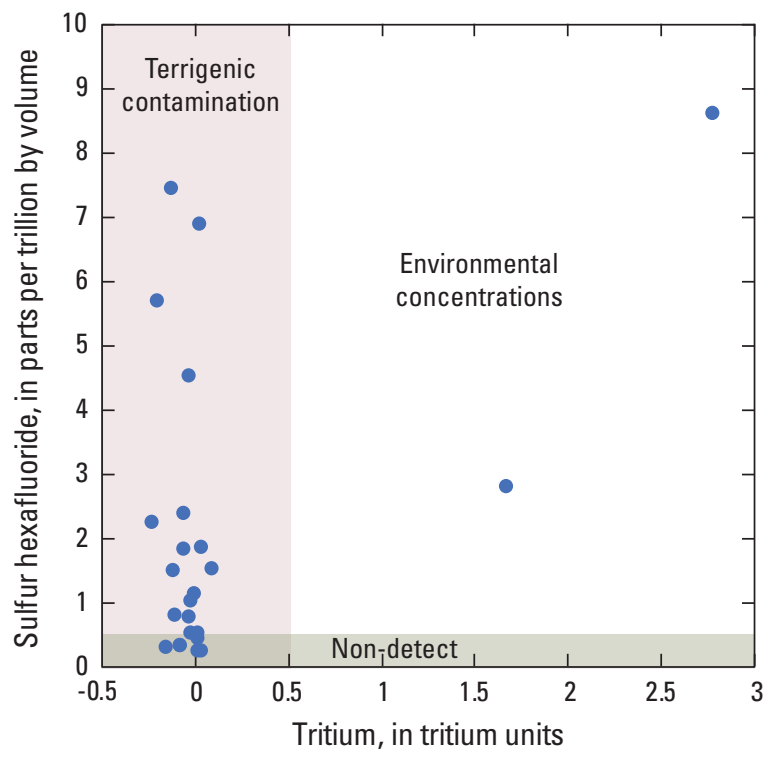

Figure 25. Tritium and sulfur hexafluoride $\left(\mathrm{SF}_{6}\right)$ concentrations in groundwater in the Texas coastal lowlands aquifer. Sulfur hexafluoride concentrations below the tritium cutoff line at 0.5 tritium unit (TU) are indicative of terrigenic sources whereas $\mathrm{SF}_{6}$ concentrations greater than $0.5 \mathrm{TU}$ generally reflect expected environmental concentrations. The presence of terrigenic $\mathrm{SF}_{6}$ may limit the utility of $\mathrm{SF}_{6}$ for determining ages of water. 


\section{Example 4-Tritiogenic Helium-3 Analysis in the Central Eastside San Joaquin Valley, California}

The following example shows how dissolved gas modeling and environmental tracer concentrations were determined for a set of samples used for determining age distributions of groundwater in wells in the central eastside of the San Joaquin Valley, California (Green and others, 2016; Jurgens and others, 2016). Even though measurements of noble gases typically provide the best way to determine air-water equilibrium conditions (for example, the temperature and excess air of recharge) in an aquifer, the data from this example do not provide strong evidence that one dissolved gas model is the best choice for determining recharge conditions. Example 4 also demonstrates the importance of Monte Carlo simulation methods for determining parameter uncertainty from CE models. Samples of dissolved gases were modeled using $\mathrm{Ne}, \mathrm{Ar}, \mathrm{Kr}$, and $\mathrm{Xe}$ concentrations and the UA (fig. 26A) and CE models (fig. 26B). To evaluate the results of the dissolved gas models, samples were assigned age classifications of Modern, PreModern, or Mixed based on their ${ }^{3} \mathrm{H}$ activity in relation to the ${ }^{3} \mathrm{H}$ in the precipitation record (Michel and others, 2018) corrected for decay from the time of precipitation to the sample date. This age classification system is described in Lindsey and others (2019). Samples with ${ }^{3} \mathrm{H}$ less than $0.34 \mathrm{TU}$ were categorized as PreModern because activities below this value would indicate that groundwater was recharged before 1950. Samples with ${ }^{3} \mathrm{H}$ greater than 2.6 TU were categorized as Modern because activities greater than this value would indicate that groundwater was recharged after 1950. Samples with activities between 0.34 and 2.6 were categorized as Mixed and indicate that groundwater was a mixture of water recharged before and after 1950 .

Comparison of CE to UA model results showed that the $\mathrm{CE}$ model generally predicted higher recharge temperatures than the UA model for the same sample (fig. 27), but gave better fits and $\mathrm{He}$ balance $\left(\mathrm{He}_{\text {terr }}=\mathrm{He}_{\mathrm{s}}-\mathrm{He}_{\mathrm{eq}}-\mathrm{He}_{\mathrm{a}} \approx 0\right)$ for most of the Modern samples ( 23 of 40). The CE model may be more relevant to samples of Modern groundwater in this region because recharge is primarily from agricultural irrigation and can produce seasonal water-table fluctuations of around $1 \mathrm{~m}$ annually (Phillips and others, 2007; Jurgens and others, 2008). These fluctuations may trap large volumes of air in water that enters the aquifer as recharge. The UA model indicated that median excess air values were $2.6 \mathrm{~cm}^{3} / \mathrm{kg}$ for Modern samples, $2.5 \mathrm{~cm}^{3} / \mathrm{kg}$ for Mixed samples, and $1.41 \mathrm{~cm}^{3} / \mathrm{kg}$ for PreModern samples, which indicates that Modern water has a larger amount of excess air than PreModern water.
Final dissolved gas models were chosen on a case-by-case basis by comparing model-fit parameters and statistics. Generally, samples with larger amounts of excess air or concentrations of gases indicative of $\mathrm{F}$ were fit better by the CE model than by the UA model (fig. 28). Final dissolved gas models are listed in the Final_ModOut worksheet in the example 4 workbook.

Chlorofluorocarbon and ${ }^{3} \mathrm{He}_{\text {trit }}$ concentrations were calculated from $\mathrm{CFC}$ and $\delta^{3} \mathrm{He}$ samples and the dissolved gas models listed in the Final_ModOut worksheet. Tracer concentrations are computed in the Final_TrcOut worksheet and values with a red font are parameter errors taken from the Monte Carlo analysis. The $\mathrm{R}_{\text {terr }}$ value was determined from a best-fit line for samples with ${ }^{3} \mathrm{H}$ activities less than $0.29 \mathrm{TU}$, which is lower than the threshold used to define PreModern groundwater above, because it isolates the samples with the lowest ${ }^{3} \mathrm{H}$ concentrations. These samples had a $\mathrm{R}_{\text {terr }}$ value of about $5.0 \times 10^{-7}$, which indicates a mixture of radiogenic $\left(2 \times 10^{-8} \mathrm{~cm}^{3} / \mathrm{g}\right)$ and mantle $\left(1 \times 10^{-5} \mathrm{~cm}^{3} / \mathrm{g}\right) \mathrm{He}($ fig. 29$)$. The amount of mantle $\mathrm{He}$ in the mixture is small, about 5 percent, and is probably derived from weathering of volcanic sediments in the aquifer (Page and Balding, 1973).

Tritiogenic helium concentrations were calculated from the He mass balance (eqs. 23-25). Calculated ${ }^{3} \mathrm{He}_{\text {trit }}$ concentrations, for samples with $\mathrm{He}_{\text {terr }}$ concentrations of greater than 70 percent of the measured He concentration, are not reported because the amount of $\mathrm{He}_{\text {terr }}$ in such samples can make it difficult to accurately determine the amount of He derived from tritium decay. Samples that plot below the best-fit line shown on figure 29 will have negative or zero concentrations of ${ }^{3} \mathrm{He}_{\text {trit }}$ even though some of the samples have measurable ${ }^{3} \mathrm{H}$. Those samples, and perhaps others, could be from sites where volcanic sediments are absent in the subsurface and have a purely radiogenic source of $\mathrm{He}_{\text {terr }}$. For those sites, the $\mathrm{R}_{\text {terr }}$ values could be individually set to $2 \times 10^{-8}$ on the _TrcOut worksheet, but the concentrations of ${ }^{3} \mathrm{He}_{\text {trit }}$ will be small. The best-fit $\mathrm{R}_{\text {terr }}$ value $\left(5 \times 10^{-7}\right)$ gives lower, more conservative estimates of ${ }^{3} \mathrm{He}_{\text {trit }}$ than a radiogenic $\mathrm{R}_{\text {terr }}$, which may be preferable for a regional dataset. Figure 30 shows how the $\delta^{3} \mathrm{He}$ graph can be manually adjusted to identify the ${ }^{3} \mathrm{He}_{\text {trit }}$ content of samples with mixtures of $\mathrm{He}_{\text {terr }}$. For that graph, a concentration of $30 \mathrm{TU}$ was set for the ${ }^{3} \mathrm{He}_{\text {trit }}$ value in the table to the right of the graph (fig. 30B). The graph shows that many samples with the $\mathrm{He}_{\text {terr }}$ plot near and along this mixing line, which indicates those samples have ${ }^{3} \mathrm{He}_{\text {trit }}$ values near $30 \mathrm{TU}$. Overall, 36 samples had calculated concentrations of ${ }^{3} \mathrm{He}_{\text {trit }}$ greater than $1 \mathrm{TU}, 24$ samples were not quantifiable, and 15 samples had calculated concentrations of less than $1 \mathrm{TU}$. 
A

Dissolved Gas Modeling

1. Select samples to model

2. Select gases to model

『 Model all samples

Sample ID Row Num

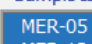

MER-12

MER-20

MERFP-01

MERMW-05

MOD-06

MOD-10

MOD-10

TRLK-02

TRLK-10

TRLK-15

TRLKMW-01

CE-QPC-01

MER-02

MER-04

MER-09

MER-11

MER-16

MER-17

MER-19

MER-19

MERMW-03

MERMW-04

\begin{tabular}{l|l|}
4 & - \\
5 \\
6 \\
7 \\
8 \\
9
\end{tabular}

$\mathrm{He}, \mathrm{cm} 3 / \mathrm{g}$

$\mathrm{Ne}, \mathrm{cm} 3 / \mathrm{g}$

$\mathrm{Ar}, \mathrm{cm} 3 / \mathrm{g}$

$\mathrm{Kr}, \mathrm{cm} 3 / \mathrm{g}$

$\mathrm{Xe}, \mathrm{cm} 3 / \mathrm{a}$

$\mathrm{N} 2, \mathrm{~cm} 3 / \mathrm{g}$

Ar, $\mathrm{mg} / \mathrm{L}$

$\mathrm{N} 2, \mathrm{mg} / \mathrm{L}$

$\mathrm{O} 2, \mathrm{mg} / \mathrm{L}$

$\mathrm{CO} 2, \mathrm{mg} / \mathrm{L}$

$\mathrm{CH} 4, \mathrm{mg} / \mathrm{L}$

$\mathrm{H} 2, \mathrm{mg} / \mathrm{L}$

$\mathrm{N} 2 \mathrm{O}, \mathrm{mg} / \mathrm{L}$

4

上. 3. Select parameters
to model

4. Select models and options

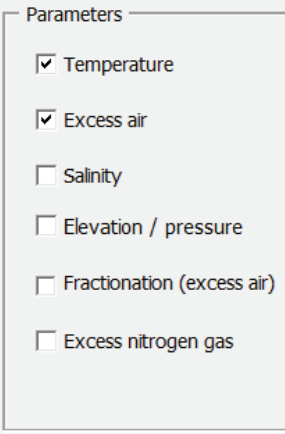

『 Unfractionated excess air (UA)

$\lceil$ Partial re-equitibration (PR)

$\lceil$ Closed-system equilibration (CE)

- Model options

厂 Use alt. search method

$\sqrt{ }$ Rerun bad fits with reduced gases

$\Gamma$ Calculate excess nitrogen gas

$\Gamma$ Run Monte Carlo simulations

CLOSE FORM

ГExcess N2 for Ar/N2 only

B

Dissolved Gas Modeling

1. Select samples to model

『 Model all samples

Sample ID

MER-05
MER-12

MER-20

MERFP-01

MERMW-05

MOD-06

MOD-10

TRLK-02

TRLK-10

TRIK-15

TRLK-15
TRIKMW-01

TRLKMW-01

CE-QPC-01

MER-02

MER-04

MER-09

MER-11

MER-16

MER-17

MER-19

MERMW-02

MERMW-03

MERMW-04

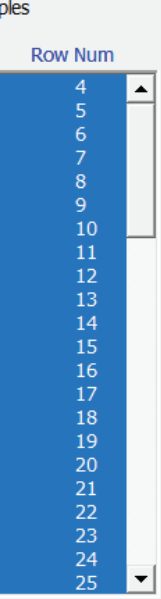

2. Select gases to model

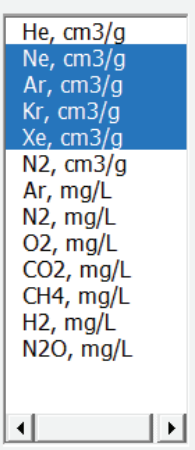

5. RUN MODELS

CLOSE FORM to model

$\lceil$ Salinity
4. Select models and options

$\lceil$ Unfractionated excess air (UA)

$\lceil$ Partial re-equitibration (PR)

『 Closed-system equilibration (CE)

ГElevation / pressure

$\sqrt{\checkmark}$ Fractionation (excess air)

$\lceil$ Excess nitrogen gas

\section{$\Gamma$ Use alt. search method}

$\Gamma$ Rerun bad fits with reduced gases

$\Gamma$ Calculate excess nitrogen gas

$\sqrt{ } \sqrt{ }$ Run Monte Carlo simulations

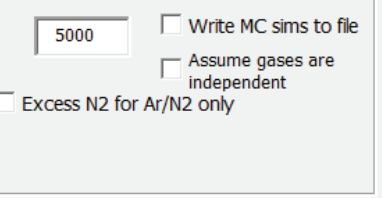

Figure 26. The Dissolved Gas Modeling form used to generate $A$, unfractionated excess air models (UA) and $B$, closed-system equilibration models (CE) of dissolved gases on the basis of dissolved neon $(\mathrm{Ne})$, argon (Ar), krypton ( $\mathrm{Kr}$ ), and xenon (Xe) concentrations in groundwater in the central eastside of the San Joaquin Valley, California, in 2006. 


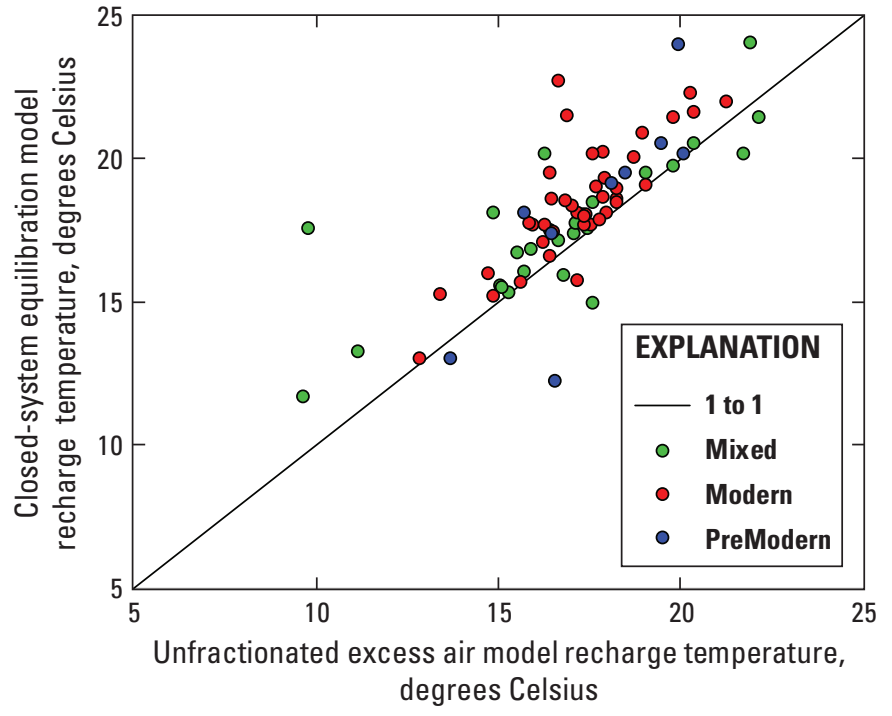

Figure 27. Comparison of closed-system equilibration and unfractionated excess air model results for recharge temperatures among different age classifications based on tritium measurements of groundwater samples from the central eastside of the San Joaquin Valley, California, in 2006.
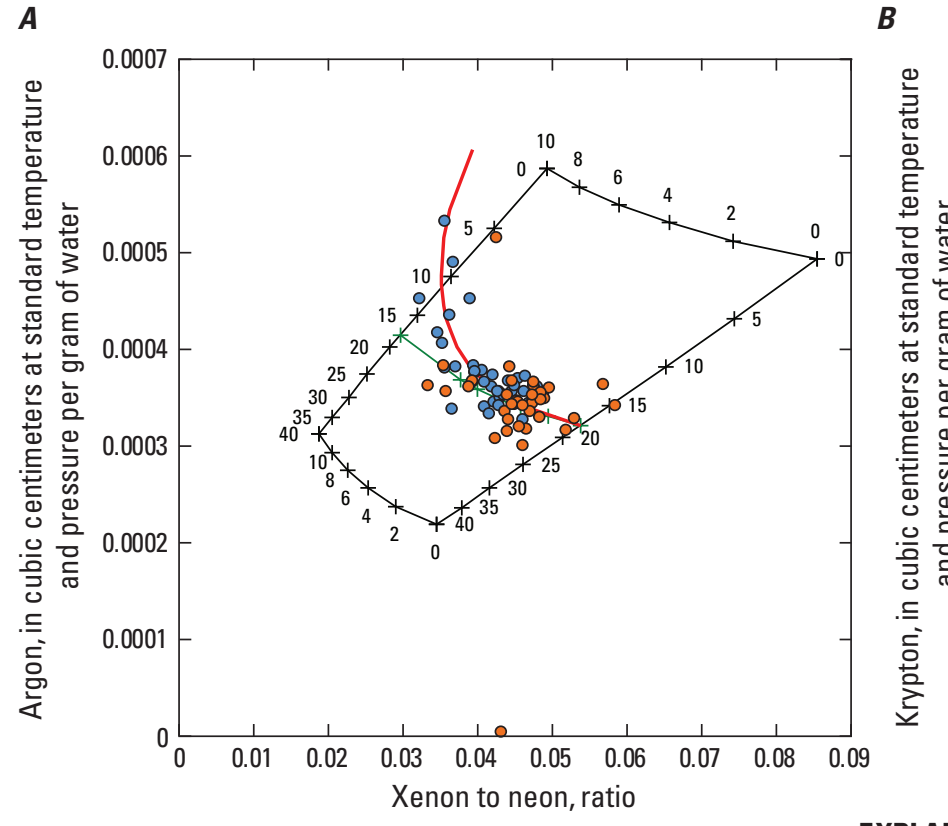

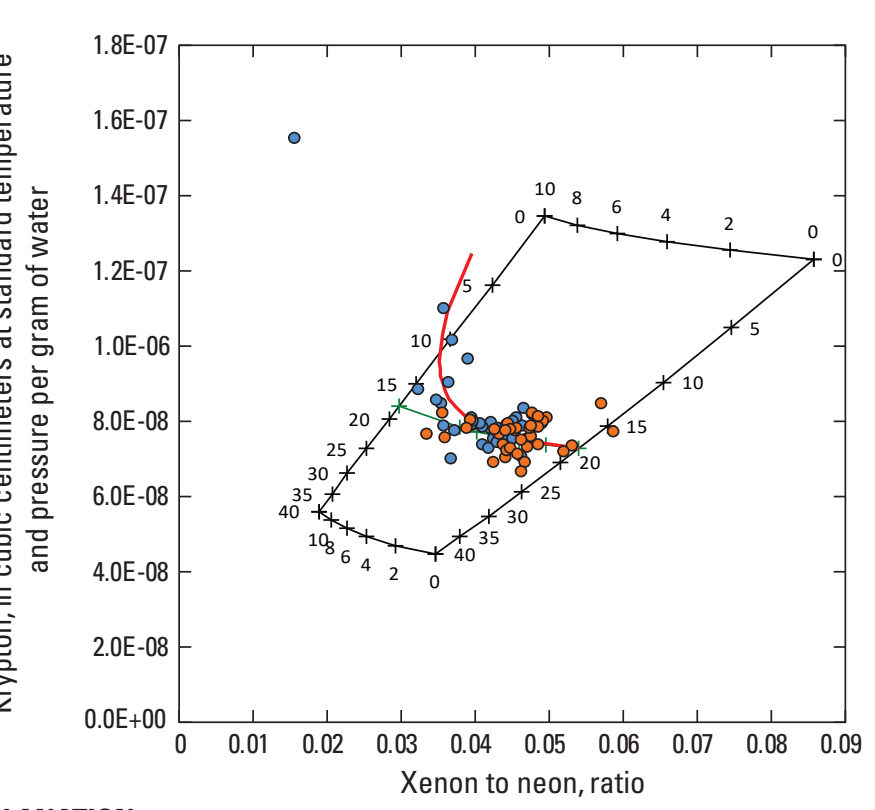

EXPLANATION
- Closed-system equilibration model

- Unfractionated excess air model

Figure 28. Graphs of sample concentrations of $A$, argon versus xenon to neon and $B$, krypton versus xenon to neon. Samples are color coded based on the final dissolved gas model for each sample. Samples where the unfractionated excess air (UA) model was used are orange and samples where the closed-system equilibration (CE) model was used are blue. Most samples that follow a UA model (orange circles) had excess air values between 1 and 4 cubic centimeters per kilogram $\left(\mathrm{cm}^{3} / \mathrm{kg}\right)$. Many samples also followed a CE model with excess air values between 3 and $7 \mathrm{~cm}^{3} / \mathrm{kg}$. The lines for the UA (green-solid line) and CE (red-dotted line) were plotted using a temperature of 17 degrees Celsius and the fractionation parameter of the CE model was set to 0.5 . 
$\boldsymbol{A}$

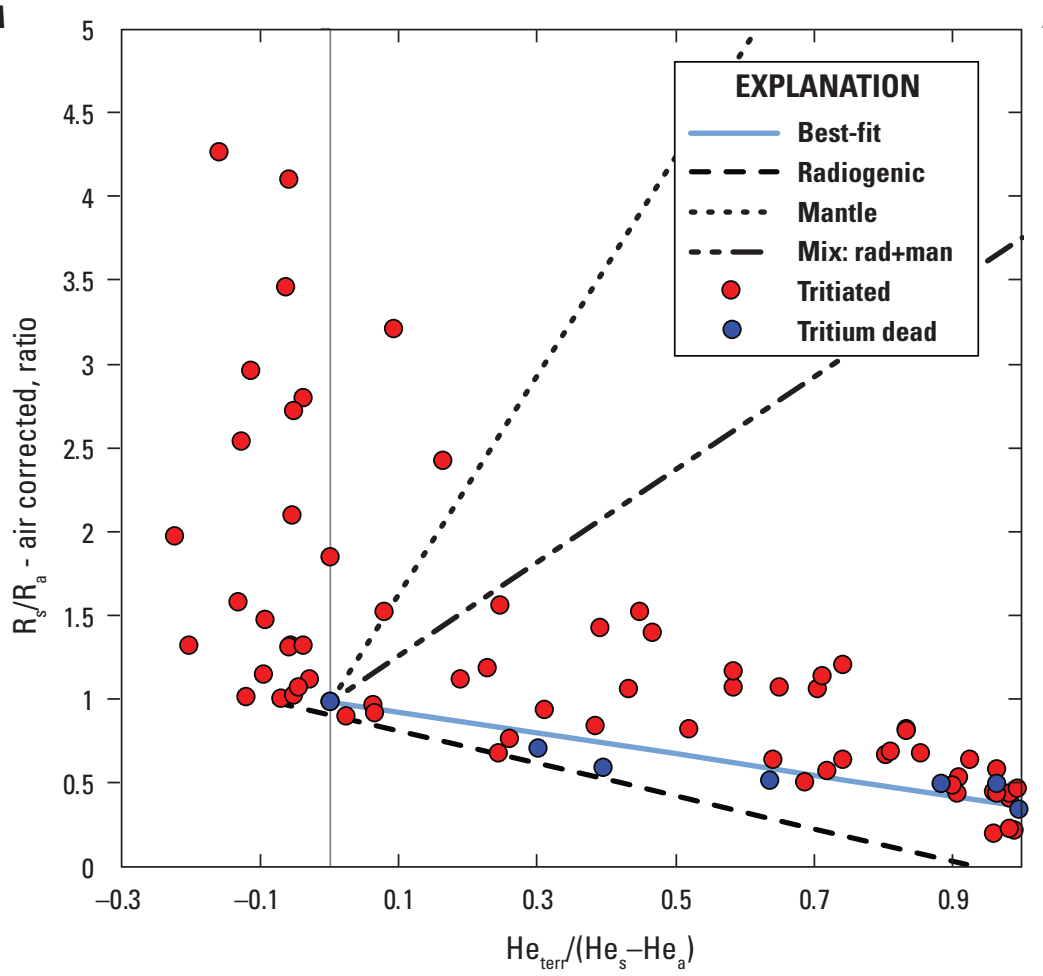

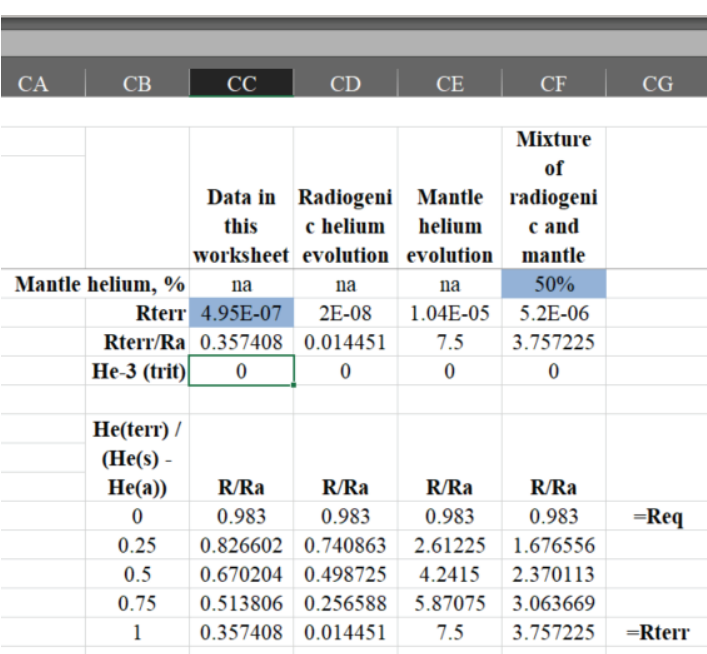

Figure 29. Views of $A$, the modified Weise plot (Weise and Moser, 1987) for samples that are tritiated (tritium concentration greater than 0.29 tritium unit; TU) and samples that are tritium-dead (less than $0.29 \mathrm{TU}$ ) and $B$, a table of helium isotope control variables on the Final_TrcOut worksheet. The best-fit line (solid blue) through tritium-dead samples has a helium-3/helium-4 of terrigenic helium $\left(R_{\text {terr }}\right)$ of about $5.0 \times 10^{-7}$ and indicates a mixture of radiogenic and mantle helium.

$\boldsymbol{A}$

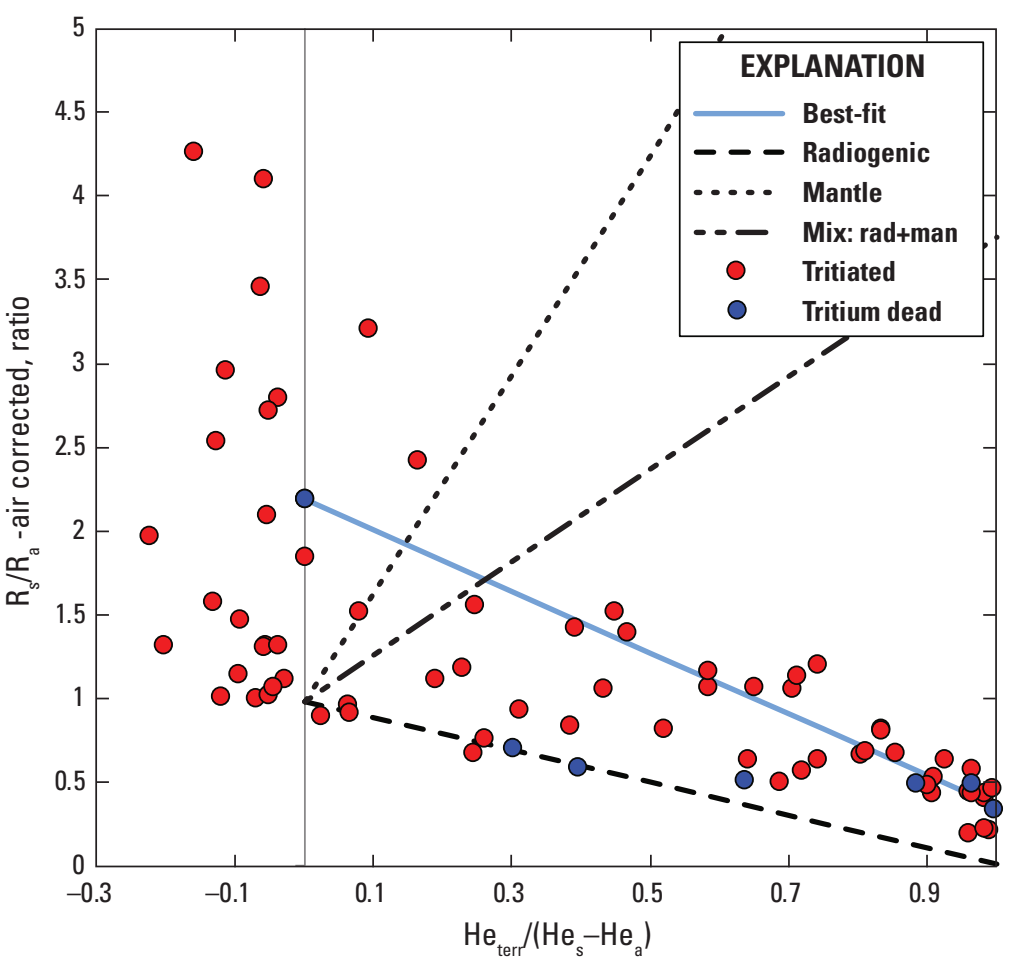

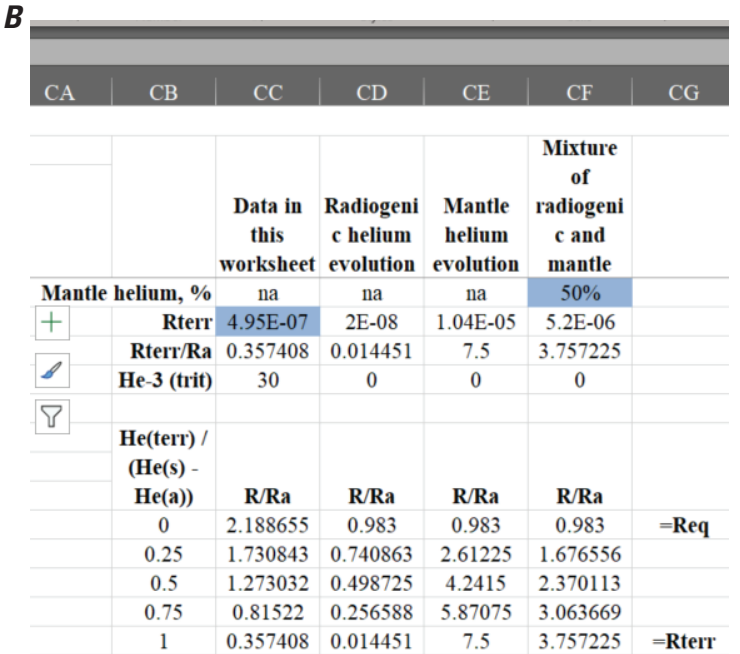

Figure 30. Views of $A$, the modified Weise plot showing mixing of groundwater endmembers and $B$, a table of helium isotope control variables on the Final_TrcOut worksheet. The blue line illustrates a mixture of water from one source that has no terrigenic helium $\left(\mathrm{He}_{\text {terr }}\right)$ and 30 tritium units (TU) of tritiogenic helium-3 $\left(3 \mathrm{He}_{\text {trit }}\right)$, and another water with $0 \mathrm{TU}$ of $3 \mathrm{He}_{\text {trit }}$ and is almost entirely composed of terrigenic helium that has a helium-3/helium-4 ratio $\left(R_{\text {terr }}\right)$ of $5.0 \times 10^{-7}$. 
Finally, the example workbook that accompanies DGMETA (DGMETA_Example_4.xlsm) has an additional _ModOut worksheet with results from the samples where the CE model was used. These results have Monte Carlo simulations that were computed assuming the gases are completely independent. These results can be compared to the Final_ModOut version that included Monte Carlo simulations that were done assuming that the gases were not independent and were randomized as a group. The gas samples generated, assuming complete independence, are truly random and provide a more accurate picture about the true range of possible solutions to the measured gas data. Thus, the parameter error estimates from this method can often be large when the range of possible solutions is large. In addition, the average results of the ensemble may not be similar to the best-fit results computed from the measured gas data. In this example, the temperature, entrapped air, and $\mathrm{F}$ results from the Monte Carlo results deviate from the best-fit results by about $-2.6,-87$, and 9.2 percent, respectively. Overall, the completely independent results produced warmer temperatures with larger amounts of entrapped air than indicated by the fit computed from the measured data. These results also could be used to compute tracer concentrations, but the atmospheric mole fractions have errors as large as the computed mole fraction, which makes the tracer results ineffective for determining ages of water.

In contrast to the completely independent set of Monte Carlo simulations, the gas samples generated as a randomized group provided a more local estimate of the range of possible solutions and, therefore, had smaller parameter errors. In addition, the Monte Carlo simulations more strongly agreed with best-fit results computed from the measured data. Here, the temperature, entrapped air, and F values of the Monte Carlo simulations deviate from the best-fit parameter estimates by about $0.3,-4.7$, and 0.17 percent, respectively. The dependent set of Monte Carlo errors also give lower computed errors associated with tracer concentrations. Consequently, this approach to parameter uncertainty can provide a reasonable substitute for the large uncertainty surrounding some CE model results.

Although this approach for dealing with large parameter uncertainties is advantageous for reporting CE model results and for computing tracer concentrations from those models, it may sidestep a more detailed analysis of Monte Carlo results recommended by Jung and Aeschbach-Hertig (2018). But more importantly, it also may mask important yet unexplained physical controls that might better explain peculiar sets of noble gas data. A more detailed analysis of the noble gas data in the context of new or existing physical processes and mixing of water with different recharge histories in the subsurface could therefore reveal a better model of the noble gas data.

\section{Example 5-Degassed Groundwater}

Aeschbach-Hertig and others (2008) showed that the CE model can explain some situations in which gases exsolve from a solution into a gas or bubble phase. Degassing can cause the gases to fractionate according to their solubility such that the lighter noble gases with lower solubilities are preferentially depleted from the solution relative to the heavier noble gases. The $\mathrm{CE}$ model simulates this behavior when $\mathrm{F}$ is greater than 1 , which physically can be interpreted as the creation of bubbles from the water in response to a drop in hydraulic pressure. Bubble creation may occur as groundwater is extracted from deeper depths or moves to an area of lower pressure or warmer temperature. This phenomenon also can occur in groundwater where oversaturation of $\mathrm{N}_{2}$ from denitrification or $\mathrm{CH}_{4}$ from methanogenesis cause other gases to exolve from a solution or to be undersaturated in the subsurface (Aeschbach-Hertig and others, 2008; Cey and others, 2009). In the mathematical formulation of the CE model, the F parameter includes the ratio of the final volume of entrapped gas to the initial volume of entrapped gas. When $\mathrm{F}$ is greater than 1, the final volume of entrapped gas is greater than the initial volume indicating the enlargement or creation of a trapped volume of gas.

DGMETA can be used to graphically identify cases in which degassing likely occurred and estimate dissolved gas model parameters in which the $\mathrm{CE}$ model describes degassing in samples. A convenient way to identify degassed samples is to make graphs of the $\mathrm{Xe} / \mathrm{Ne}$ ratio because degassing tends to cause $\mathrm{Ne}$ (a lighter gas) to be depleted relative to Xe (a heavier gas) and leads to higher $\mathrm{Xe} / \mathrm{Ne}$ ratios in comparison to samples that are not degassed. Figure 31 shows samples from Aeschbach-Hertig and others (2008) in relation to the $\mathrm{CE}$ model with a $\mathrm{F}$ parameter value set to 2 and a recharge temperature set to $9^{\circ} \mathrm{C}$ on the _GasGph worksheet. The samples plot far to the right of normal samples with dissolved excess air concentrations and higher $\mathrm{Xe} / \mathrm{Ne}$ ratios.

In order to numerically solve for the best-fit parameters of degassed samples, the initial value of the $\mathrm{F}$ parameter should be set to a value of greater than 1 on the Input_Gases worksheet because the excess air component of the $\overline{\mathrm{CE}}$ model vanishes at $\mathrm{F}=1$. For this reason, it is recommended that degassed samples first be identified through graphical inspection of gas-gas graphs. Setting the initial F factor to a value greater than 1 ensures the numerical solution will identify the proper best-fit values of degassed samples. For the degassed samples of Aeschbach-Hertig and others (2008), the initial $\mathrm{F}$ value was set to 1.5 and best-fit solutions were computed. Results computed using DGMETA were nearly the same as best-fit values reported by Aeschbach-Hertig and others (2008). 

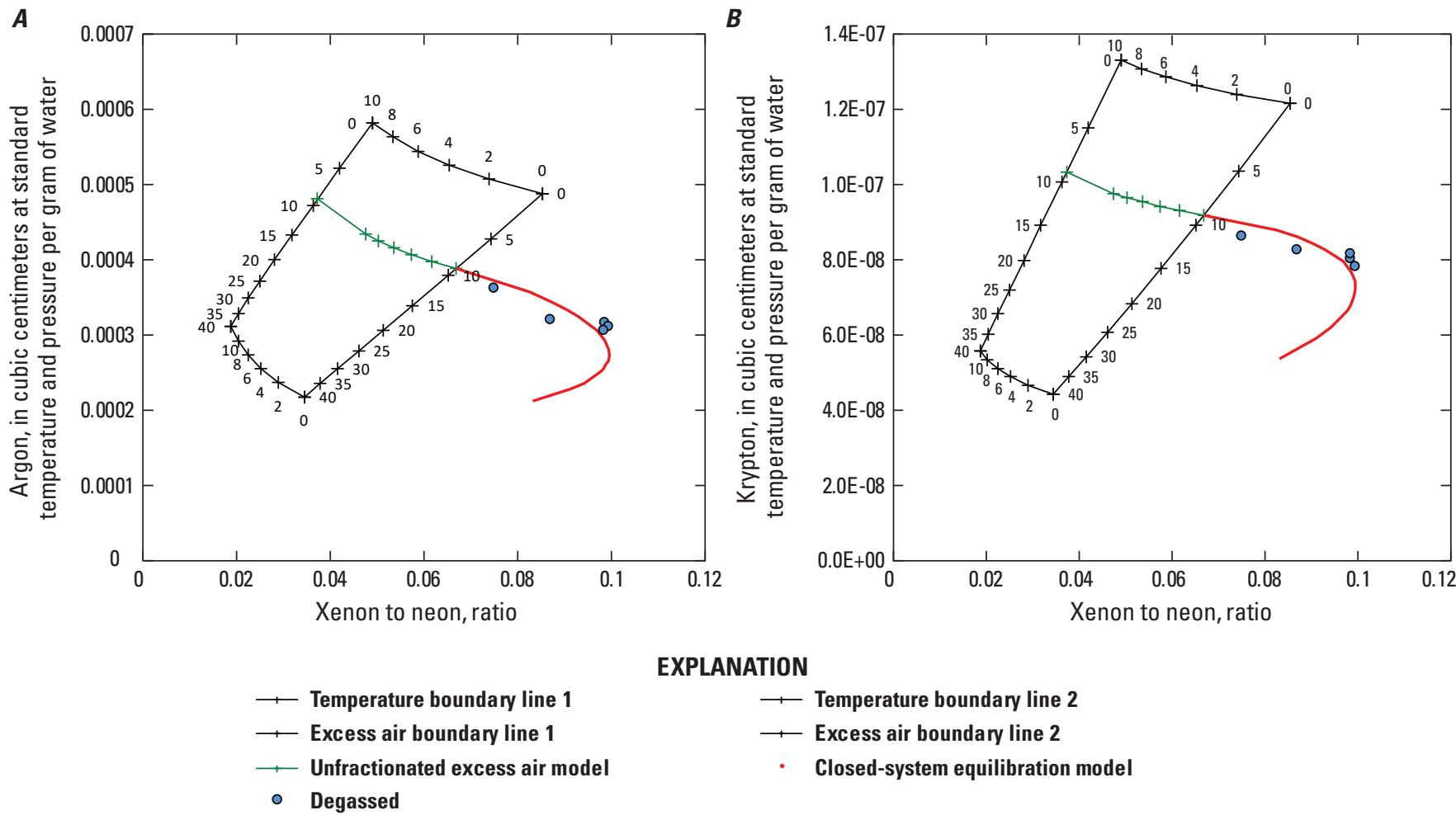

EXPLANATION

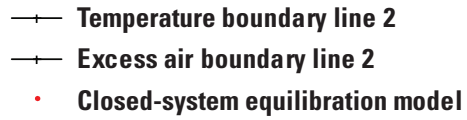

Figure 31. Solubility concentrations for $A$, argon and $B$, krypton plotted versus the ratio of the solubility concentrations of xenon and neon, in cubic centimeters per gram of water $\left(\mathrm{cm}^{3} / \mathrm{g}\right)$, for different recharge temperatures and excess air values. Degassed samples from Aeschbach-Hertig and others (2008) are plotted to show the area where degassed samples can be identified. Dissolved gas model output for the unfractionated excess air model is shown by the green line and the closed-system equilibration (CE) model is the red-dotted line. The samples are consistent with the CE dissolved gas model with a recharge temperature of 9 degrees Celsius and a fractionation value of about 2. The salinity and elevation of the degassed samples were approximately 1.3 per mil and 88 meters (pressure $=0.99 \mathrm{~atm}$ ), respectively. The red dots give CE dissolved gas model concentrations and ratios for different amounts of entrapped excess air.

\section{Installation Notes}

The program was written in Visual Basic for Applications within the Microsoft Excel environment. As such, the program requires Excel macros to be enabled in order to work. An Excel warning may appear in the toolbar when the program is first opened, indicating that macros have been detected and are disabled. Users must enable Excel macros for the program to work.

\section{Disclaimer}

This software has been approved for release by the U.S. Geological Survey (USGS). Although the software has been subjected to rigorous review, the USGS reserves the right to update the software as needed pursuant to further analysis and review. No warranty, expressed or implied, is made by the USGS or the U.S. Government as to the functionality of the software and related material nor shall the fact of release constitute any such warranty. Furthermore, the software is released on condition that neither the USGS nor the U.S. Government shall be held liable for any damages resulting from its authorized or unauthorized use. 


\section{References Cited}

Aeschbach-Hertig, W., and Solomon, D.K., 2013, Noble gas thermometry in groundwater hydrology, in Burnard, P., ed., The noble gases as geochemical tracers - advances in isotope geochemistry: Berlin, Germany, Springer, p. 81-122, https://doi.org/10.1007/978-3-642-28836-4_5.

Aeschbach-Hertig, W., Peeters, F., Beyerle, U., and Kipfer, R., 1999, Interpretation of dissolved atmospheric noble gases in natural waters: Water Resources Research, v. 35, no. 9, p. 2779-2792, https://doi.org/10.1029/1999WR900130.

Aeschbach-Hertig, W., Peeters, F., Beyerle, U., and Kipfer, R., 2000, Paleotemperature reconstruction from noble gases in groundwater taking into account equilibration with entrapped air: Nature, v. 405, no. 6790, p. 1040-1044, https://doi.org/10.1038/35016542.

Aeschbach-Hertig, W., El-Gamal, H., Wieser, M., and Palcsu, L., 2008, Modeling excess air and degassing in groundwater by equilibrium partitioning with a gas phase: Water Resources Research, v. 44, no. 8, 12 p., https://doi.org/10.1029/2007WR006454.

American Public Health Association, 2005, Standard methods for the examination of water and wastewater (21st ed.): Washington, D.C., American Public Health Association, American Water Works Association, and Water Environment Federation, p. 4-136 to 4-137, https://www.standardmethods.org/.

Andrews, J.N., and Lee, D.J., 1979, Inert gases in groundwater from the Bunter Sandstone of England as indicators of age and paleoclimatic trends: Amsterdam, Netherlands, Journal of Hydrology, v. 41, no. 3-4, p. 233-252, https://doi.org/10.1016/0022-1694(79)90064-7.

Ballentine, C.J., and Hall, C.M., 1999, Determining paleotemperature and other variables by using an error weighted, nonlinear inversion of noble gas concentrations in water: Geochimica et Cosmochimica Acta, v. 63, no. 16, p. 2315-2336, https://doi.org/10.1016/S0016-7037(99)00131-3.

Benson, B.B., and Krause, D., Jr., 1984, The concentration and isotopic fractionation of oxygen dissolved in freshwater and seawater in equilibrium with the atmosphere: Limnology and Oceanography, v. 29, no. 3, p. 620-632, https://doi.org/10.4319/1o.1984.29.3.0620.

Benson, B.B., Krause, D., Jr., and Peterson, M.A., 1979, The solubility and isotopic fractionation of gases in dilute aqueous solution-I. Oxygen: Journal of Solution Chemistry, v. 8, no. 9, p. 655-690, https://doi.org/10.1007/BF01033696.
Beyer, M., van der Raaij, R., Morgenstern, U., and Jackson, B., 2014, Potential groundwater age tracer found-Halon-1301 $\left(\mathrm{CF}_{3} \mathrm{Br}\right)$, as previously identified as CFC-13 $\left(\mathrm{CF}_{3} \mathrm{Cl}\right)$ : Water Resources Research, v. 50, no. 9, p. 7318-7331, https://doi.org/10.1002/2014WR015818.

Beyer, M., van der Raaij, R., Morgenstern, U., and Jackson, B., 2015, Assessment of Halon-1301 as a groundwater age tracer: Hydrology and Earth System Sciences, v. 19, no. 6, p. 2775-2789, https://doi.org/10.5194/hess-19-2775-2015.

Beyer, M., Morgenstern, U., van der Raaij, R., and Martindale, H., 2017, Halon-1301—Further evidence of its performance as an age tracer in New Zealand groundwater: Hydrology and Earth System Sciences, v. 21, no. 8, p. 4213-4231, https://doi.org/10.5194/hess-21-4213-2017.

Bigg, P.H., 1967a, Density of water in SI units over the range 0-40 ${ }^{\circ} \mathrm{C}$ : British Journal of Applied Physics, v. 18, no. 4, p. 521-525, https://doi.org/10.1088/0508-3443/18/4/315.

Bigg, P.H., 1967b, Density of water in SI units over the range 0-40 ${ }^{\circ} \mathrm{C}$ : British Journal of Applied Physics, v. 18, no. 11, p. 1659, https://doi.org/10.1088/0508-3443/18/11/526.

Böhlke, J.K., Verstraeten, I.M., and Kraemer, T.F., 2007, Effects of surface-water irrigation on sources, fluxes, and residence times of water, nitrate, and uranium in an alluvial aquifer: Applied Geochemistry, v. 22, no. 1, p. 152-174, https://doi.org/10.1016/j.apgeochem.2006.08.019.

Böhlke, J.K., Hatzinger, P.B., Sturchio, N.C., Gu, B., Abbene, I., and Mroczkowski, S.J., 2009, Atacama perchlorate as an agricultural contaminant in groundwaterIsotopic and chronologic evidence from Long Island, New York: Environmental Science \& Technology, v. 43, no. 15, p. 5619-5625, https://doi.org/10.1021/es9006433.

Bu, X., and Warner, M.J., 1995, Solubility of chlorofluorocarbon-113 in water and seawater: Deep Sea Research Part I-Oceanographic Research Papers, v. 42, no. 7, p. 1151-1161, https://doi.org/10.1016/0967-0637(95)00052-8.

Bullister, J.L., 1984, Atmospheric chlorofluoromethanes as tracers of ocean circulation and mixing-Studies in the Greenland and Norwegian Seas: La Jolla, Calif., University of California San Diego, Ph.D. dissertation, 172 p.

Bullister, J.L., and Weiss, R.F., 1983, Anthropogenic chlorofluoromethanes in the Greenland and Norwegian Seas: Science, v. 221, no. 4607, p. 265-268, https://doi.org/10.1126/science.221.4607.265.

Bullister, J.L., and Weiss, R.F., 1988, Determination of $\mathrm{CC}_{3} \mathrm{~F}$ and $\mathrm{CCl}_{2} \mathrm{~F}_{2}$ in seawater and air: Deep Sea Research Part A, Oceanographic Research Papers, v. 35, no. 5, p. 839-853, https://doi.org/10.1016/0198-0149(88)90033-7. 
Bullister, J.L., Wisegarver, D.P., and Menzia, F.A., 2002, The solubility of sulfur hexafluoride in water and seawater: Deep Sea Research Part I, Oceanographic Research Papers, v. 49, no. 1, p. 175-187, https://doi.org/10.1016/S0967-0637(01)00051-6.

Busenberg, E., and Plummer, L.N., 1992, Use of chlorofluorocarbons $\left(\mathrm{CCl}_{3} \mathrm{~F}\right.$ and $\left.\mathrm{CCl}_{2} \mathrm{~F}_{2}\right)$ as hydrologic tracers and age-dating tools - The alluvium and terrace system of central Oklahoma: Water Resources Research, v. 28, no. 9, p. 2257-2283, https://doi.org/10.1029/92WR01263.

Busenberg, E., and Plummer, L.N., 2000, Dating young groundwater with sulfur hexafluoride-Natural and anthropogenic sources of sulfur hexafluoride: Water Resources Research, v. 36, no. 10, p. 3011-3030, https://doi.org/10.1029/2000WR900151.

Cartwright, I., Cendón, D., Currell, M., and Meredith, K., 2017, A review of radioactive isotopes and other residence time tracers in understanding groundwater rechargePossibilities, challenges, and limitations: Amsterdam, Netherlands, Journal of Hydrology, v. 555, p. 797-811, https://doi.org/10.1016/j.jhydrol.2017.10.053.

Cey, B.D., Hudson, G.B., Moran, J.E., and Scanlon, B.R., 2008, Impact of artificial recharge on dissolved noble gases in groundwater in California: Environmental Science \& Technology, v. 42, no. 4, p. 1017-1023, https://doi.org/10.1021/es0706044.

Cey, B.D., Hudson, G.B., Moran, J.E., and Scanlon, B.R., 2009, Evaluation of noble gas recharge temperatures in a shallow unconfined aquifer: Ground Water, v. 47, no. 5, p. 646-659, https://doi.org/10.1111/j.1745-6584.2009.00562.x.

Clarke, W.B., Jenkins, W.J., and Top, Z., 1976, Determination of tritium by mass spectrometric measurement of ${ }^{3} \mathrm{He}$ : The International Journal of Applied Radiation and Isotopes, v. 27, no. 9, p. 515-522, https://doi.org/10.1016/0020-708X(76)90082-X.

Clever, H.L., ed., 1979a, Solubility data series, Volume 1Helium and neon: Oxford, United Kingdom, Pergamon Press, International Union of Pure and Applied Chemistry, https://iupac.org/what-we-do/databases/solubilitydata-series/.

Clever, H.L., ed., 1979b, Solubility data series, Volume 2Krypton, xenon, and radon: Oxford, United Kingdom, Pergamon Press, International Union of Pure and Applied Chemistry, https://iupac.org/what-we-do/databases/ solubility-data-series/.
Clever, H.L., ed., 1980, Solubility data series, Volume 4Argon: Oxford, United Kingdom, Pergamon Press, International Union of Pure and Applied Chemistry, https://iupac.org/what-we-do/databases/solubilitydata-series/.

Craig, H., Lupton, J.E., Welhan, J.A., and Poreda, R., 1978, Helium isotope ratios in Yellowstone and Lassen Park volcanic gases: Geophysical Research Letters, v. 5, no. 11, p. 897-900, https://doi.org/10.1029/GL005i011p00897.

Dalal, R.C., and Allen, D.E., 2008, Greenhouse gas fluxes from natural ecosystems: Australian Journal of Botany, v. 56, no. 5, p. 369-407, https://doi.org/10.1071/BT07128.

Deeds, D.A., 2008, The natural geochemistry of tetrafluoromethane and sulfur hexafluoride-Studies of ancient Mojave Desert groundwaters, North Pacific seawaters and the summit emissions of Kilauea Volcano: San Diego, Calif., University of California San Diego, Library-Scripps Institution of Oceanography Technical Report, PhD dissertation, accessed September 22, 2019, at https://www.escholarship.org/uc/item/1hp1f3bd.

Ekwurzel, B., Schlosser, P., Smethie, W.M., Jr., Plummer, L.N., Busenberg, E., Michel, R.L., Weppernig, R., and Stute, M., 1994, Dating of shallow groundwater-Comparison of the transient tracers ${ }^{3} \mathrm{H} /{ }^{3} \mathrm{He}$, chlorofluorocarbons and $85 \mathrm{Kr}$ : Water Resources Research, v. 30, no. 6, p. 1693-1708, https://doi.org/10.1029/94WR00156.

Ferrell, R.T., and Himmelblau, D.M., 1967, Diffusion coefficients of hydrogen and helium in water: Journal of Chemical \& Engineering Data, v. 12, no. 1, p. 702-708, https://doi.org/10.1002/aic.690130421.

Gammon, R.H., Cline, J., and Wisegarver, D., 1982, Chlorofluoromethanes in the northeast Pacific OceanMeasured vertical distribution and application as transient tracers of upper ocean mixing: Journal of Geophysical Research, v. 87, no. C12, p. 9441-9454, https://doi.org/10.1029/JC087iC12p09441.

Garcia, H.E., and Gordon, L.I., 1992, Oxygen solubility in seawater-Better fitting equations: Limnology and Oceanography, v. 37, no. 6, p. 1307-1312, https://doi.org/10.4319/1o.1992.37.6.1307.

Garcia, H.E., and Gordon, L.I., 1993, Erratum-Oxygen solubility in seawater-Better fitting equations: Limnology and Oceanography, v. 38, no. 3, p. 656.

Gilmore, T.E., Genereux, D.P., Solomon, D.K., and Solder, J.E., 2016, Groundwater transit time distribution and mean from streambed sampling in an agricultural coastal plain watershed, North Carolina, USA: Water Resources Research, v. 52, no. 3, p. 2025-2044, https://doi.org/10.1002/2015WR017600. 
Green, C.T., Jurgens, B.C., Zhang, Y., Starn, J.J., Singleton, M.J., and Esser, B.K., 2016, Regional oxygen reduction and denitrification rates in groundwater from multi-model residence time distributions, San Joaquin Valley, USA: Amsterdam, Netherlands, Journal of Hydrology, v. 543, part A, p. 155-166, https://doi.org/10.1016/j.jhydrol.2016.05.018.

Hamme, R.C., and Emerson, S.R., 2004, The solubility of neon, nitrogen, and argon in distilled water and seawater: Deep-sea Research Part I-Oceanographic Research Papers, v. 51, no. 11, p. 1517-1528, https://doi.org/10.1016/j.dsr.2004.06.009.

Heaton, T.H.E., and Vogel, J.C., 1981, "Excess air" in groundwater: Amsterdam, Netherlands, Journal of Hydrology, v. 50, p. 201-216, https://doi.org/10.1016/0022-1694(81)90070-6.

Heaton, T.H.E., Talma, A.S., and Vogel, J.C., 1983, Origin and history of nitrate in confined groundwater in the western Kalahari: Amsterdam, Netherlands, Journal of Hydrology, v. 62, no. 1-4, p. 243-262, https://doi.org/10.1016/0022-1694(83)90105-1.

Heilweil, V.M., Grieve, P.L., Hynek, S.A., Brantley, S.L., Solomon, D.K., and Risser, D.W., 2015, Stream measurements locate thermogenic methane fluxes in groundwater discharge in an area of shale-gas development: Environmental Science \& Technology, v. 49, no. 7, p. 4057-4065, https://doi.org/10.1021/es503882b.

Holocher, J., Peeters, F., Aeschbach-Hertig, W., Hofer, M., Brennwald, M., Kinzelbach, W., and Kipfer, R., 2002, Experimental investigations on the formation of excess air in quasi-saturated porous media: Geochimica et Cosmochimica Acta, v. 66, no. 23, p. 4103-4117, https://doi.org/10.1016/S0016-7037(02)00992-4.

Hunt, A.G., 2015, U.S. Geological Survey Noble Gas Laboratory's standard operating procedures for the measurement of dissolved gas in water samples: U.S. Geological Survey Techniques and Methods 5-A11, 21 p., https://pubs.usgs.gov/tm/05/a11/tm5a11.pdf.

Jähne, B., Heinz, G., and Dietrich, W., 1987, Measurement of the diffusion coefficients of sparingly soluble gases in water: Journal of Geophysical Research, v. 92, no. C10, p. 10767-10776, https://doi.org/10.1029/JC092iC10p10767.

Jeffrey, L.C., Maher, D.T., Santos, I.R., Call, M., Reading, M.J., Holloway, C., and Tait, D.R., 2018, The spatial and temporal drivers of $p \mathrm{CO}_{2}, p \mathrm{CH}_{4}$ and gas transfer velocity within a subtropical estuary: Estuarine, Coastal and Shelf Science, v. 208, p. 83-95, https://doi.org/10.1016/j.ecss.2018.04.022.
Jenkins, W.J., Lott, D.E., III, and Cahill, K.L., 2019, A determination of atmospheric helium, neon, argon, krypton, and xenon solubility concentrations in water and seawater: Marine Chemistry, v. 211, p. 94-107, https://doi.org/10.1016/j.marchem.2019.03.007.

Johnson, M.L., and Faunt, L.M., 1992, Parameter estimation by least-squares methods: Methods in Enzymology, v. 210, p. 1-37, https://www.sciencedirect.com/science/article/pii/ 007668799210003V?via\%3Dihub.

Jung, M., and Aeschbach, W., 2018, A new software tool for the analysis of noble gas data sets from (ground)water: Environmental Modelling \& Software, v. 103, p. 120-130, https://doi.org/10.1016/j.envsoft.2018.02.004.

Jurgens, B.C., Burow, K.R., Dalgish, B.A., and Shelton, J.L., 2008, Hydrogeology, water chemistry, and factors affecting the transport of contaminants in the zone of contribution of a public-supply well in Modesto, eastern San Joaquin Valley, California: U.S. Geological Survey Scientific Investigations Report 2008-5156, accessed July 6, 2009, at https://pubs.usgs.gov/sir/2008/5156/.

Jurgens, B.C., Böhlke, J.K., and Eberts, S.M., 2012, TracerLPM (Version 1)-An Excel ${ }^{\mathbb{R}}$ workbook for interpreting groundwater age distributions from environmental tracer data: U.S. Geological Survey Techniques and Methods Report 4F3, 60 p., accessed September 20, 2018, at https://pubs.usgs.gov/tm/4-f3/pdf/tm4-F3.pdf.

Jurgens, B.C., Böhlke, J.K., Kauffman, L.J., Belitz, K., and Esser, B.K., 2016, A partial exponential lumped parameter model to evaluate groundwater age distributions and nitrate trends in long-screened wells: Amsterdam, Netherlands, Journal of Hydrology, v. 543, part A, p. 109-126, https://doi.org/10.1016/j.jhydrol.2016.05.011.

King, D.B., and Saltzman, E.S., 1995, Measurement of the diffusion coefficient of sulfur hexafluoride in water: Journal of Geophysical Research, v. 100, no. C4, p. 7083-7088, https://doi.org/10.1029/94JC03313.

Kipfer, R., Aeschbach-Hertig, W., Peeters, F., and Stute, M., 2002, Noble gases in lakes and ground waters, in Porcelli, D., Ballentine, C., and Wieler, R., eds., Noble gases in geochemistry and cosmochemistry: Washington, D.C., Mineralogical Society of America, Geochemical Society, chap. 14, p. 615-700, https://doi.org/10.1515/9781501509056-016.

Lindsey, B.D., Jurgens, B.C., and Belitz, K., 2019, Tritium as an indicator of modern, mixed, and premodern groundwater age: U.S. Geological Survey Scientific Investigations Report 2019-5090, 18 p., https://doi.org/10.3133/sir20195090. 
Loose, B., and Jenkins, W.J., 2014, The five stable noble gases are sensitive unambiguous tracers of glacial meltwater: Geophysical Research Letters, v. 41, no. 8, p. 2835-2841, https://doi.org/10.1002/2013GL058804.

Lucas, L.L., and Unterweger, M.P., 2000, Comprehensive review and critical evaluation of the half-life of tritium: Journal of Research of the National Institute of Standards and Technology, v. 105, no. 4, p. 541-549, https://doi.org/10.6028/jres.105.043.

Ludin, A., Weppering, R., Bönisch, G., and Schlosser, P., 1998, Mass spectrometric measurement of helium isotopes and tritium in water samples: Palisades, N.Y., Columbia University, Lamont-Doherty Earth Observatory, Technical Report 98.6, accessed May 25, 2017, at https://www.ldeo.columbia.edu/sites/default/files/uploaded/ image/Ludin_Lamond_Mass\%20spectrometric(1).pdf.

Matthews, E., and Fung, I., 1987, Methane emission from natural wetlands - Global distribution, area, and environmental characteristics of sources: Global Biogeochemical Cycles, v. 1, no. 1, p. 61-86, https://doi.org/10.1029/GB001i001p00061.

Michel, R.L., Jurgens, B.C., and Young, M.B., 2018, Tritium deposition in precipitation in the United States, 1953-2012: U.S. Geological Survey Scientific Investigations Report 2018-5086, 11 p., https://doi.org/10.3133/sir20185086.

Millero, F.J., and Poisson, A., 1981, International one-atmosphere equation of state of seawater: Deep Sea Research Part A, Oceanographic Research Papers, v. 28, no. 6, p. 625-629, https://doi.org/10.1016/0198-0149(81)90122-9.

National Aeronautics and Space Administration, 1976, U.S. Standard Atmosphere, 1976: Washington, D.C., National Aeronautics and Space Administration, 241 p., https://ntrs.nasa.gov/archive/nasa/casi.ntrs.nasa.gov/ 19770009539.pdf.

Page, R.W., and Balding, G.O., 1973, Geology and quality of water in the Modesto-Merced area, San Joaquin Valley, California, with a brief section on hydrology: U.S. Geological Survey Water-Resources Investigations Report 73-6, https://pubs.er.usgs.gov/publication/wri736.

Peeters, F., Beyerle, U., Aeschbach-Hertig, W., Holocher, J., Brennwald, M., and Kipfer, R., 2003, Improving noble gas based paleoclimate reconstruction and groundwater dating using $20 \mathrm{Ne} / 22 \mathrm{Ne}$ ratios: Geochimica et Cosmochimica Acta, v. 67, no. 4, p. 587-600, https://doi.org/10.1016/S0016-7037(02)00969-9.
Phillips, S.P., Green, C.T., Burow, K.R., Shelton, J.L., and Rewis, D.L., 2007, Simulation of multiscale ground-water flow in part of the northeastern San Joaquin Valley, California: U.S. Geological Survey Scientific Investigations Report 2007-5009, 43 p., https://doi.org/10.3133/sir20075009.

Pickering, R.J., 1981, Water quality-New tables of dissolved oxygen saturation values: U.S. Geological Survey, Quality of Water Branch Technical Memorandum No. 81.11, accessed January 19, 2010, at https://water.usgs.gov/admin/memo/QW/qw81.11.html.

Plummer, L.N., Rupert, M.G., Busenberg, E., and Schlosser, P., 2000, Age of irrigation water in ground water from the Eastern Snake River Plain Aquifer, SouthCentral Idaho: Ground Water, v. 38, no. 2, p. 264-283, https://doi.org/10.1111/j.1745-6584.2000.tb00338.x.

Sanford, W.E., Casile, G., and Haase, K.B., 2015, Dating base flow in streams using dissolved gases and diurnal temperature changes: Water Resources Research, v. 51 , no. 12 , p. $9790-9803$, https://doi.org/10.1002/2014WR016796.

Sano, Y., and Takahata, N., 2005, Measurement of noble gas solubility in seawater using a quadrupole mass spectrometer: Journal of Oceanography, v. 61, no. 3, p. 465-473, https://doi.org/10.1007/s10872-005-0055-x.

Schlosser, P., and Winckler, G., 2002, Noble gases in ocean waters and sediments: Reviews in Mineralogy and Geochemistry, v. 47, no. 1, p. 701-730, https://doi.org/10.2138/rmg.2002.47.15.

Schlosser, P., Stute, M., Sonntag, C., and Otto Münnich, K., 1989, Tritiogenic ${ }^{3} \mathrm{He}$ in shallow groundwater: Earth and Planetary Science Letters, v. 94, no. 3-4, p. 245-256, https://doi.org/10.1016/0012-821X(89)90144-1.

Smith, S.P., and Kennedy, B.M., 1983, Solubility of noble gases in water and in $\mathrm{NaCl}$ brine: Geochimica et Cosmochimica Acta, v. 47, no. 3, p. 503-515, https://doi.org/10.1016/0016-7037(83)90273-9.

Solomon, D.K., 2000, ${ }^{4} \mathrm{He}$ in groundwater, in Cook, P.G., and Herczeg, A.L., eds., Environmental tracers in subsurface hydrology: Boston, Mass., Kluwer Academic Publishers, p. 425-439, https://doi.org/10.1007/978-1-4615-4557-6_14.

Solomon, D.K., and Cook, P.G., 2000, ${ }^{3} \mathrm{H}$ and ${ }^{3} \mathrm{He}$, in Cook, P.G., and Herczeg, A.L., eds., Environmental tracers in subsurface hydrology: Boston, Mass., Kluwer Academic Publishers, p. 397-424, https://doi.org/10.1007/978-1-4615-4557-6_13. 
Stanley, R.H.R., and Jenkins, W.J., 2013, Noble gases in seawater as tracers for physical and biogeochemical ocean processes, in Burnard, P., ed., The noble gases as geochemical tracers-Advances in isotope geochemistry: Berlin, Germany, Springer, p. 55-79, https://doi.org/10.1007/978-3-642-28836-4_4.

Stute, M., Sonntag, C., Déak, J., and Schlosser, P., 1992, Helium in deep circulating groundwater in the Great Hungarian Plain-Flow dynamics and crustal and mantle helium fluxes: Geochimica et Cosmochimica Acta, v. 56, no. 5, p. 2051-2067, https://doi.org/10.1016/0016-7037(92)90329-H.

Stute, M., Forster, M., Frischkorn, H., Serejo, A., Clark, J.F., Schlosser, P., Broecker, W.S., and Bonani, G., 1995, Cooling of tropical Brazil $\left(5^{\circ} \mathrm{C}\right)$ during the last glacial maximum: Science, v. 269 , no. 5222, p. 379-383, https://doi.org/10.1126/science.269.5222.379.

Tolstikhin, I.N., and Kamensky, I.L., 1969, Determination of groundwater age by the T-3 He method: Geochemistry International, v. 6, p. 810-811.

U.S. Geological Survey, 2011, Change to solubility equations for oxygen in water: U.S. Geological Survey, Office of Water Quality Branch Technical Memorandum No. 11.03, accessed May 26, 2012, at https://water.usgs.gov/admin/memo/QW/qw11.03.pdf.

U.S. Geological Survey, 2020, Analytical procedures for dissolved gases $\mathrm{N}_{2} /$ Ar: Reston, Va., U.S. Geological Survey, Groundwater Dating Laboratory, https://water.usgs.gov/lab/ dissolved-gas/lab/analytical_procedures/.

Warner, M.J., and Weiss, R.F., 1985, Solubilities of chlorofluorocarbons 11 and 12 in water and seawater: Deep Sea Research Part A-Oceanographic Research Papers, v. 32, no. 12, p. 1485-1497, https://doi.org/10.1016/0198-0149(85)90099-8.
Weise, S., and Moser, H., 1987, Groundwater dating with helium isotopes, in Isotope techniques in water resources development, Proceedings of a Symposium, Vienna, Austria, 30 March-3 April, 1987: Vienna, Austria, International Atomic Energy Agency, p. 105-126.

Weiss, R.F., 1970, The solubility of nitrogen, oxygen and argon in water and seawater: Deep-Sea Research, v. 17, p. 721-735, http://www.ccpo.odu.edu/ klinck/Reprints/PDF/ weissDSR1970.pdf.

Weiss, R.F., 1971, Solubility of helium and neon in water and seawater: Journal of Chemical \& Engineering Data, v. 16, no. 2, p. 235-241, https://doi.org/10.1021/je60049a019.

Weiss, R.F., 1974, Carbon dioxide in water and seawater-The solubility of a non-ideal gas: Marine Chemistry, v. 2, no. 3, p. 203-215, https://doi.org/10.1016/0304-4203(74)90015-2.

Weiss, R.F., and Kyser, T.K., 1978, Solubility of krypton in water and seawater: Journal of Chemical \& Engineering Data, v. 23, no. 1, p. 69-72, https://doi.org/10.1021/je60076a014.

Weiss, R.F., and Price, B.A., 1980, Nitrous oxide solubility in water and sea water: Marine Chemistry, v. 8, no. 4, p. 347-359, https://doi.org/10.1016/0304-4203(80)90024-9.

Wiesenburg, D.A., and Guinasso, N.L., Jr., 1979, Equilibrium solubilities of methane, carbon monoxide, and hydrogen in water and sea water: Journal of Chemical \& Engineering Data, v. 24, no. 4, p. 356-360, https://doi.org/10.1021/je60083a006.

Zheng, M., De Bruyn, W.J., and Saltzman, E.S., 1998, Measurements of the diffusion coefficients of CFC-11 and CFC-12 in pure water and seawater: Journal of Geophysical Research, v. 103, no. C1, p. 1375-1379, https://doi.org/10.1029/97JC02761. 
For additional information, contact

NAWQA Science Team

U.S. Geological Survey

12201 Sunrise Valley Drive, MS 413

Reston, VA 20192-0002

Email: (gs-w_opp_nawqa_science_team@usgs.gov)

Publishing support provided by the

U.S. Geological Survey Science Publishing Network, Sacramento Publishing Service Center 
